\title{
MXenes for Rechargeable Batteries Beyond the Lithium-Ion
}

\author{
Fangwang Ming, Hanfeng Liang, Gang Huang, Zahra Baphan, and Husam N. Alshareef**
}

Research on next-generation battery technologies (beyond Li-ion batteries, or LIBs) has been accelerating over the past few years. A key challenge for these emerging batteries has been the lack of suitable electrode materials, which severely limits their further developments. MXenes, a new class of 2D transition metal carbides, carbonitrides, and nitrides, are proposed as electrode materials for these emerging batteries due to several desirable attributes. These attributes include large and tunable interlayer spaces, excellent hydrophilicity, extraordinary conductivity, compositional diversity, and abundant surface chemistries, making MXenes promising not only as electrode materials but also as other components in the cells of emerging batteries. Herein, an overview and assessment of the utilization of MXenes in rechargeable batteries beyond LIBs, including alkali-ion (e.g., $\mathrm{Na}^{+}, \mathrm{K}^{+}$) storage, multivalent-ion (e.g., $\mathrm{Mg}^{2+}, \mathrm{Zn}^{2+}$, and $\mathrm{Al}^{3+}$ ) storage, and metal batteries are presented. In particular, the synthetic strategies and properties of MXenes that enable MXenes to play various roles as electrodes, metal anode protective layers, sulfur hosts, separator modification layers, and conductive additives in these emerging batteries are discussed. Moreover, a perspective on promising future research directions on MXenes and MXene-based materials, ranging from material design and processing, fundamental understanding of the reaction mechanisms, to device performance optimization strategies is provided.

\section{Introduction}

Environmentally friendly renewable energy sources such as wind, solar, and tide are becoming increasingly important for global sustainable development. However, these renewable energy sources are naturally intermittent, which makes the energy storage devices indispensable. Owing to the high energy conversion efficiency, relatively long lifespan, a wide range of energy and power densities, and low maintenance cost, electrochemical energy storage (EES) technologies have been playing vital roles in meeting the rapidly increasing demands of portable devices, electric vehicles, grid storage, and stationary markets. ${ }^{[1]}$ Since the successful commercialization by SONY in 1991, lithium-ion batteries (LIBs) have been dominating the market of energy storage systems over the

F. Ming, Dr. H. Liang, Dr. G. Huang, Z. Bayhan, Prof. H. N. Alshareef Materials Science and Engineering

Physical Science and Engineering Division

King Abdullah University of Science Technology (KAUST)

Thuwal 23955, Saudi Arabia

E-mail: husam.alshareef@kaust.edu.sa

The ORCID identification number(s) for the author(s) of this article can be found under https://doi.org/10.1002/adma.202004039.

DOI: 10.1002/adma.202004039 past few decades. ${ }^{[2]}$ In spite of the great 8 success of the LIBs in consumer elec- 9 tronics and electric vehicles, their grid- 10 scale implementation is hindered by the 11 limited lithium resources (only 20 ppm 12 in the earth's crust) as well as the safety 13 concerns. ${ }^{[3]}$ In this regard, many other 14 EES systems based on more abundant 15 and less active elements, such as sodium 16 (2.3\%), potassium $(2.1 \%)$, magnesium 17 (2.3\%), aluminum (8.2\%), and zinc 18 (75 ppm), have been developed and have 19 already achieved significant progress. ${ }^{[1 \mathrm{~d}, 4]} \quad 20$

Historically, 2D layered materials have 21 been employed as electrodes for batteries 22 (e.g., graphite, ${ }^{[5]} \mathrm{LiCoO}_{2},{ }^{[6]}$ and $\left.\mathrm{TiS}_{2}{ }^{[7]}\right) .23$ Since the discovery of monolayer gra- 24 phene in $2004,{ }^{[8]}$ more and more emerging 25 2D materials have quickly become popular 26 electrode materials for various EES 27 devices. This is not surprising given the 28 unique structure and property of 2D mate- 29 rials. Their relatively large interlayer space 30 allows fast ion (de)intercalation, whereas 31 the highly anisotropic 2D structure ena- 32 bles fast charge transfer. Recently, a new 33 class of 2D transition metal carbides, 34 nitrides, and carbonitrides, known as 35 MXenes, ${ }^{[9]}$ was discovered and has attracted increasing research 36 interest. Up to date, more than 30 MXenes have been suc- 37 cessfully synthesized. ${ }^{[10]}$ Similar to other 2D layered materials, 38 MXenes also possess large/tunable interlayer spaces and high 39 aspect ratios. In addition, MXenes show excellent hydrophilicity 40 (contact angle is $\approx 21.5^{\circ}-35^{\circ}$ ) $^{[11]}$ and extraordinary conductivity 41 (e.g., $\approx 9880 \mathrm{~S} \mathrm{~cm}^{-1}$ for $\mathrm{Ti}_{3} \mathrm{C}_{2} \mathrm{~T}_{x}, 3250 \pm 100 \mathrm{~S} \mathrm{~cm}^{-1}$ for $\mathrm{V}_{2} \mathrm{CT}_{x}$ ). ${ }^{[12]} 42$ Further, MXenes are coupled with various terminations (e.g., 43 $-\mathrm{OH},-\mathrm{O}$, and $-\mathrm{F}$ ), which endow rich surface chemistries. 44 These unique properties make them appealing in various appli- 45 cations, especially for energy storage devices such as batteries 46 and supercapacitors. ${ }^{[1 \mathrm{~d}, 4 \mathrm{i}, 13]}$

We noted that there have already been several excellent 48 reviews on the application of MXenes for energy storage and 49 conversion, which cover a wide range of topics including for 50 LIBs, supercapacitors, electrocatalysis, photocatalysis, elec- 51 tromagnetic interference, and so on. ${ }^{[10 a, 14]}$ However, a more 52 specific summary focuses on the rechargeable batteries is 53 required and beneficial for the researchers working on next- 54 generation batteries. Moreover, the study and investigation 55 on MXenes for other EES systems beyond LIB are rapidly 56 developing and have achieved great progress very recently. 57 For example, great research efforts have been invested in 58 exploring the application of MXenes in Li-sulfur batteries 59 
1 (Li-SBs), sodium-ion batteries (SIBs), potassium-ion batteries 2 (PIBs), and multivalent-ion (i.e., $\mathrm{Mg}^{2+}, \mathrm{Zn}^{2+}, \mathrm{Al}^{3+}$ ). Besides 3 being directly used as electrodes, MXenes are also employed 4 as protective layers for metal anodes to prevent the growth of 5 dendrites. Thus, a timely and comprehensive review of the 6 latest progress of MXenes in emerging EES applications is 7 needed. However, the use of MXenes for LIBs, supercapaci8 tors, and energy conversion will not be covered in this review. 9 Readers who are interested in these topics can refer to the 10 information provided elsewhere ${ }^{[14 c-e, 15]}$. In the present review, 11 we will start with a brief introduction to MXenes, followed by an overview of the preparation strategies and the properties of MXenes. Next, we will highlight the recent advances in using MXenes for rechargeable batteries beyond LIBs, including Li-SBs, SIBs, PIBs, multivalent-ion (i.e., Mg, Al, Zn) batteries as well as the utilization of MXenes for metal anode protection. Finally, we will present our perspective on the current challenges and problems, and promising future research directions.

\section{MXene in Brief}

MXenes are a new class of 2D transition metal carbides, carbonitrides, and nitrides that are generally produced by selectively removing the A" layer from their parent MAX phases. The term "MXene" was coined aiming at emphasizing the removal of "A" layer from the MAX phase as well as its 2D nature that is analogous to "graphene."[9,10b] The general formula of their parental MAX phases can be expressed as $\mathrm{M}_{n+1} \mathrm{AX}_{n}(n=1,2,3$ or 4), where " $M$ " represents the early transition metal (e.g., Ti, $\mathrm{V}, \mathrm{Nb}, \mathrm{Mo}$ ), "A" is an A-group (mostly groups 13 and 14, i.e., groups IIIA and IVA) element (e.g., $\mathrm{Al}, \mathrm{Si}, \mathrm{Ga}$ ), and " $\mathrm{X}$ " is carbon and/or nitrogen (Figure 1a). All known MAX phases are layered structures with $\mathrm{P} 63 / \mathrm{mmc}$ symmetry, where the $\mathrm{XM}_{6}$ octahedra " $\mathrm{M}_{n+1} \mathrm{X}_{n}$ " layers are separated by the atomic "A" layers. In other words, the structure of MAX phase can be viewed as the alternative stacking of " $\mathrm{M}_{n+1} \mathrm{X}_{n}$ " layers and "A" layers along with the $c$ direction (Figure $1 \mathrm{~b}$ ). In addition to the ordered transition metal structural crystals, MAX phases can also be solid
1 2 3 4 5 6 7 8 9
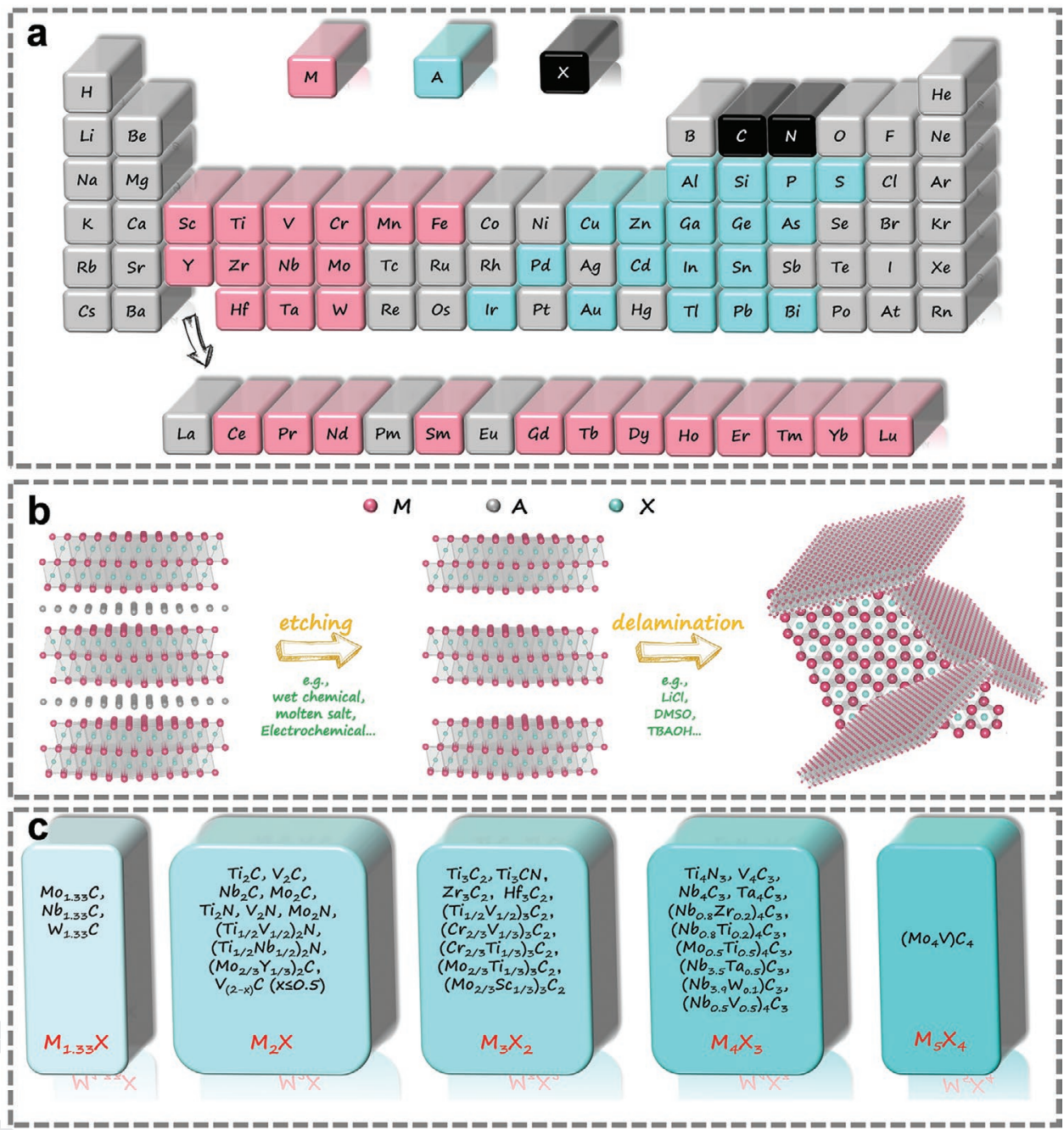

Figure 1. a) Fragment of periodic table showing the " $M$, , "A," and " $X$ " elements of the known MAX phases. b) The typical preparation process of $M_{3} X_{2} M X e n e$ from the corresponding $M_{3} A X_{2}$ phase. c) Reported MXenes up to date. Three $M_{1.33} X^{[116]} 11 M_{2} X^{[13 e, 17]} 9 M_{3} X_{2},{ }^{[9,17 a, 18]} 10 M_{4} X_{3}{ }^{[17 a, 18 d, 19]}$ and $1 \mathrm{M}_{5} \mathrm{X}_{4}{ }^{[20]} \mathrm{MXenes}$. Note that the terminal functional groups $\left(\mathrm{T}_{x}\right)$ are omitted here.

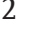

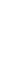

.

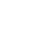

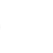

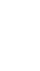

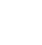

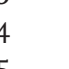

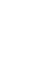

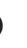


solutions of " $\mathrm{M}$," "A," and "X," as seen in $\left(\mathrm{Nb}_{0.8}, \mathrm{Ti}_{0.2}\right)_{4} \mathrm{AlC}_{3},{ }^{[19 \mathrm{i}]}$ $\left(\mathrm{Nb}_{0.8}, \mathrm{Zr}_{0.2}\right){ }_{4} \mathrm{AlC}_{3},{ }^{[19 \mathrm{i}]} \mathrm{Ti}_{2} \mathrm{Al}_{(1-x)} \mathrm{Sn}_{x} \mathrm{C},{ }^{[21]} \mathrm{Ti}_{3} \mathrm{Al}\left(\mathrm{C}_{0.5}, \mathrm{~N}_{0.5}\right)_{2},{ }^{[22]}$ and $\mathrm{Ti}_{2} \mathrm{Al}\left(\mathrm{C}_{0.5}, \mathrm{~N}_{0.5}\right){ }^{[22]}$ This enables the possibility of preparing MXenes with diverse compositions, ${ }^{[18 d, 19 i, 23]}$ leading to different chemical/physical properties that could be used in specific scenarios as needed. Up to now, more than 150 kinds of MAX phases and over 30 kinds of MXenes (Figure 1c) have been experimentally prepared, and the list is still rapidly expanding. It should be mentioned that, during the etching process, the " $\mathrm{A}$ " layers are often replaced by some functional groups, which appear as the surface terminations on the MXenes. Therefore, the general formula of MXene is denoted as $\mathrm{M}_{n+1} \mathrm{X}_{n} \mathrm{~T}_{x}$, where $\mathrm{T}_{x}$ represents the functional groups such as $-\mathrm{OH},-\mathrm{O},-\mathrm{F}$, and $-\mathrm{Cl}$.

As mentioned above, most of the MXenes are made from MAX phases, however, there are some exceptions. For example, $\mathrm{Mo}_{2} \mathrm{CT}_{x}$ is the first MXene that has been derived from $\mathrm{Mo}_{2} \mathrm{Ga}_{2} \mathrm{C}$, ${ }^{[17 \mathrm{~d}, \mathrm{e}]}$ which is a non-MAX phase, regardless of its similar crystal structure to MAX phase. Two layers of Ga need to be selectively etched off, which makes it more challenging to obtain the $\mathrm{Mo}_{2} \mathrm{CT}_{x}$ MXene. Later, other MXenes, such as $\mathrm{Zr}_{3} \mathrm{C}_{2} \mathrm{~T}_{x}$ and $\mathrm{Hf}_{3} \mathrm{C}_{2} \mathrm{~T}_{x}$ were also successfully synthesized from the non-MAX phases, i.e., $\mathrm{Zr}_{3} \mathrm{Al}_{3} \mathrm{C}_{5}$ and $\mathrm{Hf}_{3}\left[\mathrm{Al}(\mathrm{Si})_{4}\right] \mathrm{C}_{6}$, respectively. ${ }^{[18 \mathrm{~b}, \mathrm{c}]}$ In most MXenes, the $n$ is an integer between 1 and 3, such as in $\mathrm{Ti}_{3} \mathrm{C}_{2} \mathrm{~T}_{x}, \mathrm{~V}_{2} \mathrm{CT}_{x}, \mathrm{Mo}_{2} \mathrm{TiC}_{2} \mathrm{~T}_{x}$, and $\mathrm{Nb}_{4} \mathrm{C}_{3} \mathrm{~T}_{x}$. However, very recently, Yury's group synthesized a $\mathrm{Mo}_{4} \mathrm{VC}_{4} \mathrm{~T}_{x}$ MXene from the $\mathrm{Mo}_{4} \mathrm{VAlC}_{4}$ MAX phase (i.e., a "514" phase), which means the $n$ has now been extended to $4 .{ }^{[20]}$ In addition, a series of new MXene phases with a general formula of $\mathrm{M}_{1.33} \mathrm{CT}_{x}$ ( $\mathrm{M}$ = transition metal, e.g., Mo, Nb, W) was discovered by Rosen's group. ${ }^{[16,24]}$ These MXenes were synthesized from quaternary $\left(\mathrm{M}_{2 / 3}^{1} \mathrm{M}_{1 / 3}^{2}\right)_{2} \mathrm{AX}$, wherein the $\mathrm{M}^{1}$ and $\mathrm{M}^{2}$ are ordered inplane ( $i$-MAX, ${ }^{[16 a, f, 25]}$ distinguished from those out-of-plane MAX phases, i.e., o-MAX). Up to date, more than 10 different $i$-MAX phases were reported. ${ }^{[16 a, c, 25,26]}$ Different from other MXenes that only selectively remove the "A" layer, the $\mathrm{M}_{1.33} \mathrm{CT}_{x}$ MXenes are prepared by selectively etching both " $\mathrm{M}^{2}$ " and " $\mathrm{A}$ " layers, which consequently leads to the formation of ordered divacancies in MXenes. For instance, $\mathrm{Mo}_{1.33} \mathrm{CT}_{x}$ MXene was obtained by simultaneously removing $\mathrm{Sc}$ and $\mathrm{Al}$ in $\left(\mathrm{Mo}_{2 / 3} \mathrm{Sc}_{1 / 3}\right)_{2} \mathrm{AlC}$ using hydrofluoric acid (HF). ${ }^{[16 a]}$ Similarly, $\mathrm{V}_{2-x} \mathrm{C}$ MXene was also prepared from a solid solution of $\left(\mathrm{V}_{2-x} \mathrm{Sc}_{x}\right)_{2} \mathrm{AlC}(x \leq 0.05)$ MAX phase. ${ }^{[17]]}$ The discovery of $\mathrm{M}_{1.33} \mathrm{CT}_{x}$ and $\mathrm{V}_{2-x} \mathrm{C}$ MXenes greatly increases the ability and possibility to regulate and control the physical/chemical properties of the MXene family. The presence of vacancies also makes this kind of material more appealing for energy-related and catalysis applications.

\section{Synthesis Strategies}

Graphene and some other 2D materials (e.g., black phosphorus) have their corresponding natural 3D bulk precursors. Generally, the weak van der Waal force between adjacent layers makes it possible to directly exfoliate/delaminate the $3 \mathrm{D}$ precursors into the ultrathin single/few-layer 2D flakes by simple physical or chemical exfoliation strategies. ${ }^{[8,27]}$ In contrast, MXenes do not have the straightforward precursors in nature, and instead are generally derived from the corresponding MAX phases, where the $\mathrm{M}-\mathrm{X}$ and $\mathrm{M}-\mathrm{A}$ bonds possess much stronger interaction force compared to the van der Waals force. Fortunately, thanks 1 to the difference in the formation energy of the $\mathrm{M}-\mathrm{X}$ (covalent 2 and ionic bonds) and $\mathrm{M}-\mathrm{A}$ bonds (metallic bonds), the selec- 3 tive removal of "A" layers from the MAX phases is possible. ${ }^{[10]} 4$ In this way, 3D multilayer MXenes can be synthesized from 5 their parent MAX phases. Through further delamination/exfo- 6 liation (will be discussed later), 2D single/few-layer MXene 7 sheets could be readily obtained. A typical etching and delami- 8 nation process from $M_{3} A X_{2}$ phase to $M_{3} X_{2}$ MXene is schemati- 9 cally displayed in Figure $1 \mathrm{~b}$.

\subsection{Etching (Removal of "A" Layers)}

Since the first discovery of $\mathrm{Ti}_{3} \mathrm{C}_{2} \mathrm{~T}_{x}$ MXene in 2011, which was 15 obtained by selectively etching off $\mathrm{Al}$ layers from the $\mathrm{Ti}_{3} \mathrm{AlC}_{2} \quad 16$ MAX using $\mathrm{HF}^{\left[{ }^{[9]}\right.}$ increasing efforts have been devoting to 17 developing various etching approaches. Among them, the wet 18 chemical etching is the most prevalent and mature method, 19 which can generally be divided into HF-containing (direct 20 use of $\mathrm{HF}$ or in situ formed HF) and HF-free routes. The 21 HF-containing routes are dominant and proven to be the most 22 efficient ways, though HF is extremely harmful and requires 23 extra caution during the operation. The HF-free strategies are 24 much safer and thus are highly desired yet quite challenging. 25 In addition, new etching methods such as molten salt and elec- 26 trochemical routes have also been explored for the preparation 27 of MXenes.

\subsubsection{Wet Chemical Routes}

Although the M-A bonds are intrinsically weaker than the M-X 33 bonds in MAX phases, they are still much stronger than the 34 van der Waals force between the adjacent layers in the typical 35 bulk 2D materials (e.g., graphite). Prior to the use of HF for 36 etching, researches also tried other methods but did not suc- 37 ceed. For instance, Barsoum et al. heated the MAX phases 38 at high temperature under various ambiances, including in 39 molten salts (cryolite, ${ }^{[28]} \mathrm{LiF}^{124}$ ), molten metals (e.g., molten 40 Al with $\left.\mathrm{Ti}_{3} \mathrm{SiC}_{2}\right),{ }^{[29]}$ and vacuum ${ }^{[30]}$ to selectively remove the 41 "A" elements. However, detwinning of the "MX" layers occurs 42 at elevated temperatures, which consequently leads to 3D 43 "MX" rock salt structures rather than 2D MXenes. Thereafter, 44 chemical etching has become the dominant route for pro- 45 ducing MXenes. It should be noted that weak etchants cannot 46 completely remove the "A" layers, whereas strong etchants 47 (e.g., $\mathrm{Cl}_{2}$ gas $^{[31]}$ ) could possibly destroy the "MX" 2D structure, 48 resulting in the formation of carbons. Besides the chemical 49 activity of etchants, the reaction temperature should also be 50 carefully investigated. For example, the reaction of $\mathrm{Ti}_{2} \mathrm{AlC}$ and 51 $\mathrm{HF}$ at $55^{\circ} \mathrm{C}$ would result in $\mathrm{Ti}_{2} \mathrm{AlF}_{9}$ but not $\mathrm{Ti}_{2} \mathrm{AlC}$ MXene. ${ }^{[32]}$ In 52 this regard, a thorough understanding of the etching reactions 53 is required to optimize the etching process and thus to produce 54 high-quality MXenes. Using $\mathrm{Ti}_{3} \mathrm{AlC}_{2} \mathrm{MAX}$ as an example, the 55 etching reactions in $\mathrm{HF}$ at room temperature can be reasonably 56 described as follows ${ }^{[9]}$

$\mathrm{Ti}_{3} \mathrm{AlC}_{2}+3 \mathrm{HF} \rightarrow \mathrm{AlF}_{3}+3 / 2 \mathrm{H}_{2}+\mathrm{Ti}_{3} \mathrm{C}_{2}$ 
$\mathrm{Ti}_{3} \mathrm{C}_{2}+2 \mathrm{H}_{2} \mathrm{O} \rightarrow \mathrm{Ti}_{3} \mathrm{C}_{2}(\mathrm{OH})_{2}+\mathrm{H}_{2}$

$\mathrm{Ti}_{3} \mathrm{C}_{2}+2 \mathrm{HF} \rightarrow \mathrm{Ti}_{3} \mathrm{C}_{2} \mathrm{~F}_{2}+\mathrm{H}_{2}$

Reaction (1) is essential to produce MXenes from MAX phases. Upon etching, the "A" layers are replaced by $-\mathrm{OH}$, -F surface terminations. Reactions (2) and (3) are simplified based on the assumption that the terminations are $-\mathrm{OH}$, or $-\mathrm{F}$. The HF is proven to be an effective MAX etchant and has been used to prepare many MXenes, including $\mathrm{V}_{2} \mathrm{CT}_{x}$, $\mathrm{Ti}_{2} \mathrm{CT}_{x}, \mathrm{Nb}_{2} \mathrm{CT}_{x}, \mathrm{Mo}_{2} \mathrm{CT}_{x}, \mathrm{Ti}_{2} \mathrm{NT}_{x},\left(\mathrm{Ti}_{0.5}, \mathrm{Nb}_{0.5}\right)_{2} \mathrm{CT}_{x}, \mathrm{Mo}_{1.33} \mathrm{CT}_{x}$, $\mathrm{Nb}_{1.33} \mathrm{CT}_{x}, \quad \mathrm{~W}_{1.33} \mathrm{CT}_{x}, \quad \mathrm{~V}_{(2-x)} \mathrm{CT}_{x}, \quad\left(\mathrm{~V}_{0.5} \mathrm{Cr}_{0.5}\right)_{3} \mathrm{C}_{2} \mathrm{~T}_{x}, \quad \mathrm{Ti}_{3} \mathrm{CNT}_{x}$, $\mathrm{Mo}_{2} \mathrm{TiC}_{2} \mathrm{~T}_{x}, \mathrm{Mo}_{2} \mathrm{Ti}_{2} \mathrm{C}_{3} \mathrm{~T}_{x}, \mathrm{Ta}_{4} \mathrm{C}_{3} \mathrm{~T}_{x}, \mathrm{~V}_{4} \mathrm{C}_{3} \mathrm{~T}_{x}, \mathrm{Nb}_{4} \mathrm{C}_{3} \mathrm{~T}_{x}, \quad \mathrm{Zr}_{3} \mathrm{C}_{2} \mathrm{~T}_{x}$, $\mathrm{Hf}_{3} \mathrm{C}_{2} \mathrm{~T}_{x}$, etc. ${ }^{[13 e, 16 a, c, e, f, 17 a, c-f, j, 18 b-d, 19 b-g, 23 c, 33]}$ The concentration, temperature, and reaction time vary from case to case, mainly depending on the particle size of MAXs and the strength of the $\mathrm{M}-\mathrm{A}$ bonds. Consequently, appropriate etching conditions are essential and critical for obtaining well-defined, high quality, as well as high yield MXenes.

Although HF can effectively etch MAX phases while preserving their 2D nature, it is highly hazardous and toxic. Other approaches have therefore been explored to either reduce or even avoid the use of HF. A straightforward route would be using mixtures of a small amount of HF and other acids. For 1 example, Dirscoll et al. successfully etched $\mathrm{Ti}_{3} \mathrm{AlC}_{2}$ MAX powder 2 by a mixture of $\mathrm{HCl}$, deionized water, and $\mathrm{HF}$ with a volumetric 3 ratio of $6: 3: 1{ }^{[34]}$ This method greatly reduces the amount of 4 HF by $90 \%$ compared to the method that use HF solely. In 5 addition, MXene nanosheets with large lateral size and fewer 6 defects can be obtained with high throughput at room temperature $\left(25^{\circ} \mathrm{C}\right)$. In 2014 , a milder synthesis route was developed 8 by Ghidiu et al., in where the HF acid was in situ formed by the reaction of $\mathrm{LiF}$ and $\mathrm{HCl}$ (the molar ratio of $\mathrm{Ti}_{3} \mathrm{AlC}_{2}: \mathrm{LiF}: \mathrm{HCl}$ is 1:0.5:11.7). ${ }^{[11 a]}$ This method not only avoids the direct use of $\mathrm{HF}$, but also results in nanosheets with larger lateral sizes and fewer defects compared to HF-etched MXenes. ${ }^{[35]}$ Later, the $\mathrm{LiF} / \mathrm{HCl}$ route was optimized by increasing the amount of LiF salt and $\mathrm{HCl}$ acid. ${ }^{[36]}$ The optimal method is referred to as Minimally Intensive Layer Delamination (MILD) method. It is worth mentioning that the MILD method doesn't require sonication but instead only manual handshaking, which can produce even larger MXene flakes with fewer defects compared to the original $\mathrm{HF} / \mathrm{HCl}$ process. ${ }^{[36 \mathrm{~b}]}$ A comparison of the $\mathrm{LiF} /$ $\mathrm{HCl}$ route followed by sonication and the MILD route is shown in Figure 2 and Table 1. Similarly, $\mathrm{NaBF}_{4} / \mathrm{HCl}$ was also shown to be able to etch $\mathrm{Ti}_{3} \mathrm{AlC}_{2}$ MAX in hydrothermal conditions at

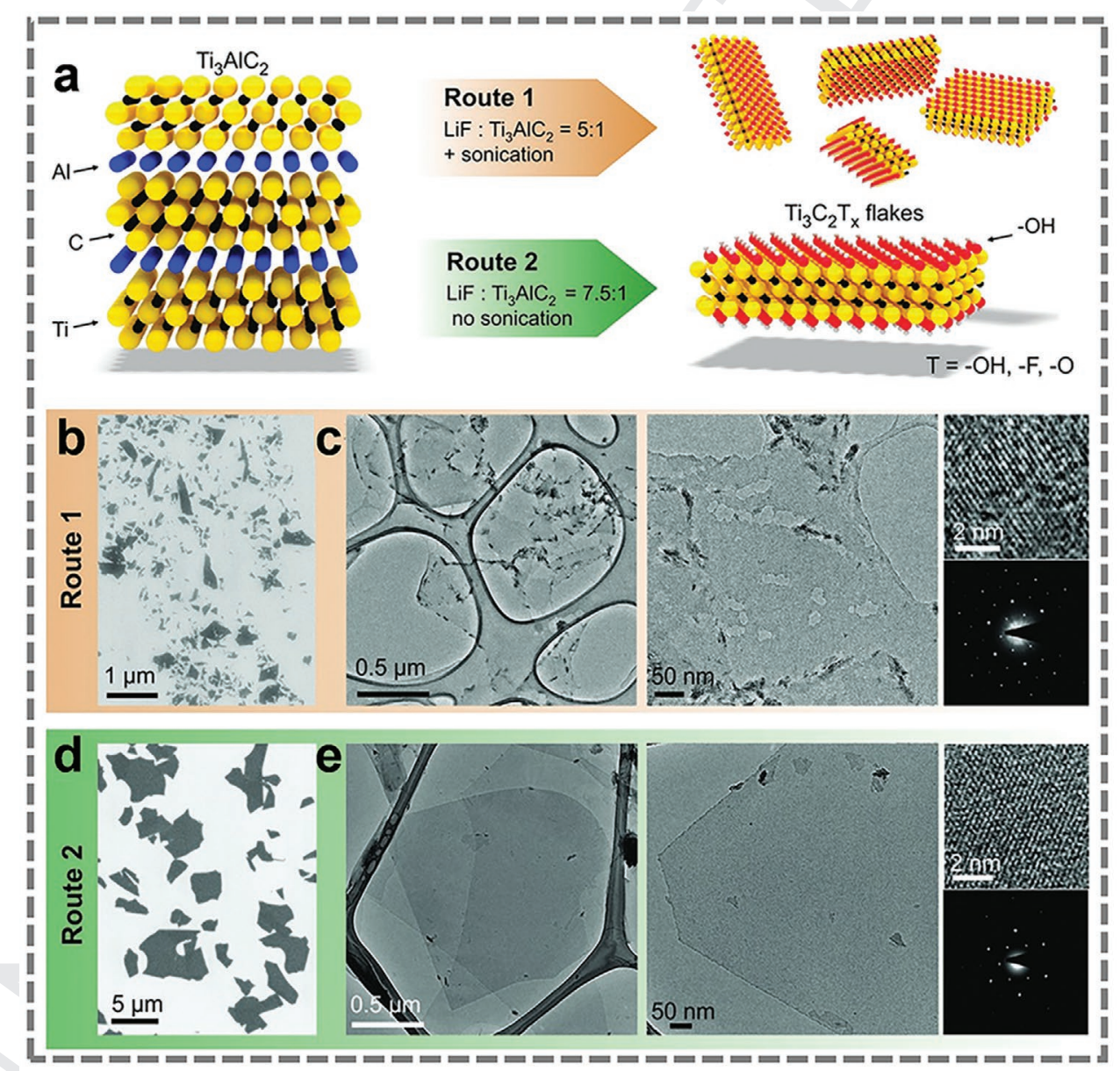

Figure 2. a) Schematic summary of Routes 1 ( $\mathrm{HF}+\mathrm{HCl}$ etching followed by sonication) and 2 (MILD method). b,c) Scanning electron microscope (SEM) and transmission electron microscopy (TEM) characterizations of $\mathrm{Ti}_{3} \mathrm{C}_{2} \mathrm{~T}_{x}$ flakes produced through Route 1 . d,e) SEM and TEM characterizations of $\mathrm{Ti}_{3} \mathrm{C}_{2} \mathrm{~T}_{x}$ flakes synthesized through Route 2. Reproduced with permission. ${ }^{366]}$ Copyright 2016, Wiley. 
Table 1. Summary of the experimental parameters for Route 1 and Route 2. Reproduced with permission. ${ }^{[36 b]}$ Copyright 2016, Wiley.

\begin{tabular}{|c|c|c|c|c|c|c|c|}
\hline Method & Mass $\left(\mathrm{Ti}_{3} \mathrm{AlC}_{2}\right)[\mathrm{g}]$ & Mass (LiF) [g] & Volume $(6 \mathrm{M} \mathrm{HCl})[\mathrm{mL}]$ & $\begin{array}{c}\text { Molar ratio } \\
\mathrm{Ti}_{3} \mathrm{AlC}_{2}: \mathrm{LiF}: \mathrm{HCl}\end{array}$ & Etching time $[\mathrm{h}]$ & $\begin{array}{l}\text { Centrifugation } \\
\text { speed/time }\end{array}$ & Sonication \\
\hline $\mathrm{LiF} / \mathrm{HCl}$ (route 1) & 1 & 0.67 & 10 & 1.0: 5.0: 11.7 & 24 & $3500 \mathrm{rpm} / 1 \mathrm{~h}$ & Yes, $1 \mathrm{~h}$ \\
\hline MILD (route 2) & 1 & 1 & 20 & 1.0: $7.5: 23.4$ & 24 & $3500 \mathrm{rpm} / 1 \mathrm{~h}$ & No \\
\hline
\end{tabular}

$180^{\circ} \mathrm{C}$ without the use of HF. ${ }^{[37]}$ Importantly, such a fluoride salt (e.g., $\mathrm{LiF}, \mathrm{NaF}, \mathrm{KF}, \mathrm{NH}_{4} \mathrm{~F}, \mathrm{CsF}, \mathrm{CaF}_{2}$, and tetrabutylammonium fluoride) and acid (e.g., $\mathrm{HCl}$ and $\mathrm{H}_{2} \mathrm{SO}_{4}$ ) combination protocol can be extended to synthesize other MXenes (e.g., $\mathrm{V}_{2} \mathrm{CT}_{x}$, $\left.\mathrm{Nb}_{2} \mathrm{CT}_{x}, \mathrm{Mo}_{2} \mathrm{CT}_{x}, \mathrm{Ti}_{2} \mathrm{CT}_{x}, \mathrm{Ti}_{3} \mathrm{CNT}_{x}, \mathrm{Cr}_{2} \mathrm{TiC}_{2} \mathrm{~T}_{x}, \mathrm{~W}_{1.33} \mathrm{CT}_{x}\right) \cdot{ }^{[17 \mathrm{e}, 37,38]}$ Generally, the kind of fluoride salts does not have a significant impact on the resulting products. ${ }^{[38 c]}$ Interestingly, it was found that only the $\mathrm{NaF} / \mathrm{HCl}$ combination could efficiently etch the $\mathrm{V}_{2} \mathrm{AlC}$ MAX while $\mathrm{LiF} / \mathrm{HCl}$ and $\mathrm{KF} / \mathrm{HCl}$ could not. ${ }^{[38 a, b]}$ Though the reason is unclear, it might be associated with the hydrated cation radius and the solubility of the fluoride salts. ${ }^{[38 b]}$

Apart from the fluoride salt/acid combinations, $\mathrm{NH}_{4} \mathrm{HF}_{2}$, an environmentally friendly weak acid, was also able to etch $\mathrm{Ti}_{3} \mathrm{AlC}_{2}$ MAX, though a much longer time was needed compared to $H F$. ${ }^{[39]}$ The resulting $\mathrm{Ti}_{3} \mathrm{C}_{2} \mathrm{~T}_{x}$ MXene exhibits a larger interlayer spacing (the $c$ lattice parameter is $24.7 \AA$ ) than the HF etched one $(19.8 \AA)$. This strongly indicates that the intercalation of the cations $\left(\mathrm{NH}^{4+}\right)$ and/or $\mathrm{NH}_{3}$ takes place during the etching process, as confirmed by X-ray photoelectron spectroscopy (XPS) and TEM analysis. Besides, $\mathrm{NH}_{4} \mathrm{~F}$ was also introduced solely as an etchant to synthesize $\mathrm{Ti}_{3} \mathrm{C}_{2} \mathrm{~T}_{x}$ MXene using a hydrothermal method at $150{ }^{\circ} \mathrm{C}$ for 24 h. ${ }^{[40]}$ Furthermore, it is noteworthy that inspired by the Bayer process, $\mathrm{Li}$ et al. demonstrated that the multilayer $\mathrm{Ti}_{3} \mathrm{C}_{2} \mathrm{~T}_{x}$ powder with a high purity of $\approx 92 \mathrm{wt} \%$ could be obtained via an alkali treatment $(27.5 \mathrm{~m} \mathrm{NaOH})$ at $270{ }^{\circ} \mathrm{C} .{ }^{[41]}$ Additionally, very recently, Mei et al. successfully synthesized the fluorine-free mesoporous $\mathrm{Mo}_{2} \mathrm{C}$ MXene using a UV light-induced method in the phosphoric acid etching solution. ${ }^{[42]}$ These new HF-free approaches are of great importance and interest as they are much safer and endow the possibility to obtain MXenes with surface terminations other than F, which could have significant impacts on the properties and thus the electrochemical performance of the MXenes.

In order to obtain high quality MXenes, the etching process and condition should be carefully manipulated. Usually, longer etching time and/or higher reaction temperatures are expected for weak etchants (e.g., $\mathrm{LiF} / \mathrm{HCl}, \mathrm{NH}_{4} \mathrm{HF}_{2}, \mathrm{NH}_{4} \mathrm{~F}$ ). When using the same etchant for etching different MAX phases, the reaction conditions should also be regulated accordingly. Generally, the reaction time, reaction temperature, and the fluorine ion concentration need to be adjusted according to the following parameters: the atomic number of $\mathrm{M}$ and the number of $n$. In most cases, the energy of the $\mathrm{M}-\mathrm{A}$ bonds increases with the increase of the atomic number of $\mathrm{M}$, thus longer time and/or higher temperatures are needed. A larger $n$ value also requires a higher fluorine ion concentration and longer reaction time. ${ }^{[18 \mathrm{~h}]}$

\subsubsection{Molten Salt Method}

The molten salt method was also applied to etch MAX phases. Urbankowski et al. used the molten salt as the etchant to synthesize $\mathrm{Ti}_{4} \mathrm{~N}_{3} \mathrm{~T}_{x}$ MXene, which is the first nitride com- 8 pound of MXene family (Figure 3a). ${ }^{[19 a]}$ Besides, Huang's 9 group recently reported an element replacement approach 10 to the synthesis of novel $\mathrm{Zn}$-MAX phases, such as $\mathrm{Ti}_{3} \mathrm{ZnC}_{2}, 11$ $\mathrm{Ti}_{2} \mathrm{ZnC}, \mathrm{Ti}_{2} \mathrm{ZnN}$, and $\mathrm{V}_{2} \mathrm{ZnC}$, and further the preparation of 12 Cl-terminated MXenes (such as $\mathrm{Ti}_{3} \mathrm{C}_{2} \mathrm{Cl}_{2}$ and $\mathrm{Ti}_{2} \mathrm{CCl}_{2}$ ). ${ }^{[43]}$ As 13 schematically shown in Figure $3 \mathrm{~b}$, the strong Lewis acidity of 14 molten $\mathrm{ZnCl}_{2}$ enables the $\mathrm{Zn}$ atoms to occupy the A sites in 15 the MAX (i.e., $\mathrm{Al}$ in $\mathrm{Ti}_{3} \mathrm{AlC}_{2}$ ). When excessive $\mathrm{ZnCl}_{2}$ salt was 16 used, the $\mathrm{Zn}$ atoms could be removed, and thus the Cl-termi- 17 nated MXenes were obtained. More importantly, they extended 18 this strategy to a wide range of A-site elements not only $\mathrm{Zn}, 19$ but also Al, Si, and Ga from various MAX precursors (e.g., 20 $\left.\mathrm{Ti}_{2} \mathrm{AlC}, \mathrm{Ti}_{3} \mathrm{AlCN}\right) \cdot{ }^{[44]}$ This is achieved by selectively etching A 21 elements through a redox substitution reaction between the 22 Lewis acid molten salts and the A elements. Such an approach 23 further expands the MAX family and is able to synthesize 24 MXenes without $-\mathrm{F}$ terminations. Very recently, Talapin et al. 25 developed a general strategy to install and remove surface func- 26 tional groups by using the molten salts method. ${ }^{[45]}$ Specifically, 27 MXenes with $-\mathrm{O},-\mathrm{NH},-\mathrm{S},-\mathrm{Cl},-\mathrm{Se},-\mathrm{Br}$, and $-\mathrm{Te}$ termina- 28 tions, as well as bare MXenes without any surface groups were 29 successfully synthesized (Figure 3c). These MXenes exhibit 30 distinctive properties. Notably, it was found that $\mathrm{Nb}_{2} \mathrm{C}$ MXenes 31 display surface group dependent superconductivity. This work 32 suggests that the surface terminations are controllable and the 33 bare MXenes are achievable via post treatments. More impor- 34 tantly, it also enables more potential applications of MXenes. $\quad 35$

\subsubsection{Electrochemical Method}

Electrochemical etching was also proven to be an efficient way to obtain MXenes without the involvement of fluorine. Specifically, $\mathrm{Ti}_{2} \mathrm{CT}_{x}$ and $\mathrm{Ti}_{3} \mathrm{C}_{2} \mathrm{~T}_{x}$ MXenes can be synthesized by electrochemically etching off $\mathrm{Al}$ from $\mathrm{Ti}_{2} \mathrm{AlC}$ and $\mathrm{Ti}_{3} \mathrm{AlC}_{2}$ MAX in the electrolyte of $2 \mathrm{M} \mathrm{HCl}$, and $1 \mathrm{M} \mathrm{NH}_{4} \mathrm{Cl}+0.2 \mathrm{M}$ tetramethylammonium hydroxide (TMAOH), respectively. ${ }^{[46]}$ Moreover, in the 45 latter case, the resulting $\mathrm{Ti}_{3} \mathrm{C}_{2} \mathrm{~T}_{x}$ possesses an average lateral 46 size of $2.4 \mu \mathrm{m}$ (ranging from 1 to $5 \mu \mathrm{m}$ with some flakes up to 47 $18.6 \mu \mathrm{m}$ in diameter), which is comparable to that prepared by 48 MILD method. ${ }^{[46 \mathrm{~b}]}$ It should be noted that the excessive etching 49 would convert the MAX phase to carbon due to the simulta- 50 neous dissolution of "A" and "M" elements. ${ }^{\text {[6a] }} 51$

\subsubsection{Other Methods}

Bottom-up approaches such as chemical vapor deposition are 56 possible for MXene synthesis. For instance, 2D ultrathin $\mathrm{Mo}_{2} \mathrm{C} 57$ crystals were produced by chemical vapor deposition (CVD). ${ }^{[47]} 58$ The MXenes obtained from this method possess a large lateral 59 


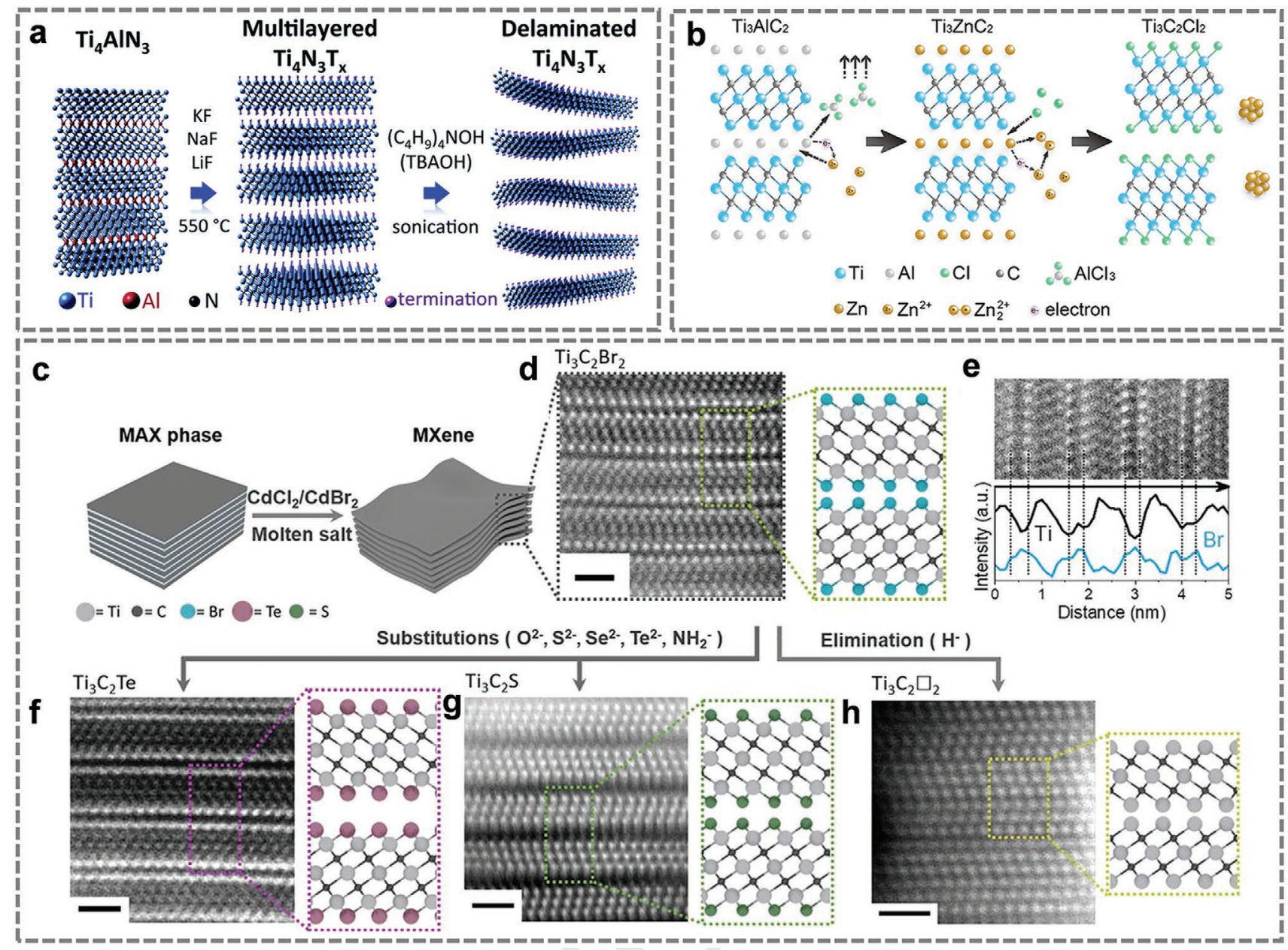

Figure 3. Schematic illustration of the synthesis of a) $\mathrm{Ti}_{4} \mathrm{~N}_{3} \mathrm{~T}_{x}$ MXene using molten fluoride salts. Reproduced with permission. [19a] Copyright 2016, Royal Society of Chemistry, and b) Schematic illustration of the synthesis of $\mathrm{Ti}_{2} \mathrm{C}_{2} \mathrm{Cl}_{2}$ using molten $\mathrm{ZnCl}_{2}$. Reproduced with permission. ${ }^{[43]}$ Copyright 2019, American Chemical Society. c) Schematics for etching of MAX phases in Lewis acidic molten salts. $d-h)$ Atomic resolution TEM images of MXenes terminated with various surface groups obtained via direct molten salt etching, substitution, and elimination, respectively. Reproduced with permission. ${ }^{[45]}$ Copyright 2020, American Association for the Advancement of Science.

size and few defects, which are beneficial for investigating their intrinsic properties. Besides, a two-step approach that involves the deposition of MAX thin films and the subsequent etching process was also demonstrated to synthesis MXene thin films. For example, magnetron sputtering was used to deposit $\mathrm{Ti}_{3} \mathrm{AlC}_{2}$ MAX thin films on the surface of TiC. Then, the $\mathrm{Ti}_{3} \mathrm{C}_{2} \mathrm{~T}_{x}$ MXene was synthesized by a subsequent $\mathrm{HF}$ or $\mathrm{NH}_{4} \mathrm{HF}_{2}$ etching. ${ }^{[3]}$ $\mathrm{Mo}_{2} \mathrm{CT}_{x}$ MXene thin films were also synthesized by a similar strategy except using the $\mathrm{Mo}_{2} \mathrm{Ga}_{2} \mathrm{C}$ MAX as the precursor. ${ }^{[17 \mathrm{~d}]}$

Table 2 summarizes the different etching approaches to the preparation of MXenes reported in the literature. Overall, the most efficient and prevalent methods are the HF-containing ones, whereas other methods, especially those HF-free protocols are still challenging but under rapid development. Since the surface terminations of MXenes are largely determined by the etchants, different etching methods therefore not only affect the etching result but could also tune the properties of 7 MXenes. HF-free methods provide the possibility to synthe58 size $\mathrm{F}$ terminations-free MXenes, thus new fundamental pro59 perties of MXenes with various terminations can be further investigated. It is worth mentioning that, currently, the HF-free methods are mainly applied to synthesize Ti-based MXenes (i.e., $\mathrm{Ti}_{2} \mathrm{CT}_{x}$ and $\mathrm{Ti}_{3} \mathrm{C}_{2} \mathrm{~T}_{x}$ ), their versatility in preparing many other MXenes remains to be explored.

\subsection{Delamination}

After the etching process, the "A" layers are selectively removed and replaced by various functional groups. The resulting MXene layers are held together by the weak van der Waals and/or hydrogen bonds. This allows the formation of single/few-layer MXene flakes by further delamination/exfoliation treatment. Typically, the delamination process involves the intercalation of inorganic cations, organic or ionic molecules, and the subsequent handshaking and/or ultrasonication. Thanks to their negatively charged surfaces, the as-obtained flakes can be well suspended in water or organic solvents without the need of surfactants. Many cations (e.g., $\mathrm{Na}^{+}, \mathrm{K}^{+}, \mathrm{NH}^{4+}, \mathrm{Mg}^{2+}, \mathrm{Al}^{3+}$ ) have been used for the chemical/electrochemical intercalation
1 
Table 2. A summary of different etching approaches used to prepare MXenes.

\begin{tabular}{|c|c|c|c|c|}
\hline Type of etching methods & & Etchant & Type of MXenes & References \\
\hline \multirow[t]{5}{*}{ Wet chemical etching } & $\mathrm{HF}$ containing & $\mathrm{HF}, \mathrm{HF}+\mathrm{HCl}$ & $\begin{array}{c}\mathrm{Ti}_{3} \mathrm{C}_{2} \mathrm{~T}_{x}, \mathrm{~V}_{2} \mathrm{CT}_{x}, \mathrm{Ti}_{2} \mathrm{CT}_{x}, \mathrm{Nb}_{2} \mathrm{CT}_{x}, \mathrm{Mo}_{2} \mathrm{CT}_{x}, \mathrm{Ti}_{2} \mathrm{NT}_{x} \\
\left(\mathrm{Ti}_{0.5}, \mathrm{Nb}_{0.5}\right)_{2} \mathrm{CT}_{x}, \mathrm{Mo}_{1.33} \mathrm{CT}_{x}, \mathrm{Nb}_{1.33} \mathrm{CT}_{x}, \mathrm{~W}_{1.33} \mathrm{CT}_{x} \\
\mathrm{~V}_{(2-x)} \mathrm{CT}_{x},\left(\mathrm{~V}_{0.5} \mathrm{Cr}_{0.5}\right)_{3} \mathrm{C}_{2} \mathrm{~T}_{x}, \mathrm{Ti}_{3} \mathrm{CNT}_{x}, \mathrm{Mo}_{2} \mathrm{TiC}_{2} \mathrm{~T}_{x} \\
\mathrm{Mo}_{2} \mathrm{Ti}_{2} \mathrm{C}_{3} \mathrm{~T}_{x}, \mathrm{Ta}_{4} \mathrm{C}_{3} \mathrm{~T}_{x}, \mathrm{~V}_{4} \mathrm{C}_{3} \mathrm{~T}_{x}, \mathrm{Nb}_{4} \mathrm{C}_{3} \mathrm{~T}_{x}, \mathrm{Zr}_{3} \mathrm{C}_{2} \mathrm{~T}_{x} \text {, etc. }\end{array}$ & $\begin{array}{l}{[9,13 e, 16 a, c, e, f, 17 a, c-f, j,} \\
18 b-d, 19 b-g, 23 c, 33,34]\end{array}$ \\
\hline & Fluoride salt/acid & $\begin{array}{c}\text { Salt: LiF, } \mathrm{NaF}, \mathrm{KF}, \mathrm{NH}_{4} \mathrm{~F}, \mathrm{CsF}, \mathrm{CaF}_{2} \text {, etc. } \\
\text { Acid: } \mathrm{HCl}, \mathrm{H}_{2} \mathrm{SO}_{4}\end{array}$ & $\begin{array}{c}\mathrm{Ti}_{3} \mathrm{C}_{2} \mathrm{~T}_{x}, \mathrm{~V}_{2} \mathrm{CT}_{x}, \mathrm{Nb}_{2} \mathrm{CT}_{x}, \mathrm{Mo}_{2} \mathrm{CT}_{x}, \mathrm{Ti}_{2} \mathrm{CT}_{x} \\
\mathrm{Ti}_{3} \mathrm{CNT}_{x}, \mathrm{Cr}_{2} \mathrm{TiC}_{2} \mathrm{~T}_{x}, \mathrm{~W}_{1.33} \mathrm{CT}_{x} \text { etc. }\end{array}$ & {$[11 a, 17 e, 36-38]$} \\
\hline & Fluoride salt & $\mathrm{NH}_{4} \mathrm{HF}_{2}, \mathrm{NH}_{4} \mathrm{~F}$ & $\mathrm{Ti}_{3} \mathrm{C}_{2} \mathrm{~T}_{x}$ & {$[39,40]$} \\
\hline & Alkali treatment & $\mathrm{NaOH}$ & $\mathrm{Ti}_{3} \mathrm{C}_{2} \mathrm{~T}_{x}$ & [41] \\
\hline & UV-induced & UV light $+\mathrm{H}_{3} \mathrm{PO}_{4}$ & $\mathrm{Mo}_{2} \mathrm{CT}_{x}$ & [42] \\
\hline \multirow[t]{2}{*}{ Molten salt etching } & Fluoride salt & $\mathrm{KF}+\mathrm{LiF}+\mathrm{NaF}$ & $\mathrm{Ti}_{4} \mathrm{~N}_{3} \mathrm{~T}_{x}$ & [19a] \\
\hline & Lewis acid salt & $\begin{array}{c}\mathrm{ZnCl}, \mathrm{CuCl}_{2}, \mathrm{NiCl}_{2}, \mathrm{FeCl}_{2}, \mathrm{AgCl}, \mathrm{CoCl}_{2}, \\
\mathrm{CdCl}_{2}, \mathrm{CdCl}_{2}, \mathrm{CdBr}_{2}, \text { etc. }\end{array}$ & $\mathrm{Ti}_{3} \mathrm{C}_{2} \mathrm{~T}_{x}, \mathrm{Ti}_{3} \mathrm{CNT}_{x}, \mathrm{Nb}_{2} \mathrm{CT}_{x}, \mathrm{Ta}_{2} \mathrm{CT}_{x}, \mathrm{Ti}_{2} \mathrm{CT}_{x}$, etc. & [43-45] \\
\hline Electrochemical etching & & $\mathrm{HCl}, \mathrm{NH}_{4} \mathrm{Cl}+\mathrm{TMAOH}$ & $\mathrm{Ti}_{2} \mathrm{CT}_{x}, \mathrm{Ti}_{3} \mathrm{C}_{2} \mathrm{~T}_{x}$ & [46] \\
\hline
\end{tabular}

of MXene hosts. ${ }^{[50]}$ It is worth mentioning that in the case of MILD method, the $\mathrm{Li}^{+}$ions simultaneously intercalate into the MXene layers during the etching of $\mathrm{Ti}_{3} \mathrm{AlC}_{2} \mathrm{MAX}$, which weakens the interactions of layers thus allows the delamination by simple handshaking. ${ }^{[36]}$ However, it turns out that some intercalants such as $\mathrm{Li}^{+}$ions and dimethyl sulfoxide (DMSO) are not effective in delaminating other MXenes. In light of this, organic isopropylamine has been chosen as the intercalant of $\mathrm{Nb}_{2} \mathrm{CT}_{x}$ MXene for the following reasons: a) it can form positively charged $\mathrm{R}^{-\mathrm{NH}^{3+}}$ (ammonium cation) in aqueous solution, which would then intercalate into the $\mathrm{Nb}_{2} \mathrm{CT}_{x}$ layers because of the electrostatic attractions; b) the three-carbonatom alkyl tail of isopropylamine molecule is small enough to overcome the steric hindrance upon intercalation, on the other hand, is large enough to push the MXene layers apart. ${ }^{[4]}$ The delaminated single/few-layer $\mathrm{Nb}_{2} \mathrm{CT}_{x}$ sheets can be obtained by subsequent sonication (Figure $4 \mathrm{a}$ ). Naguib et al. also found that several organic bases (e.g., tetrabutylammonium hydroxide (TBAOH), choline hydroxide, $n$-butylamine) could be used as intercalants (Figure 4b). ${ }^{[49]}$ This method can be extended to delaminate various MXenes, including $\mathrm{Ti}_{3} \mathrm{C}_{2} \mathrm{~T}_{x}, \mathrm{~V}_{2} \mathrm{CT}_{x}, \mathrm{Ti}_{3} \mathrm{CN}$, $\mathrm{Mo}_{2} \mathrm{C}, \mathrm{Mo}_{1.33} \mathrm{CT}_{x}, \mathrm{Mo}_{2} \mathrm{TiC}_{2} \mathrm{~T}_{x}$, and $\mathrm{Mo}_{2} \mathrm{Ti}_{2} \mathrm{C}_{3} \mathrm{~T}_{x}$, etc. ${ }^{[12 \mathrm{c}, 16 \mathrm{a}, 17 \mathrm{e}, 23 \mathrm{c}, 49]}$ Among those organic intercalants investigated, compounds with long chains (e.g., TBAOH) are generally more difficult to intercalate into the layers than those with short molecular chains (e.g., TMAOH) because of the steric hindrance, thus are often less efficient in delaminating MXenes. ${ }^{[51]}$

\section{Properties of MXenes}

\subsection{Structural Properties}

As mentioned earlier, the "MX" and "A" layers are alternatively stacked in the MAX phases. The arrangement of the " $M$ " and "X" atoms in MXenes is almost the same as that in their parent MAX phases, where $\mathrm{X}$ atoms occupy the center of " $\mathrm{XM}_{6}$ " octahedrons (Figure 1b). Owing to the unique synthetic routes of MXenes, the exposed metal elements of MXenes are always terminated with surface functional groups (e.g., $-\mathrm{O},-\mathrm{OH}$, and $-\mathrm{F}$ ), which could significantly affect their properties.
For example, it is predicted that the $-\mathrm{O}$ terminated MXenes 19 exhibit the highest theoretical metal ion (e.g., $\mathrm{Li}^{+}, \mathrm{Na}^{+}, \mathrm{K}^{+}, 20$ $\mathrm{Mg}^{2+}, \mathrm{Ca}^{2+} \mathrm{Al}^{3+}$ ) storage capacity. ${ }^{[52]}$ The $\mathrm{S}$-functionalized $\mathrm{Ti}_{3} \mathrm{C}_{2} 21$ MXene not only shows high capacity for sodium-ion storage, 22 but also exhibits excellent affinity to polysulfide species that 23 could be potentially used as the host for Li-SBs. ${ }^{[53]}$ The $-\mathrm{OH} 24$ terminations are vulnerable and can be replaced by metals $(\mathrm{Li}, \quad 25$ $\mathrm{Na}, \mathrm{K}, \mathrm{Mg}, \mathrm{Ca}, \mathrm{Pb}) \cdot{ }^{\left[{ }^{[2 a}, \mathrm{b}, 54\right]}$ Further, the $-\mathrm{OH}$ groups can also 26 be converted into $-\mathrm{O}$ by high-temperature annealing, similar 27 to the hydroxide/oxide conversion. Obviously, the termina- 28 tions play a pivotal role in determining the surface chemistry 29 of MXenes. Tuning the type of terminations, therefore, could 30 serve as a powerful approach to improve the electrochemical 31 performance of MXenes, which fortunately can be achieved 32

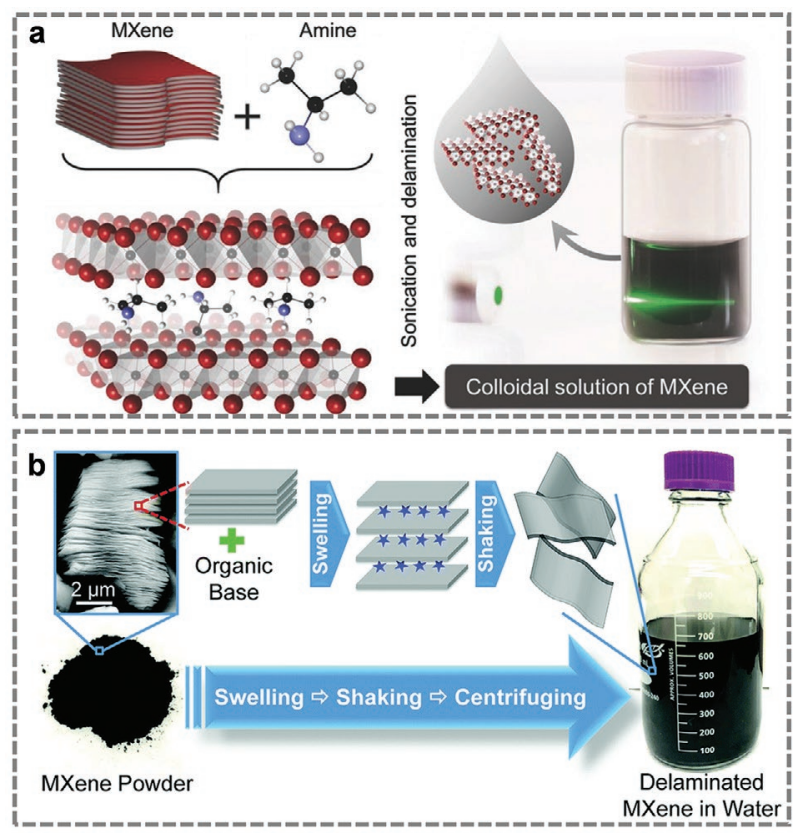

Figure 4. Schematic of a) $\mathrm{Nb}_{2} \mathrm{CT}_{x} \mathrm{MXene}$ delamination process. Reproduced with permission. ${ }^{[48]}$ Copyright 2015, Wiley. b) MXene delamination process by reacting MXenes with an organic base. Reproduced with permission. ${ }^{[49]}$ Copyright 2015, Royal Society of Chemistry. 

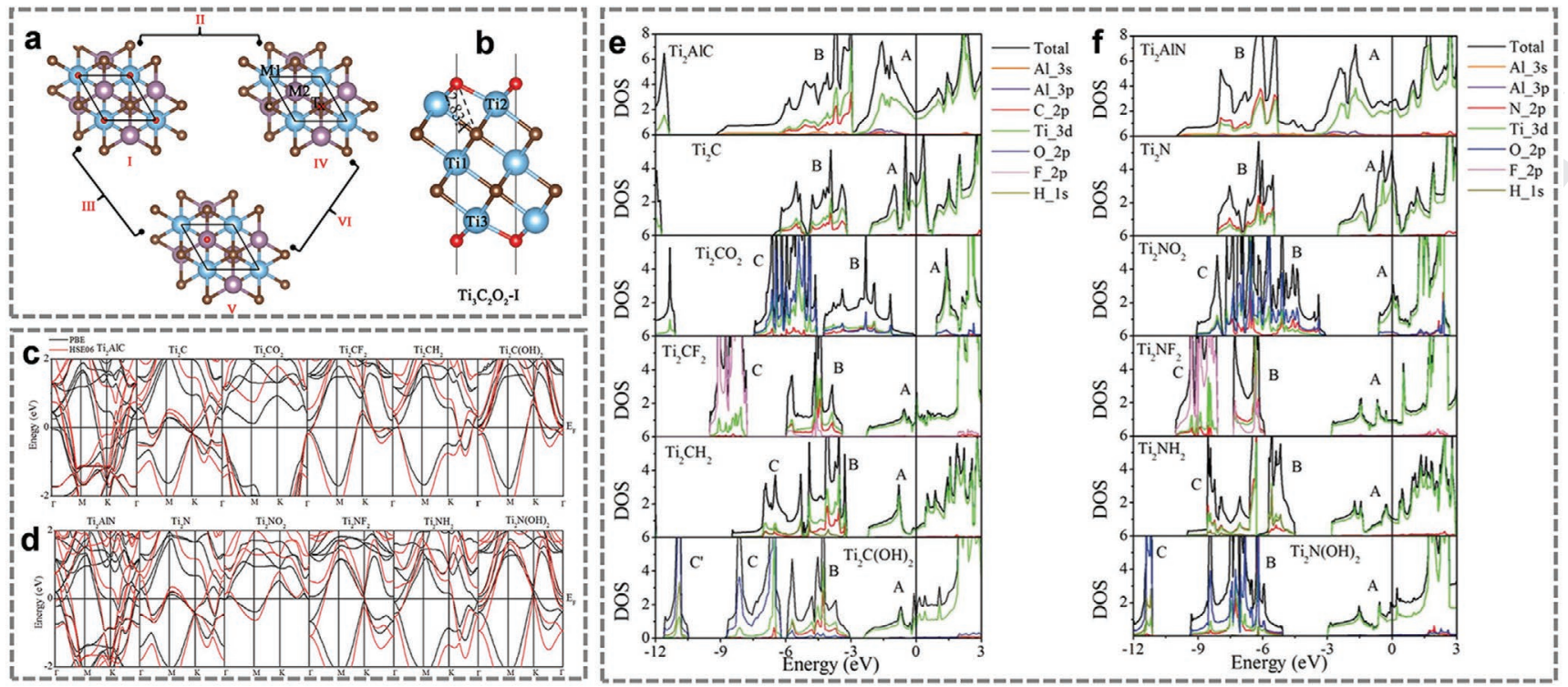

Figure 5. Structural configurations of functionalized MXenes with different arrangements of the surface atoms $T_{X}$. a) Top views of configurations I, IV, and $\mathrm{V}$. The mixture configurations II, III, and VI are not shown. Light turquoise (M1): Ti; light purple (M2): Ti; red ( $\left.\mathrm{T}_{x}\right)$ : $\mathrm{O} / \mathrm{OH} / \mathrm{F}$; and brown: carbon. b) Side views of the most energy favorable structure of $\mathrm{Ti}_{3} \mathrm{C}_{2} \mathrm{O}_{2}$. Reproduced with permission. ${ }^{[56]}$ Copyright 2016, Elsevier. Band structures of c) $\mathrm{Ti}_{2} \mathrm{CT}_{2}$

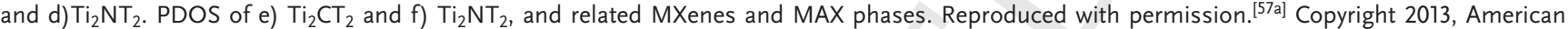
Physical Society.

by using different etchants. For instance, etching MAX by HFcontaining aqueous solutions could result in MXenes with $-\mathrm{O}$, $-\mathrm{OH}$, and $-\mathrm{F}$ terminations, ${ }^{[55]}$ while the use of Lewis acid salts $\left(\mathrm{ZnCl}_{2}, \mathrm{CuCl}_{2}\right.$, etc.) etchants leads to the formation of MXenes with $-\mathrm{Cl}$ termination. ${ }^{[3,44]}$ In addition, the relative content of the terminations can be regulated by adjusting the concentration of etchants. For example, the HF etching results in more -F terminations in $\mathrm{Ti}_{3} \mathrm{C}_{2} \mathrm{~T}_{x}$ than the MILD method, in which a much smaller amount of HF is used. ${ }^{[55 b]}$

Multiple terminations might lead to enhanced performance but also bring about complexity. Understanding their configurations can be helpful for the design and synthesis of MXenes with specific terminations. $\mathrm{Li}$ investigated the stability of $\mathrm{Ti}_{3} \mathrm{C}_{2} \mathrm{~T}_{x}$ with various terminations (e.g., $-\mathrm{O},-\mathrm{OH}$, and $-\mathrm{F}$ ) using the density functional theory (DFT) calculations. ${ }^{[56]} \mathrm{As}$ shown in Figure 5a,b, six possible configurations are taken into consideration: I) the $\mathrm{T}_{x}$ groups are on the hollow site of the M2 (topmost three $\mathrm{Ti}$ atoms) and point to the M1 ( $\mathrm{Ti}$ atom in the second layer) on both sides of $\mathrm{Ti}_{3} \mathrm{C}_{2} \mathrm{~T}_{x}$; IV) both two $\mathrm{T}_{x}$ groups are above the hollow site of the $\mathrm{M} 2$ and point to the $\mathrm{C}$ atom in the first layer; V) $\mathrm{T}_{x}$ groups are located on the $\mathrm{M} 2$ on both sides; II) a combination of types I and IV; III) a combination of I and $\mathrm{V}$; VI) a combination of IV and V. The result suggests that configuration I is the most energy favorable structure with lowest total energy regardless of the type of terminations. ${ }^{[56]}$ This is mainly because in type $\mathrm{I}$, the terminations are close to carbon atoms, which can provide electrons. ${ }^{[57]}$ It should be noted that there are also studies that predicted type IV is the most stable geometry. ${ }^{[58]}$ Therefore, further studies, especially through experimental characterizations, are required. Fortunately, the surface chemistry of MXenes can now be investigated at the atomic level using advanced techniques such as nuclear magnetic resonance (NMR) and aberration-corrected STEM-electron energy loss spectroscopy (EELS). ${ }^{[9,50 \mathrm{~b}, 55 \mathrm{a}, 59]}$ For example, it has been experimentally demonstrated that the surface of $\mathrm{Ti}_{3} \mathrm{C}_{2} \mathrm{~T}_{x}$ MXene is covered by both the functional groups and $\mathrm{TiO}_{x}$ adatom complexes. The O-based surface groups are found to draw valence charge from the MXene. It is also observed that the atoms and terminations at the surfaces are mobile, leading to the migration and ripening of the $\mathrm{TiO}_{x}$ adatom complexes and terminations. ${ }^{[59 b]}$

In addition to the surface functional group, the interlayer spacing of MXenes is also tunable, depending on the composition of MXenes and the size of intercalants. A comparison of the $c$-lattice parameter for various MXenes is shown in Table 3. Generally, the $c$-lattice parameter increases with increasing $n$ value $\left(\mathrm{M}_{n+1} \mathrm{X}_{n} \mathrm{~T}_{x}\right)$. For example, $\mathrm{Ti}_{3} \mathrm{C}_{2} \mathrm{~T}_{x}(20.51 \AA)$ and $\mathrm{Nb}_{4} \mathrm{C}_{3} \mathrm{~T}_{x}$ $(30.47 \AA)$ exhibit larger $c$-lattice parameters than that of $\mathrm{Ti}_{2} \mathrm{CT}_{x}$ $(15.04 \AA)$ and $\mathrm{Nb}_{2} \mathrm{CT}_{x}(22.34 \AA)$. The particle size of the parent MAXs also plays an important role in determining the $c$ value of MXenes. For example, $\mathrm{V}_{2} \mathrm{CT}_{x}$ MXene with a $c$-lattice parameter of $23.96 \AA$ can be obtained by using the attrition milled $\mathrm{V}_{2} \mathrm{AlC}$ MAX, while this value is only $19.73 \AA$ using the unmilled one. The interlayer spacing can also be adjusted by using different intercalant species. Mashtalir et al. demonstrated that the intercalation of hydrazine and further its cointercalation with $\mathrm{N}, \mathrm{N}$ dimethylformamide increased the $c$-lattice parameter of $\mathrm{Ti}_{3} \mathrm{C}_{2} \mathrm{~T}_{x}$ from 19.5 to 25.48 and further to $26.8 \AA .^{[50 \mathrm{~b}]}$ It was also reported the cation (e.g., $\mathrm{Li}^{+}, \mathrm{Na}^{+}, \mathrm{K}^{+}, \mathrm{Rb}^{+}, \mathrm{Mg}^{2+}, \mathrm{Ca}^{2+}$ )-intercalated $\mathrm{Ti}_{3} \mathrm{C}_{2} \mathrm{~T}_{x}$ MXenes showed reversible humidity-dependent expansion and the interlayer spacing varied from 12.5 to $15.5 \AA .{ }^{[61]}$ Luo et al. systematically investigated the influence of cationic surfactants with various lengths of hydrophobic alkyl chains on the interlayer spacing of $\mathrm{Ti}_{3} \mathrm{C}_{2} \mathrm{~T}_{x}$ MXene. Remarkably, the cetyltrimethylammonium bromide (CTAB)-intercalated $\mathrm{Ti}_{3} \mathrm{C}_{2} \mathrm{~T}_{x}$ MXene with pillared structure exhibits an expanded interlayer
1 2 3 4 5 6 7 8 9 10 11 12 13 14 15 16 17 18 19 
Table 3. A comparison of $c$-lattice parameter for MAX phases and corresponding MXenes. Reproduced with permission. ${ }^{[10 b]}$ Copyright 2014 , Wiley.

\begin{tabular}{|c|c|c|c|c|c|c|c|}
\hline \multirow[t]{2}{*}{ MAX structure } & \multirow[t]{2}{*}{ MAX } & \multirow[t]{2}{*}{ MXene } & \multicolumn{2}{|c|}{ RT etching conditions } & \multicolumn{2}{|c|}{ c lattice parameter $[\AA ̊]$} & \multirow[t]{2}{*}{ Ref. } \\
\hline & & & HF conc. [\%] & Time [h] & MAX & MXene & \\
\hline \multirow[t]{3}{*}{211} & $\mathrm{Ti}_{2} \mathrm{AlC}$ & $\mathrm{Ti}_{2} \mathrm{CT}_{x}$ & 10 & 10 & 13.6 & 15.04 & [17a] \\
\hline & $\mathrm{Nb}_{2} \mathrm{AlC}$ & $\mathrm{Nb}_{2} \mathrm{CT}_{x}$ & 50 & 90 & 13.88 & 22.34 & [17c] \\
\hline & $\left(\mathrm{Ti}_{0.5}, \mathrm{Nb}_{0.5}\right)_{2} \mathrm{AlC}$ & $\left(\mathrm{Ti}_{0.5}, \mathrm{Nb}_{0.5}\right)_{2} \mathrm{CT}_{x}$ & 50 & 28 & 13.79 & 14.88 & [17a] \\
\hline & & & 40 & 20 & 18.62 & 20.89 & {$[60]$} \\
\hline & $\left(\mathrm{V}_{0.5}, \mathrm{Cr}_{0.5}\right)_{3} \mathrm{AlC}_{2}$ & $\left(\mathrm{~V}_{0.5}, \mathrm{Cr}_{0.5}\right){ }_{3} \mathrm{C}_{2} \mathrm{~T}_{x}$ & 50 & 69 & 17.73 & 24.26 & [17a] \\
\hline & $\mathrm{Ti}_{3} \mathrm{AlCN}$ & $\mathrm{Ti}_{3} \mathrm{CNT}_{x}$ & 30 & 18 & 18.41 & 22.28 & [17a] \\
\hline \multirow[t]{2}{*}{413} & $\mathrm{Ta}_{4} \mathrm{AlC}_{3}$ & $\mathrm{Ta}_{4} \mathrm{C}_{3} \mathrm{~T}_{x}$ & 50 & 72 & 24.08 & 30.34 & [17a] \\
\hline & $\mathrm{Nb}_{4} \mathrm{AlC}_{3}$ & $\mathrm{Nb}_{4} \mathrm{C}_{3} \mathrm{~T}_{x}$ & 50 & 90 & 24.19 & 30.47 & [17c] \\
\hline
\end{tabular}

spacing of $2.708 \mathrm{~nm}$, which is $177 \%$ larger than that of the pristine MXene $(0.977 \mathrm{~nm}) \cdot{ }^{[62]}$ Besides, $\mathrm{TBA}^{+}$, $\mathrm{TMA}^{+}$, and a series of alkylammonium cations have also been intercalated into the MXenes. ${ }^{[17 e, 23 c, 63]}$ The easily tunable interlayer spacing of MXenes makes them promising candidates for energy storage applications, especially as intercalation-type electrodes.

\subsection{Electronic Properties}

Electronic properties have a critical impact on the electrochemical performance of MXene electrodes for energy-related applications. Both theoretical studies and experimental characterizations have been employed to study the electronic properties of MXenes. ${ }^{[57 a, 64]}$ The band structure and density of states (DOS) of MXenes have been investigated by DFT calculation (Figure $5 c-f$ ). The Fermi energy of the bare MXene shifts down compared to the MAX precursor, and further shifts down after adding the surface terminations. The DOS at Fermi level $\left(N\left(E_{\mathrm{f}}\right)\right)$ is dominated by Ti $3 \mathrm{~d}$ orbitals of the MAX phases. The valence states below the Fermi level can be divided into two sub-bands, i.e., band A (formed by hybridized Ti 3d-C $2 \mathrm{p}$ and Ti $3 \mathrm{~d}-\mathrm{Al} 3 \mathrm{~s}$ orbitals) and band B (Ti 3d-Al 3p orbitals). After the removal of $\mathrm{Al}$ atoms, both bands $\mathrm{A}$ and $\mathrm{B}$ are narrowed. The $N\left(E_{\mathrm{f}}\right)$ increases from 1.88 to $3.15 \mathrm{eV}$ and from 2.77 to $4.84 \mathrm{eV}$ for the conversions of $\mathrm{Ti}_{2} \mathrm{AlC}$ to $\mathrm{Ti}_{2} \mathrm{C}$ and $\mathrm{Ti}_{2} \mathrm{AlN}$ to $\mathrm{Ti}_{2} \mathrm{~N}$, respectively, because of the breaking of $\mathrm{Ti}-\mathrm{Al}$ bonds. With the addition of functional groups, the Fermi level shifts down to lower energy and the $N\left(E_{\mathrm{f}}\right)$ decreases due to the interactions between Ti and terminations. ${ }^{[57 \mathrm{a}]}$ Shein et al. reported that the $N\left(E_{\mathrm{f}}\right)$ of the $\mathrm{Ti}_{n+1} \mathrm{C}_{n}$ and $\mathrm{Ti}_{n+1} \mathrm{~N}_{n}$ MXenes is 2.5-4.5 times higher than that of the corresponding MAX precursors. ${ }^{[65]}$ Though most bare MXenes are predicted to be metallic, ${ }^{[57,66]}$ in reality, the electronic properties are greatly influenced by the surface terminations and the $\mathrm{M}$ elements. For instance, the small bandgaps of 0.05 and $0.1 \mathrm{eV}$ were revealed for $\mathrm{Ti}_{3} \mathrm{C}_{2}(\mathrm{OH})_{2}$ and $\mathrm{Ti}_{3} \mathrm{C}_{2} \mathrm{~F}_{2}$, respectively. ${ }^{[9]}$ In fact, because of the hybridization of $\mathrm{p}$ orbitals in $\mathrm{F}$ and $\mathrm{O}$, and d orbitals in $\mathrm{M}$, the metallic $\mathrm{M}_{2} \mathrm{C}$ and $\mathrm{M}_{2} \mathrm{~N}$ MXenes could become semiconductors after surface functionalization. $\mathrm{Sc}_{2} \mathrm{C}(\mathrm{OH})_{2}$ exhibits a direct semiconducting characteristic, while $\mathrm{Sc}_{2} \mathrm{CF}_{2}$ has an indirect bandgap of
$1.03 \mathrm{eV}{ }^{[57 \mathrm{c}]}$ It was also found that not only the type but also the 19 arrangement/orientation of terminations could alter the elec- 20 tronic properties of MXenes. ${ }^{[58,67]}$ Additionally, transition metal 21 $\mathrm{M}$ also plays a vital role in regulating the electronic properties. 22 Anasori et al. ${ }^{[68]}$ demonstrated the transition from metallic to 23 semiconducting behavior by replacing Ti with Mo atoms in the 24 outer layers of $\mathrm{Ti}_{3} \mathrm{C}_{2}$ and $\mathrm{Ti}_{4} \mathrm{C}_{3}$ MXenes. Moreover, $\mathrm{Zr}_{2} \mathrm{CO}_{2}$ has 25 been predicted to have a bandgap of $0.88 \mathrm{eV}$ while the bandgap 26 for $\mathrm{Hf}_{2} \mathrm{CO}_{2}$ is $1 \mathrm{eV} \cdot{ }^{[57 c]}$ Interestingly, the oxygen functionalized 27 $\mathrm{M}_{2} \mathrm{C}(\mathrm{M}=\mathrm{W}, \mathrm{Mo}$, and $\mathrm{Cr})$ MXenes and some ordered double 28 transition metals MXenes, $\mathrm{M}_{2}{ }_{2} \mathrm{M}^{\prime \prime} \mathrm{C}_{2}\left(\mathrm{M}^{\prime}=\mathrm{Mo}, \mathrm{W} ; \mathrm{M}^{\prime \prime}=\mathrm{Ti}, \mathrm{Zr}, 29\right.$ $\mathrm{Hf})$ are predicted to be topological insulators. ${ }^{[57 b, 69]} 30$

Besides the simulations, efforts have also been devoted to 31 directly measure the conductivity of MXenes. Hu et al. dem- 32 onstrated the anisotropic electronic conduction of individual 33 $\mathrm{Ti}_{3} \mathrm{C}_{2} \mathrm{~T}_{x}$ particulates using $I-V$ measurement. ${ }^{[70]}$ Lipatov et al. 34 reported that individual $\mathrm{Ti}_{3} \mathrm{C}_{2} \mathrm{~T}_{x}$ flakes exhibit a high conduc- 35 tivity of $4600 \pm 1100 \mathrm{~S} \mathrm{~cm}^{-1}$, and a field-effect electron mobility 36 of $2.6 \pm 0.7 \mathrm{~cm}^{2} \mathrm{~V}^{-1} \mathrm{~s}^{-1}$. ${ }^{[36 \mathrm{~b}]}$ Zhang et al. demonstrated that 37 $\mathrm{Ti}_{3} \mathrm{C}_{2} \mathrm{~T}_{x}$ MXene films $(\approx 88 \mathrm{~nm})$ have a DC conductivity of 38 $\approx 9880 \mathrm{~S} \mathrm{~cm}^{-1} \cdot{ }^{[12 \mathrm{~b}]}$ It was also reported that $\mathrm{Ti}_{3} \mathrm{C}_{2} \mathrm{~T}_{x}$ films exhibit 39 metallic characteristic down to $100 \mathrm{~K}$ and below. ${ }^{[39]}$ Interestingly, 40 the conductivity of $\mathrm{Ti}_{3} \mathrm{C}_{2} \mathrm{~T}_{x}$ transparent thin films obtained 41 by spin coating was measured to be as high as $6500 \mathrm{~S} \mathrm{~cm}^{-1}, 42$ superior to other solution-processed 2D materials. The high 43 conductivity can be ascribed to the metal-like free-electron den- 44 sity and the high degree of coplanar alignment of individual 45 MXene flakes. ${ }^{[71]}$ Apart from $\mathrm{Ti}_{3} \mathrm{C}_{2} \mathrm{~T}_{x},{ }^{[72]}$ the electronic proper- 46 ties of many other MXenes, including $\mathrm{V}_{2} \mathrm{CT}_{x},{ }^{[12 \mathrm{c}]} \mathrm{Mo}_{1.33} \mathrm{CT}_{x},{ }^{[16 a]} 47$ $\mathrm{Mo}_{2} \mathrm{CT}_{x},{ }^{[17 \mathrm{e}]}$ and $\mathrm{Ti}_{2} \mathrm{CT}_{x},{ }^{[73]}$ were also experimentally investi- 48 gated. In summary, both the computational and experimental 49 studies imply that most of the MXenes have outstanding elec- 50 tronic conductivities that are favorable for fast electron trans- 51 port and charge transfer for electrochemical applications. 52

\section{Applications in Electrochemical Energy Storage}

Since the discovery of $\mathrm{Ti}_{3} \mathrm{C}_{2} \mathrm{~T}_{x}$, research on MXene electrodes 57 for emerging EES systems (batteries and supercapacitors) has 58 flourished. Most studies focus on $\mathrm{Ti}_{3} \mathrm{C}_{2} \mathrm{~T}_{x}$ MXene for LIBs, 59 
despite the big family of MXenes and various EES systems. Nevertheless, the investigations on MXenes for other EES technologies beyond LIBs are rapidly developing and great progress has been achieved very recently. In the following sections, we will summarize the recent developments of MXene-based materials for EES beyond LIBs, including Li-SBs, SIBs, PIBs, and multivalent ion (e.g., $\mathrm{Mg}^{2+}, \mathrm{Zn}^{2+}, \mathrm{Al}^{3+}$ ) batteries.

\subsection{Lithium-Sulfur Batteries}

In recent years, Li-SBs have attracted intensive attention by virtue of their very high capacity/energy density and low cost, yet still face significant obstacles, including the lithium polysulfide (LiPS) shuttle effect, the intrinsic insulating characteristic of sulfur and the growth of Li dendrites. ${ }^{[74]}$ MXene materials with high electronic conductivity, large surface area, and rich and tunable functional groups hold promising potentials for Li-SBs, where MXenes can be used for the sulfur host, separator modification/interlayer, and anode protection. The following section discusses the recent progress in theoretical computations, experimental findings and reaction mechanisms in Li-SBs. ${ }^{[74 d, 75]}$

\subsubsection{Theoretical Investigations}

The pioneering work of $\mathrm{Ti}_{2} \mathrm{CT}_{x}$ MXene materials for $\mathrm{Li}-\mathrm{SBs}$ was conducted by Nazar's group in 2015. [76] Later in 2017, a more comprehensive study on Ti-based MXenes $\left(\mathrm{Ti}_{2} \mathrm{C}, \mathrm{Ti}_{3} \mathrm{C}_{2}\right.$, and $\mathrm{Ti}_{3} \mathrm{CN}$ ) for $\mathrm{Li}-\mathrm{SBs}$ was carried out with the support of theoretical calculations. ${ }^{[7]}$ Based on the XPS and DFT results, a unique double mechanism of entrapping polysulfides was proposed. It has been demonstrated that the $-\mathrm{OH}$ terminations on the surface of Ti-based MXenes would gradually react with the polysulfides upon the formation of thiosulfate intermediates, followed by the Ti-S bond formation through a Lewis acid-base interaction. ${ }^{[7,77]}$ Rao et al. explored the behaviors of LiPSs on bare Ti-based MXenes $\left(\mathrm{Ti}_{n} \mathrm{X}_{n-1}\right.$, where $\left.\mathrm{X}=\mathrm{C}, \mathrm{N} ; n=2,3,4\right)$ and terminated $\mathrm{Ti}_{2} \mathrm{C} .{ }^{[78]}$ They found that both the long-chain and short-chain sulfides can be entrapped by bare MXenes. However, selectivity can be achieved by modifying the surface group of MXenes. The $-\mathrm{OH}$ terminations are effective in entrapping long-chain sulfides such as $\mathrm{Li}_{2} \mathrm{~S}_{4}, \mathrm{Li}_{2} \mathrm{~S}_{6}$, and $\mathrm{Li}_{2} \mathrm{~S}_{8}$, while the short-chain sulfides can be entrapped by the $-\mathrm{O}$ terminations. The Coulombic interactions between LiPSs and bare MXene or MXene terminations result in the formation of Ti-S, $\mathrm{H}-\mathrm{S}$, and $\mathrm{Li}-\mathrm{O}$ bonds, contributing to the binding between them. ${ }^{[78]}$

The anchoring effects of various MXenes functionalized by different terminal groups has also been intensively investigated. Zhao et al. demonstrated that $\mathrm{Ti}_{2} \mathrm{CF}_{2}$ and $\mathrm{Ti}_{3} \mathrm{C}_{2} \mathrm{~F}_{2}$ MXenes have low binding energies with LiPSs, resulting in their inability to suppress the shuttle effect, while $\mathrm{Ti}_{2} \mathrm{C}(\mathrm{OH})_{2}$ and $\mathrm{Ti}_{3} \mathrm{C}_{2}(\mathrm{OH})_{2}$ MXenes show poor stability toward Li-SBs. In contrast, $\mathrm{Ti}_{2} \mathrm{CO}_{2}$ and $\mathrm{Ti}_{3} \mathrm{C}_{2} \mathrm{O}_{2}$ MXenes could effectively immobilize the soluble LiPS species and maintain the LiPSs intact thanks to the moderate attractions between the $\mathrm{O}$ groups in MXene $\left(\mathrm{Ti}_{2} \mathrm{CO}_{2}\right.$ or $\mathrm{Ti}_{3} \mathrm{C}_{2} \mathrm{O}_{2}$ ) monolayers and the Li ions in LiPS species. Interestingly, Chung's group reported that both $\mathrm{Ti}_{2} \mathrm{CF}_{2}$ and $\mathrm{Ti}_{2} \mathrm{CO}_{2}$ can suppress the shuttle effect, however, through different mecha- 1 nisms. ${ }^{[79]}$ The former is owing to the fact that the binding energies of LiPS intermediates with the MXene are always larger than those with electrolytes. Whereas the latter is due to the conversion of soluble long-chain LiPSs to insoluble elemental sulfur on the $\mathrm{Ti}_{2} \mathrm{CO}_{2}$ MXene surfaces. ${ }^{\left[{ }^{[9]}\right.}$ Despite some discrepancies in these theoretical simulations, both studies clearly indicate that the oxygen functionalized Ti-based MXenes exhibit good anchoring effect toward LiPSs.

To better simulate the actual situation, Chung's group further studied the anchoring behavior of both F- and O-terminated $\mathrm{Ti}_{2} \mathrm{C}$ MXene in a nonuniform surface form. ${ }^{[0]}$ Specifically, the models with the vacancy, substitutional and S-trapped sites of $\mathrm{F}$ - and $\mathrm{O}$-terminated $\mathrm{Ti}_{2} \mathrm{C}$ MXenes were designed. In addition, the adsorption energy of LiPS, the reactivity of the matrix with $\mathrm{Li}$ atoms, and the reduction states of $\mathrm{S}$ atoms were taken into consideration (Figure 6a-f). The result implies that on the F-substituted sites of the O-functionalized surface, the suppression mechanism changes from neutralization of the $\mathrm{S}$ atoms to anchoring of the LiPSs. On the other hand, at the vacancy sites, the strong interaction between the exposed $\mathrm{Ti}$ atoms and the $\mathrm{S}$ atoms in LiPSs leads to the trapping of the $\mathrm{S}$ atoms. As a result, the amount of active materials decreases (Figure 6g). It is therefore important to minimize the formation of vacancies in $\mathrm{Ti}_{2} \mathrm{C}$ MXene in order to achieve the optimal anchoring effect. ${ }^{[80]}$ Liu et al. also investigated the anchoring effect of S-terminated $\mathrm{Ti}_{2} \mathrm{C}$ MXene for Li-SBs. They found that compared to $\mathrm{Ti}_{2} \mathrm{CO}_{2}$ and $\mathrm{Ti}_{2} \mathrm{CF}_{2}$ MXenes, $\mathrm{Ti}_{2} \mathrm{CS}_{2}$ has the highest binding energy with LiPSs, thus the best performance in suppressing the shuttling effect. ${ }^{[53 a]}$ Moreover, the electrocatalytic mechanism of the $\mathrm{Ti}_{3} \mathrm{C}_{2} \mathrm{~T}_{2}$ MXenes was proposed by Wang et al. ${ }^{[81]}$ It was found that the energy barrier of $\mathrm{Li}_{2} \mathrm{~S}$ decomposition can be significantly reduced from 3.390 to $0.4 \mathrm{eV}$ when $\mathrm{Ti}_{3} \mathrm{C}_{2} \mathrm{~S}_{2}$ or $\mathrm{Ti}_{3} \mathrm{C}_{2} \mathrm{O}_{2}$ was used as the host material, resulting in a fast $\mathrm{Li}^{+}$diffusion.

Apart from Ti-based carbide MXenes, research on other MXenes was also carried out. ${ }^{[85,86]}$ For instance, Li et al. thoroughly studied the interactions between LiPSs and $\mathrm{Ti}_{2} \mathrm{CO}_{2}$ as well as six other MXenes $\left(\mathrm{M}_{3} \mathrm{C}_{2} \mathrm{O}_{2}\right.$, where $\mathrm{M}=\mathrm{Cr}, \mathrm{V}, \mathrm{Ti}, \mathrm{Nb}, \mathrm{Hf}$, and $\mathrm{Zr}$ ) host materials using DFT computations. ${ }^{[85]}$ Benefiting from the strong $\mathrm{Li}-\mathrm{O}$ interactions between the $-\mathrm{O}$ termination on MXene surface and the Li in LiPSs, all MXenes exhibit anchoring ability toward LiPSs. Among them, the $\mathrm{Cr}_{3} \mathrm{C}_{2} \mathrm{O}_{2}$ shows the largest binding energy toward both the $\mathrm{Li}_{2} \mathrm{~S}_{8}$ and $\mathrm{Li}_{2} \mathrm{~S}_{4}$ (Figure 6h), which is possibly associated with its small lattice constant. As shown in Figure 6i, the binding energy decreases with the increasing lattice constant of the $\mathrm{M}_{3} \mathrm{C}_{2} \mathrm{O}_{2}$ MXene. It is noted that the metallic character of all six $\mathrm{M}_{3} \mathrm{C}_{2} \mathrm{O}_{2}$ MXenes is well preserved during the whole adsorption process as verified by the DOS computations. ${ }^{[85]}$ Additionally, sulfur-terminated vanadium carbide $\left(\mathrm{V}_{2} \mathrm{CS}_{2}\right)$ MXene and $\mathrm{Li}_{2} \mathrm{~S} @ \mathrm{~V}_{2} \mathrm{CT}_{x}$ hybrid composite were also predicted to be promising anchoring materials for Li-SBs via the first-principles calculations. ${ }^{[87]}$

As discussed above, the theoretical predictions strongly indicate that various MXenes exhibit excellent anchoring effects to immobilize the LiPSs. It should be noted that these simulations are mostly based on ideal models, whereas in reality, the situation is much more complicated. Nonetheless, these investigations shed light on the modeling of MXenes and provide guidance for the design of MXene matrixes for high-performance Li-SBs. 

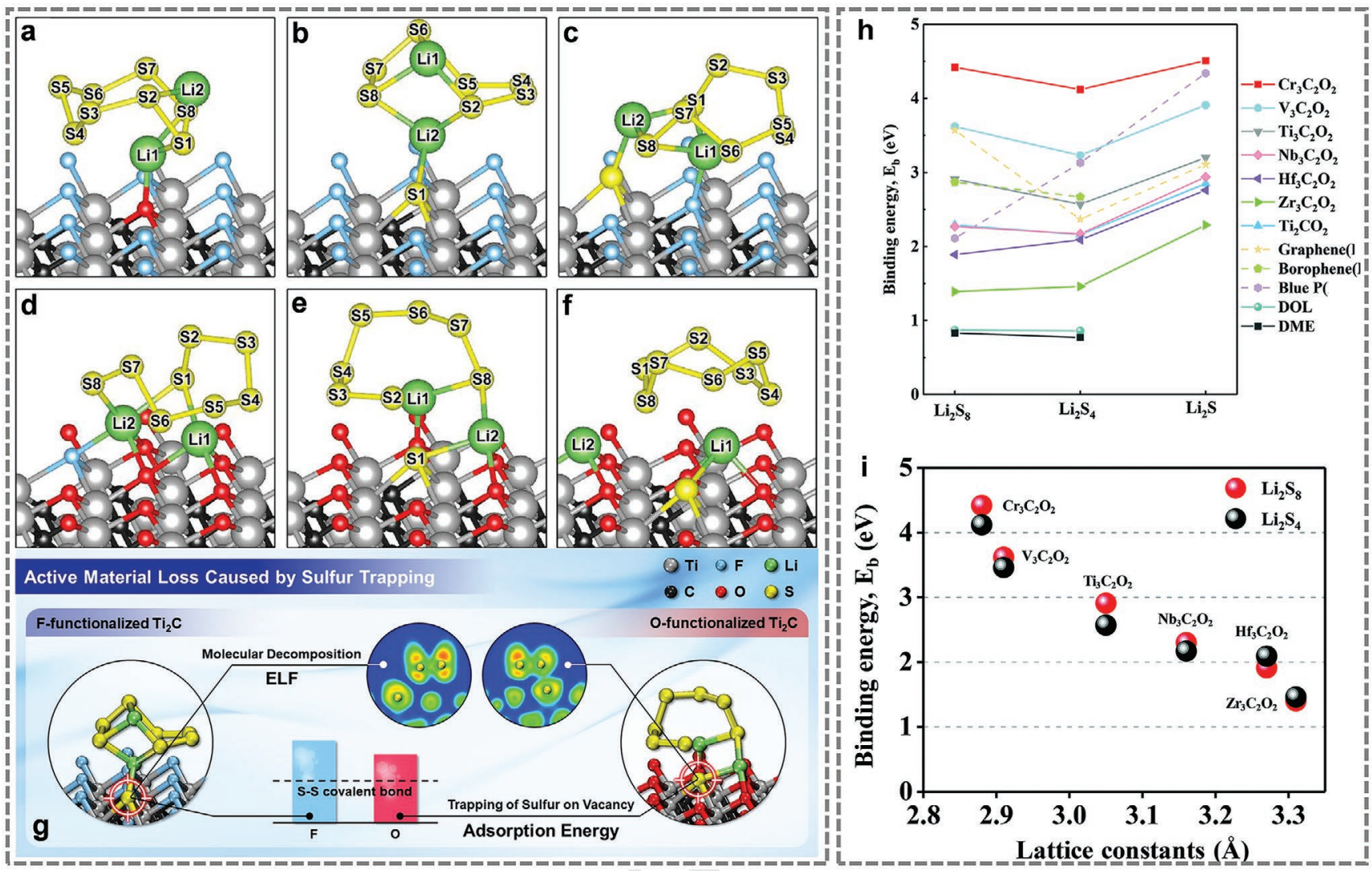

1

Figure 6. Optimized configurations of $\mathrm{Li}_{2} \mathrm{~S}_{8}$ anchored on the a) substitutional, b) vacancy, and c) S-trapped sites of $\mathrm{F}$-functionalized $\mathrm{Ti}_{2} \mathrm{C}$, and on 30 the d) substitutional, e) vacancy, and f) S-trapped sites of O-functionalized $\mathrm{Ti}_{2} \mathrm{C}$. g) Schematic illustration of the anchoring behavior of both $\mathrm{F}$ - and 31 O-terminated $\mathrm{Ti}_{2} \mathrm{C}$ MXene in a nonuniform surface form. Reproduced with permission. ${ }^{[80]}$ Copyright 2017, Elsevier. h) Plots of the calculated binding 32 energies between LiPSs and various MXenes, graphene, ${ }^{[82]}$ borophene, ${ }^{[83]}$ blue $\mathrm{P},{ }^{[84]}$ and 1,3-dioxolane (DOL), 1,2-dimethoxyethane (DME) electrolytes. i) The binding energies between the MXenes and $\mathrm{Li}_{2} \mathrm{~S}_{8}$ and $\mathrm{Li}_{2} \mathrm{~S}_{4}$ species, as a function of the lattice constants of MXenes. Reproduced with permission. ${ }^{[85]}$ Copyright 2019, Royal Society of Chemistry.

\subsubsection{MXene Sulfur Host}

Please replace Figure 6 with uploaded one

via a similar protocol for Li-SBs (Figure 7f). ${ }^{[90]}$ As illustrated in 36 Figure $7 \mathrm{~g}$, the porous structure of the P-NTC can provide rich 37 active sites for the adsorption and conversion of LiPS species. 38 The nitrogen doping not only enhances the interfacial interac- 39 tion between the P-NTC and $\mathrm{Li}$ atoms and $\mathrm{Li}_{2} \mathrm{~S}$ cluster, thus 40 facilitating the $\mathrm{Li}_{2} \mathrm{~S}$ nucleation kinetics, but also decreases the 41 dissociation barrier of $\mathrm{Li}_{2} \mathrm{~S}$ on P-NTC, resulting in accelerated 42 $\mathrm{Li}_{2} \mathrm{~S}$ decomposition. Moreover, the low diffusion barrier of 43 $\mathrm{Li}$ atoms on the surface of P-NTC promotes the sulfur redox 44 kinetics. Based on these findings, a multifunctional electro- 45 catalytic mechanism was proposed instead of conventional 46 chemical adsorption behavior. The as-fabricated P-NTC not 47 only immobilizes the LiPSs, but also acts as a multifunctional 48 catalyst to enhance both the decomposition and precipitation 49 of $\mathrm{Li}_{2} \mathrm{~S} \cdot{ }^{\left[{ }^{[0]}\right.}$ In addition, Zhang et al. developed robust, flexible, 50 highly conductive free-standing $\mathrm{S} @ \mathrm{Ti}_{3} \mathrm{C}_{2} \mathrm{~T}_{x}$ ink and $\mathrm{Ti}_{3} \mathrm{C}_{2} \mathrm{~T}_{x} / \mathrm{S} 51$ paper as sulfur hosts by two different strategies. ${ }^{[91]}$ Remarkably, 52 the $\mathrm{Ti}_{3} \mathrm{C}_{2} \mathrm{~T}_{x} / \mathrm{S}$ electrode exhibited outstanding stability with 53 a low capacity decay rate of $0.014 \%$ per cycle for 1500 cycles, 54 which is due to the conversion of initially formed thiosulfate 55 species to sulfates during cycling. ${ }^{[91 b]}$ Wang's group presented 56 a $\mathrm{Ti}_{3} \mathrm{C}_{2} \mathrm{~T}_{x}$ nanodots-interspersed $\mathrm{Ti}_{3} \mathrm{C}_{2} \mathrm{~T}_{x}$ nanosheets struc- 57 ture that could significantly reduce the interfacial resistance 58 and accelerate the redox kinetics of the reactions for Li-SBs. $\left.{ }^{[2]}\right] 59$ 


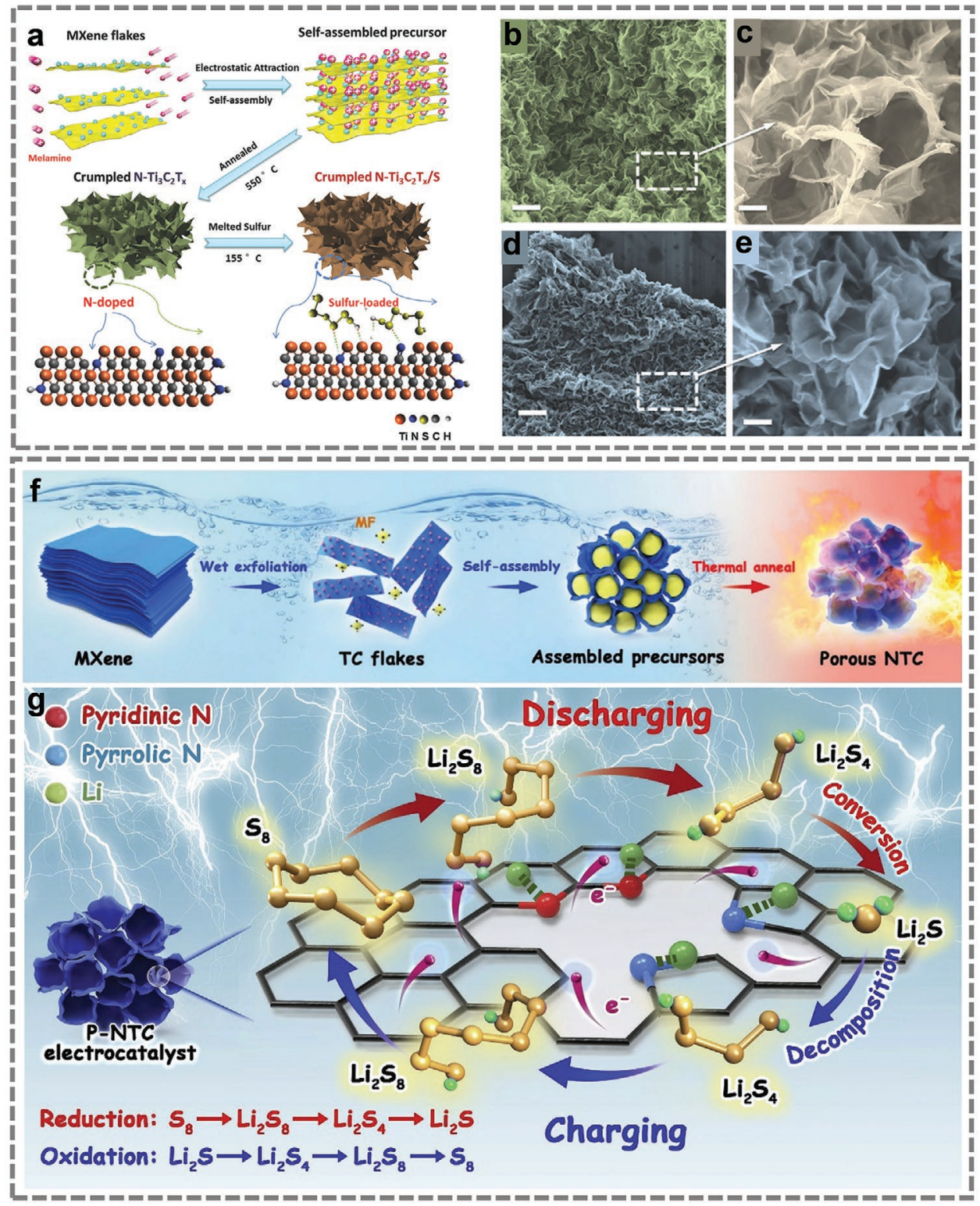

Figure 7. a) Schematic of the synthesis of $\mathrm{N}-\mathrm{Ti}_{3} \mathrm{C}_{2} \mathrm{~T}_{x} / \mathrm{S}$ electrode. SEM images of the b,c) $\mathrm{N}-\mathrm{Ti}_{3} \mathrm{C}_{2} \mathrm{~T}_{x}$ and d,e) $\mathrm{N}-\mathrm{Ti}_{3} \mathrm{C}_{2} \mathrm{~T}_{x} / \mathrm{S}$ samples, respectively. Reproduced with permission. ${ }^{[89]}$ Copyright 2018, Wiley. f) Schematic illustration of the synthesis of P-NTC. g) Schematic illustration of the mechanism of the P-NTC electrocatalyst in Li-SBs. Reproduced with permission. Copyright 2020, ${ }^{[90]}$ Elsevier.

Meanwhile, they also synthesized a 3D flower-like porous $\mathrm{Ti}_{3} \mathrm{C}_{2} \mathrm{~T}_{x}$ to accommodate sulfur. The electrode exhibited a high areal capacity of $10.04 \mathrm{mAh} \mathrm{cm}^{-2}$ and ultrahigh volumetric capacity of $2009 \mathrm{mAh} \mathrm{cm}^{-3}$. [93]

\subsubsection{MXene Composite-Based Sulfur Hosts}

MXene-Carbon Composites: Besides building up 3D MXene structures, combining MXene with other materials is also an effective strategy to improve the overall performance toward Li-SBs. Among various materials, carbons (graphene, carbon nanotube (CNT), porous carbon, etc.) with high conductivity and strong mechanical strength are popular candidates. ${ }^{[94]}$ Their merits of lightweight, high surface area and large pore volume could adequately accommodate solid charge/discharge products of $\mathrm{S} / \mathrm{Li}_{2} \mathrm{~S}$, and inhibit the restacking of MXene flakes simultaneously. On the other hand, the weak adsorption and conversion abilities of carbons toward LiPS species can be compensated by MXenes. For example, CNTs have been widely used for Li-SBs, however, they suffer from weak interactions with sulfur species. ${ }^{[95]}$ Therefore, MXenes with polar property and rich surface functional groups are ideal candidates to hybridize with CNTs to tackle this issue. In return, the introduction of CNTs can enlarge the specific surface area, buffer the volumetric variation and maintain the structural integrity of the composites. ${ }^{[94 \mathrm{e}, \mathrm{f}]}$ For instance, the $\mathrm{Mo}_{2} \mathrm{C}-\mathrm{CNT} / \mathrm{S}$ cathodes deliver a high reversible capacity of $1235 \mathrm{mAh} \mathrm{g}^{-1}$, with $925 \mathrm{mAh} \mathrm{g}^{-1}$ maintained 
after 250 cycles. In contrast, the capacity falls from 1034 to $639 \mathrm{mAh} \mathrm{g}^{-1}$ after 250 cycles for the $\mathrm{Mo}_{2} \mathrm{C} / \mathrm{S}$ cathodes. Incorporating MXene into reduced graphene oxide (rGO) aerogels is also an efficient way (note that the preparation of MXene aerogels without additives is challenging). Wang et al. fabricated free-standing 3D porous $\mathrm{Ti}_{3} \mathrm{C}_{2} \mathrm{~T}_{x}$ MXene/rGO hybrid aerogels to accommodate the liquid $\mathrm{Li}_{2} \mathrm{~S}_{6}$ electrolyte. ${ }^{[94 \mathrm{~b}]}$ The MXene can provide rich functional groups to anchor the LiPSs, while the rGO aerogels can inhibit the restacking of MXene. Consequently, the optimized composite electrode (30 wt\% MXene) can deliver a high reversible capacity of $1270 \mathrm{mAh} \mathrm{g}^{-1}$ at $0.1 \mathrm{C}$, compared to only $753 \mathrm{mAh} \mathrm{g}^{-1}$ of bare rGO. Metal-organic framework (MOF) derived mesoporous carbon has also been used as a space vector to prevent the restacking of MXene nanosheets (Figure $8 \mathrm{a}-\mathrm{e}){ }^{\left[{ }^{[4 c]}\right.}$ Thanks to the MOF-derived carbon, the 2D MXene nanosheets can be homogeneously distributed without aggregation. The as-prepared $\mathrm{Ti}_{3} \mathrm{C}_{2} \mathrm{~T}_{x} @$ Meso- $\mathrm{C}$ host material can achieve a significantly improved cycling performance with a capacity of $704.6 \mathrm{mAh} \mathrm{g}^{-1}$ retained after 300 cycles at $0.5 \mathrm{C}$ (against $470.2 \mathrm{mAh} \mathrm{g}^{-1}$ for the Meso-C/S cathode). ${ }^{[94 \mathrm{c}]}$

MXene-Metal Oxides Composites: Metal oxides were among the first investigated anchoring materials for stabilizing soluble
LiPSs. They can efficiently inhibit the leakage of active mate- 1 rials into the electrolytes, thus preventing the commonly 2 observed fast irreversible capacity fading and ultimately bat- 3 tery failure in Li-SBs. ${ }^{[97]}$ The high surface polarity in metal 4 oxides induced by the difference in electronegativity between 5 oxygen and transition metal atoms endows them strong inter- 6 actions with polar LiPSs. ${ }^{[96]}$ However, most metal oxides are 7 semiconductors with low electronic conductivity. Hybridizing 8 metal oxides with highly conductive MXenes is therefore a 9 reasonable approach to enhance the conductivity and thus the 10 overall performance. ${ }^{[96,98]}$ On the other hand, the metal oxides 11 can improve surface adsorption ability of MXenes toward 12 LiPSs. For instance, $\mathrm{TiO}_{2}$ is a polar metal oxide with strong 13 polysulfide adsorption ability, but suffers from low electronic 14 conductivity $\left(10^{-12}\right.$ to $\left.10^{-7} \mathrm{~S} \mathrm{~cm}^{-1}\right)$ and poor $\mathrm{Li}^{+}$ion diffusion 15 coefficient $\left(10^{-12}\right.$ to $\left.10^{-9} \mathrm{~cm}^{2} \mathrm{~s}^{-1}\right)$. To solve this issue, Gao et al. 16 developed a simple CTAB-assisted approach for the growth of 17 $\mathrm{TiO}_{2}$ quantum dots (QDs) on the highly conductive $\mathrm{Ti}_{3} \mathrm{C}_{2} \mathrm{~T}_{x} 18$ MXene flakes (Figure 8f). ${ }^{[96]}$ The DFT simulation (Figure 8g-j) 19 suggests weak chemical interactions of -2.62 and $-0.29 \mathrm{eV} 20$ between $\mathrm{Li}_{2} \mathrm{~S}_{4}$ and the $\mathrm{Ti}_{3} \mathrm{C}_{2}(\mathrm{OH})_{x}$ and $\mathrm{Ti}_{3} \mathrm{C}_{2} \mathrm{~F}_{x}$, respectively. 21 However, the introduction of $\mathrm{TiO}_{2}$ QDs on MXene surface 22

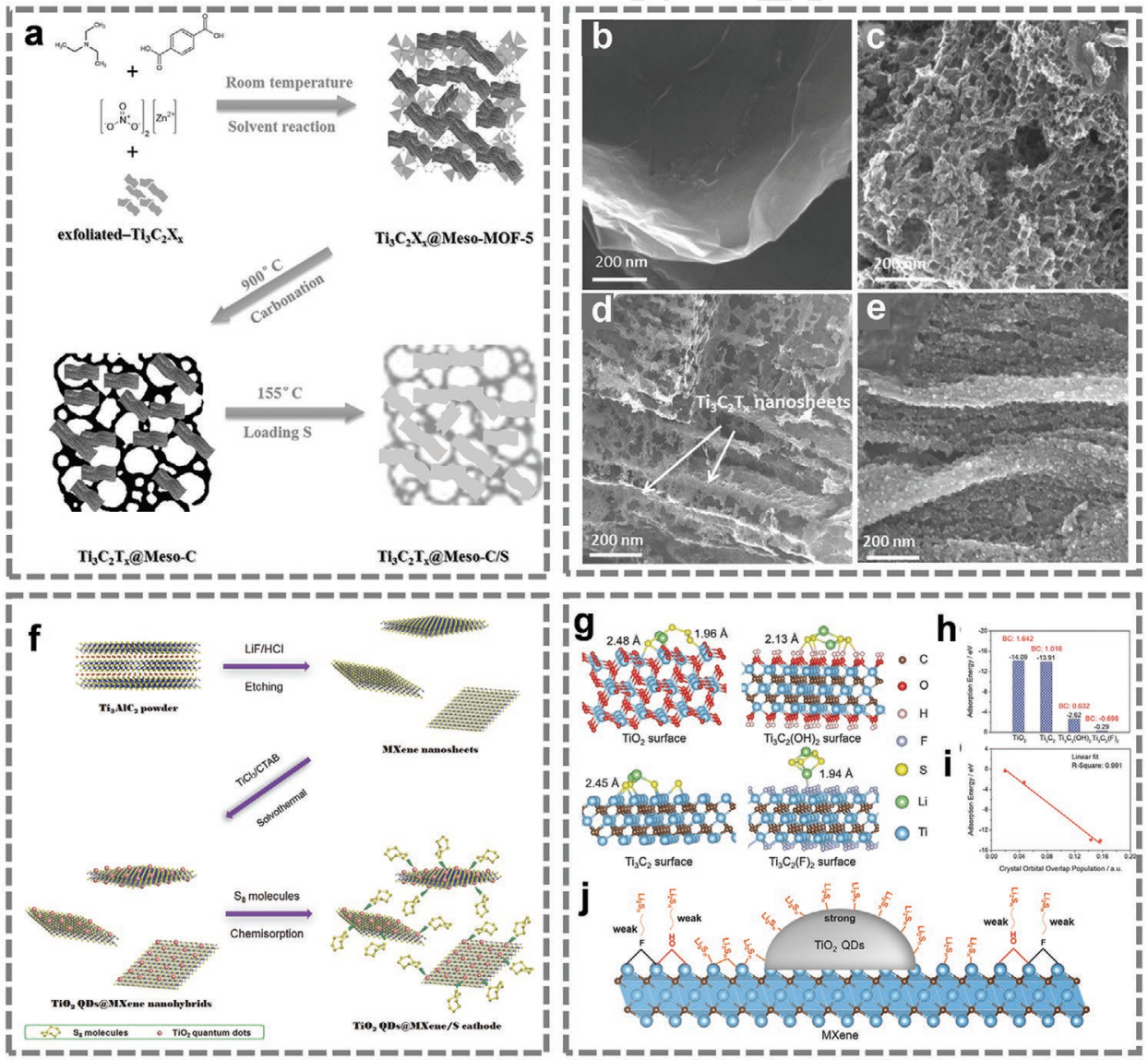

Figure 8. a) Synthesis strategy of the $\mathrm{Ti}_{3} \mathrm{C}_{2} \mathrm{~T}_{x} @$ @eso- $\mathrm{C} / \mathrm{S}$ electrode. SEM images of b) delaminated $\left.\left.\mathrm{Ti}_{3} \mathrm{C}_{2} \mathrm{~T}_{x}, \mathrm{c}\right) \mathrm{Meso}-\mathrm{C}, \mathrm{d}\right) \mathrm{Ti}{ }_{3} \mathrm{C}_{2} \mathrm{~T}_{x} @ M$ Meso-C, and e) $\mathrm{Ti}_{3} \mathrm{C}_{2} \mathrm{~T}_{x} @ M e s o-C / S$ composites. Reproduced with permission. ${ }^{[94 c]}$ Copyright 2016, Wiley. f) Synthesis route of the TiO ${ }_{2}$ QDs@MXene/S cathode. g) Optimized structures of $\mathrm{Li}_{2} \mathrm{~S}_{4}$ adsorbed on $\mathrm{TiO}_{2}, \mathrm{Ti}_{3} \mathrm{C}_{2}, \mathrm{Ti}_{3} \mathrm{C}_{2}(\mathrm{OH})_{2}$, and $\mathrm{Ti}_{3} \mathrm{C}_{2}(\mathrm{~F})_{2}$ surfaces. $\mathrm{h}$ ) Adsorption energies of $\mathrm{Li}_{2} \mathrm{~S}_{4}$ on different surfaces. i) Linear fit between adsorption energy and the crystal orbital overlap populations. j) Proposed strategy for suppressing the shuttling effect of LiPSs by the growth of $\mathrm{TiO}_{2}$ QDs on MXene nanosheets. Reproduced with permission. ${ }^{[96]}$ Copyright 2018, Wiley. 
1 could significantly enhance the polysulfides fixation ability of

2 MXene with an adsorption energy of $-14.09 \mathrm{eV}$. As a result, the

$3 \mathrm{TiO}_{2}$ QDs@MXene/S cathode shows superior performance

4 to that of MXene/S cathode in terms of long-term stability

5 and rate performance. ${ }^{[96]}$ What's more, by taking advantage of

6 Ti-based MXene (e.g., $\mathrm{Ti}_{3} \mathrm{C}_{2} \mathrm{~T}_{x}$ ) and their intrinsic susceptibility

7 to oxidation, $\mathrm{TiO}_{2} / \mathrm{MXene}$ composites can be easily achieved by

8 in-situ partial oxidation of the MXene precursors and further

9 serve as sulfur host. ${ }^{[98 a, c]}$

10 MXene-Polymer Composites: Although 2D materials exhibit

11 many advantages as sulfur hosts, a serious drawback is that

12 the openly accessible structure could eventually lead to the

13 leakage of the active materials into the electrolytes. Although

14 the dissolution of LiPS species can be mitigated by the strong

15 chemisorption of MXenes to some degree, the leakage of

16 active materials is inevitable when the interaction between the

17 host and outermost LiPS is insufficiently strong. In fact, the

18 LiPS dissolution into the electrolytes is intensified with their

19 accumulation on the outer surface. To solve this problem,

20 organic polydopamine (PDA) has been proposed as an over-

21 coat of MXene/S composites. ${ }^{[99]}$ The PDA coating layer could

22 trap sulfur species in the MXene nanosheets physically and

23 chemically. In the meantime, it can protect sulfur from direct

24 contact with the liquid electrolyte. The shuttle effect of LiPSs

25 can be mitigated by the strong Ti-S bonds originating from

26 the Lewis acid-base mechanism of MXene and the polar-

27 polar interaction/chemical adsorption between the PDA and

$28 \mathrm{LiPSs}{ }^{[99]}$ It is worth mentioning that the PDA coating process

29 in aqueous solution requires violent stirring overnight, which

30 may cause active sulfur loss and therefore it is hard to pre-

31 cisely control the sulfur loading. Yu et al. developed a similar

32 PDA coating process that shortened the reaction time to $6 \mathrm{~h}$,

33 which effectively improves the performance. ${ }^{[100]}$ Furthermore,

34 a self-assembly strategy was developed to fabricate $\mathrm{Ti}_{3} \mathrm{C}_{2} \mathrm{~T}_{x}$

35 MXene/polyethyleneimine functionalized CNT (T@CP) com-

36 posite for both sulfur host and antifouling separator. The as-

37 prepared T@CP product exhibits superb mechanical strength,

38 high conductivity, dual polarity and well-organized porosity,

39 which enable excellent electrochemical performance toward

40 the Li-SBs. ${ }^{[101]}$
The first MXene-functionalized separator for Li-SBs was reported by Lin et al. ${ }^{[104]}$ In the case of the $\mathrm{Ti}_{3} \mathrm{C}_{2}$ MXene modified glass fiber separator, the batteries can deliver an initial capacity of $1462 \mathrm{mAh} \mathrm{g}^{-1}$, which is $395 \mathrm{mAh} \mathrm{g}^{-1}$ higher than the pure glass fiber separator. Moreover, after 100 cycles, $820 \mathrm{mAh} \mathrm{g}^{-1}$ of capacity can be retained compared to $\approx 320 \mathrm{mAh} \mathrm{g}^{-1}$ using the commercial separator. $\mathrm{Ti}_{3} \mathrm{C}_{2}$ modified polypropylene separator was also developed for Li-SBs. ${ }^{[105]}$ The uniform surface MXene coating can be considered as a second current collector that decreases the internal resistance of the battery and thus facilitates the redox kinetics. Besides, the ultrathin (mass loading: $0.1 \mathrm{mg} \mathrm{cm}{ }^{-2}$, thickness: $522 \mathrm{~nm}$ ) but dense MXene coating can inhibit the shutting effect of LiPSs by its polar surface and Lewis acidbase mechanism, confining the polysulfides in the cathode region (Figure 9a). ${ }^{[105]}$ Later, Yin et al. developed a functional separator by coating $\mathrm{Ti}_{3} \mathrm{C}_{2} \mathrm{~T}_{x}$ MXene debris on the eggshell membrane (MXene/ESM) (Figure 9b). ${ }^{[106]}$ The as-obtained MXene/ESM separator showed a porous structure, good conductivity, excellent mechanical strength, and high thermal stability. By using MXene/ESM separator, the cycling performance was greatly enhanced with $74 \%$ capacity retention after 250 cycles at $0.5 \mathrm{C}$, in sharp contrast to only $11 \%$ for

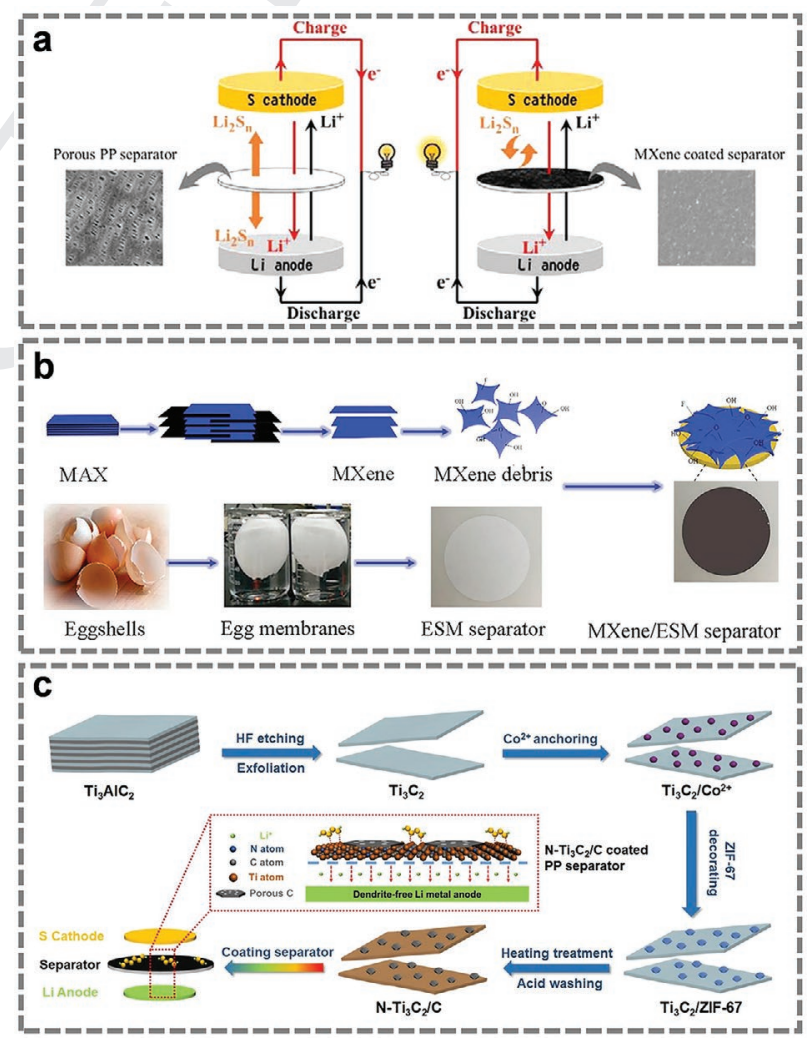

Figure 9. a) Schematic configurations of Li-SBs using commercial polypropylene (PP) membrane and MXene-modified polypropylene (MPP) separator, respectively. Reproduced with permission. ${ }^{[05]}$ Copyright 2016, American Chemical Society. b) Scheme of synthesis route of the MXene/ ESM. Reproduced with permission. ${ }^{106]}$ Copyright 2018, Elsevier. c) Schematic illustration of the preparation process of $\mathrm{N}-\mathrm{Ti}_{3} \mathrm{C}_{2} / \mathrm{C}$ nanosheets and the modified PP separator. Reproduced with permission. ${ }^{[108]}$ Copyright 2019, Elsevier. 2 3 4 5 6 7 


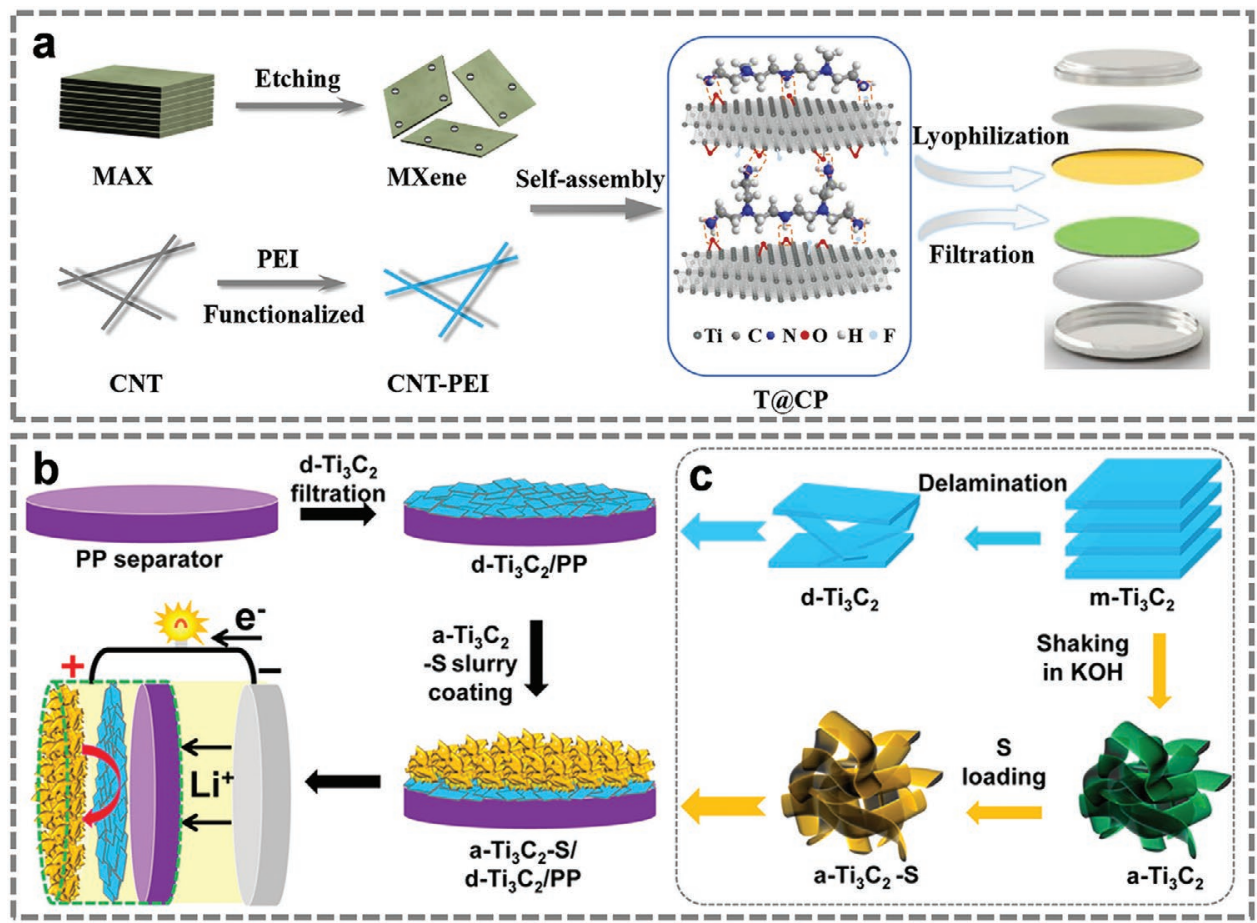

Figure 10. a) Schematic of the fabrication of T@CP nanohybrids for sulfur cathode and modified separator. Reproduced with permission. ${ }^{[01]}$ Copyright 26 2019, Elsevier. b) Schematic of the fabrication of the dual-functional a- $\mathrm{Ti}_{3} \mathrm{C}_{2}-\mathrm{S} / \mathrm{d}-\mathrm{Ti}_{3} \mathrm{C}_{2} / \mathrm{PP}$ electrode for $\mathrm{Li}-\mathrm{S}$ batteries. c) Schematic of the synthesis of 27 $\mathrm{Ti}_{3} \mathrm{C}_{2} \mathrm{~T}_{x}$ nanosheets and $\mathrm{a}-\mathrm{Ti}_{3} \mathrm{C}_{2}-\mathrm{S}$ hybrid. Reproduced with permission. ${ }^{[109]}$ Copyright 2018, American Chemical of Society.

the commercial separator. ${ }^{[106]}$ Han et al. further studied the thickness-dependent electrochemical performance of MXene modified separator for Li-SBs. ${ }^{[107]}$ They found that the lithium ion diffusion coefficient increases with the decrease of thickness of MXene layers on the separator. The shuttling of LiPS species was efficiently inhibited even at the lowest MXene mass loading of $0.016 \mathrm{mg} \mathrm{cm}^{-2}$, corresponding to a thickness of $100 \mathrm{~nm} .{ }^{[107]}$ Though ultrathin MXenes show excellent performance, they suffer from serious restacking. To solve this problem, a MXene/MOF derivative $2 \mathrm{D}$ hybrid $\left(\mathrm{N}-\mathrm{Ti}_{3} \mathrm{C}_{2} / \mathrm{C}\right)$ was synthesized by in situ growth of zeolitic imidazolate framework (ZIF-67) particles on delaminated MXene nanosheets, followed by vacuum annealing (Figure 9c). ${ }^{[108]}$ The resulting $\mathrm{N}-\mathrm{Ti}_{3} \mathrm{C}_{2} / \mathrm{C}$ can prevent MXene flakes from restacking and preserve their $2 \mathrm{D}$ nature. In this way, the $\mathrm{N}-\mathrm{Ti}_{3} \mathrm{C}_{2} / \mathrm{C}$ ensures the exposure of active Lewis acidic surface that has a strong interaction with the LiPSs. The theoretical calculation showed that N-doped MXene has higher adsorption energy than pristine MXene. The as-fabricated $\mathrm{N}-\mathrm{Ti}_{3} \mathrm{C}_{2} / \mathrm{C} @ \mathrm{PP}$ separator not only enabled the good ability to prevent the LiPSs migration, but also suppressed the dendrite growth of lithium anode. ${ }^{108]}$ Other MXene-based composites including 3D CNTs/ MXene ${ }^{[94 \mathrm{f}]}$ and $\mathrm{TiO}_{2} / \mathrm{MXene}^{[98 \mathrm{c}]}$ have also been used as the separator coating or interlayer between separator and cathode and achieved improved electrochemical performance.

In some cases, MXenes and their composites can be employed as dual-functional materials. For instance, Guo et al. fabricated a 3D MXene/polyethyleneimine (PEI) grafted CNTs composite and used it as both the sulfur host and interlayer for Li-SBs. The integrated design could simultaneously suppress the LiPSs shuttling and the growth of lithium den- 30 drite (Figure 10a). Consequently, a high reversible capacity of 31 $980 \mathrm{mAh}^{-1} \mathrm{~cm}^{-2}$ at $5 \mathrm{~mA} \mathrm{~cm}{ }^{-2}$ for 500 cycles was achieved. ${ }^{[101]} 32$ Wu et al. used alkali treated $\mathrm{Ti}_{3} \mathrm{C}_{2}$ MXene nanoribbons as $\mathrm{S} / 33$ polysulfides host and $2 \mathrm{D}$ exfoliated $\mathrm{Ti}_{3} \mathrm{C}_{2}$ MXene nanosheets 34 as interlayer and achieved a high reversible capacity of 35 $1062 \mathrm{mAh} \mathrm{g}^{-1}$ at $0.2 \mathrm{C}$ (Figure 10b,c). ${ }^{[109]}$ It should be men- 36 tioned that Yang et al. pointed out that the alkali treatment of 37 $\mathrm{Ti}_{3} \mathrm{C}_{2}$ MXene would lead to the formation of amorphous tita- 38 nium oxides. ${ }^{[110]}$

Metal lithium has been regarded as an optimal anode mate- 40 rial owing to its high theoretical capacity $\left(3680 \mathrm{mAh} \mathrm{g}^{-1}\right)$ and 41 low redox potential $(-3.04 \mathrm{~V}$ vs standard hydrogen electrode). 42 Nevertheless, the flammable characteristic and the formation 43 of dendrite during the repeated charge/discharge cycles pose a 44 safety hazard. Moreover, these issues are even severer in Li-SBs 45 because LiPS species also involve in the formation of solid elec- 46 trolyte interphase (SEI) layers. Recently, MXene has been suc- 47 cessfully used to protect the lithium anode in Li-SB system. ${ }^{[111]} 48$ We will systematically discuss this topic later in Section 5.4. 49

In this section, we have summarized both the theoretical and 50 experimental progress of MXene-based materials for Li-SBs. A 51 summary of the electrochemical performance of MXene-based 52 materials for Li-SBs is shown in Table 4. The use of versatile 53 MXene-based composites for the sulfur host, separator modi- 54 fication, and anode protection is proven to be able to effec- 55 tively suppress the shuttling effects of LiPS species, as well 56 as the lithium dendrite formation, therefore resulting in high 57 reversible capacity, enhanced rate capability, and better cycling 58 stability. 
Table 4. Summary of the electrochemical performance of MXene-based materials for Li-SBs $\left(1 \mathrm{C}\right.$ rate $\left.=1675 \mathrm{~mA} \mathrm{~g}^{-1}\right)$.

Material Sulfur loading $\left[\mathrm{mg} \mathrm{cm}^{-2}\right]$

\begin{tabular}{ccc} 
& \multicolumn{2}{c}{ Cycling performance } \\
\hline Current & Initial Capacity & Cycle \\
density $[\mathrm{C}]$ & {$\left[\mathrm{mAh} \mathrm{g}^{-1}\right]$} & number
\end{tabular}

Capacity
retention

Rate performance Capacity at current density [mAh g ${ }^{-1} @$ C rate]

Sulfur host $\mathrm{Ti}_{2} \mathrm{C}$

$0.5 \mathrm{C} \quad 1090$

650

$200 \mathrm{~mA} \mathrm{~g}^{-1}$

1291

$\mathrm{Ti}_{3} \mathrm{C}_{2} \mathrm{~T}_{x} @$ Meso-C

$0.5 \mathrm{C}$

1225.8

$\mathrm{Ti}_{3} \mathrm{C}_{2} \mathrm{~T}_{x} / \mathrm{rGO}$

$0.2 \mathrm{C}$

$0.5 \mathrm{C}$

CNT- $\mathrm{Ti}_{3} \mathrm{C}_{2} \mathrm{~T}_{x}$

1.5

$0.5 \mathrm{C}$

$0.2 \mathrm{C}$

$0.2 \mathrm{C}$

$\mathrm{N}-\mathrm{Ti}_{3} \mathrm{C}_{2} \mathrm{~T}_{x}$

1.5

$\mathrm{Ti}_{3} \mathrm{C}_{2} \mathrm{~T}_{x} / 1 \mathrm{~T}-2 \mathrm{H} \mathrm{MoS}_{2}-\mathrm{C}$

$2 \mathrm{C}$

$0.2 \mathrm{C}$

$0.5 \mathrm{C}$

1190

1144.2

1216

910

1144

825

765

7

$\mathrm{TiO}_{2} \mathrm{QDs} @ \mathrm{Ti}_{3} \mathrm{C}_{2} \mathrm{~T}_{x}$
$\mathrm{Ti}_{3} \mathrm{C}_{2} \mathrm{~T}_{x}$ ink
$\mathrm{Ti}_{3} \mathrm{C}_{2} \mathrm{~T}_{x}$ nanodot/xnanosheet
$\mathrm{Ti}_{3} \mathrm{C}_{2} \mathrm{~T}_{x} /$ Ultramicroporous carbon
S@ $@ \mathrm{TiO}_{2} / \mathrm{Ti}_{2} \mathrm{CT} \mathrm{T}_{x}$
$\mathrm{Ti}_{3} \mathrm{C}_{2} \mathrm{~T}_{x} / \mathrm{rGO}$
$\mathrm{Mo}_{2} \mathrm{C}-\mathrm{CNTs}$
$\mathrm{Ti}_{3} \mathrm{C}_{2} \mathrm{~T}_{x}$ flower

$\mathrm{TiO}_{2}-\mathrm{Ti}_{3} \mathrm{C}_{2}$
$\mathrm{Ti}_{3} \mathrm{C}_{2} \mathrm{~T}_{x}$ paper
$\mathrm{S} @ \mathrm{Ti}_{3} \mathrm{C}_{2} @ \mathrm{PDA}$
$\mathrm{Ti}_{3} \mathrm{C}_{2} / \mathrm{S} @ \mathrm{PDA}$
$\mathrm{Ti}_{3} \mathrm{C}_{2} / \mathrm{C}$

1

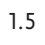

$$
\approx 2.5
$$

$\approx 2.5$

$$
\begin{aligned}
& 1.8 \\
& 9.2
\end{aligned}
$$

9.2

1
$8-2.0$

1.57

$\mathrm{MnO}_{2} @ \mathrm{Ti}_{3} \mathrm{C}_{2}$

$\mathrm{Ti}_{3} \mathrm{C}_{2} @$ carbon fiber

1.5

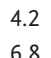

6.8
10.5

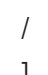

$1 \mathrm{C}$

$0.5 \mathrm{C}$

$0.5 \mathrm{C}$

$0.2 \mathrm{C}$

$0.5 \mathrm{C}$

$1 \mathrm{C}$

1014.1

100

300

100

100
300

1200

$$
\begin{aligned}
& 1200 \\
& 300
\end{aligned}
$$

200

1000

500

300

723

970

704.6

984.6

878.4

450

$\approx 450$

950

610

588

799.3

$2 \mathrm{C}$
$0.2 \mathrm{C}$

812

$\approx 900$

1184

$2 \mathrm{C}$

$0.05 \mathrm{C}$

$2 \mathrm{C}$

$1 \mathrm{C}$

$0.1 \mathrm{C}$

$1 / 30 \mathrm{C}$

$1 / 30 \mathrm{C}$

$1 / 30 \mathrm{C}$

1058

$9.5 \mathrm{mAh} \mathrm{cm}^{-2}$

1029

782.9

946

1235

1.0

1.2

$1 \mathrm{C}$

$1 \mathrm{C}$

$1.4-1.6$

$$
\mathrm{N}-\mathrm{Ti}_{3} \mathrm{C}_{2}
$$

$\mathrm{Ti}_{3} \mathrm{C}_{2} /$ glass fiber

$\mathrm{Ti}_{3} \mathrm{C}_{2} \mathrm{~T}_{x}$

Eggshell membrane

$$
\mathrm{CNT} / \mathrm{Ti}_{3} \mathrm{C}_{2} \mathrm{~T}_{x}
$$

$$
\mathrm{Ti}_{3} \mathrm{C}_{2} \mathrm{~T}_{x}
$$

$\mathrm{TiO}_{2}-\mathrm{Ti}_{3} \mathrm{C}_{2} \mathrm{~T}_{x} /$ graphene

$\mathrm{N}-\mathrm{Ti}_{3} \mathrm{C}_{2} / \mathrm{C}$

$\begin{array}{ccc}1.9 & 500 \mathrm{~mA} \mathrm{~g}^{-1} & 820 \\ 2.07 & 0.5 \mathrm{C} & 1185 \\ & 1 \mathrm{C} & 948 \\ 0.8 & 0.1 \mathrm{C} & 1415 \\ 2.5 & 1 \mathrm{C} & 987 \\ & 1 \mathrm{C} & \approx 570 \\ 1.2 & 0.5 \mathrm{C} & 848.7 \\ & 1 \mathrm{C} & 743.7 \\ 1.2 & 2 \mathrm{C} & \approx 800 \\ 3.4 & 0.5 \mathrm{C} & 945\end{array}$

1178

957

1417

1169

1439

798

1197

1001

1180

$\approx 707$

$\approx 716$

1058.4

820

820

1185

1415

1415
987

$\approx 570$

848.7

743.7

$\approx 800$

945

$\begin{array}{ll}500 & 680 \\ 100 & 533\end{array}$

$800 \quad 724$

400

815

$6 \mathrm{mAh} \mathrm{cm}^{-2}$

946.7

464.0

596

925

855

805

662

1000

1500

$$
150
$$$$
200
$$$$
1000
$$

$$
200
$$$$
500
$$$$
500
$$$$
1000
$$$$
1200
$$

100

250$$
150
$$

100
600

$$
600
$$$$
500
$$$$
500
$$$$
1000
$$$$
500
$$$$
970
$$$$
1044
$$$$
556
$$$$
1096
$$$$
651
$$$$
790
$$$$
530
$$$$
501
$$$$
626
$$$$
\approx 495
$$$$
721
$$$$
\begin{aligned}
& 862 \\
& 672
\end{aligned}
$$$$
\begin{aligned}
& 992 \\
& 614
\end{aligned}
$$$$
400
$$$$
550
$$$$
495
$$$$
\approx 576
$$$$
716
$$

$660 @ 4 C \quad$ [76]

$520 @ 3.2 \mathrm{Ag}^{-1} \quad[88]$

$544.3 @ 4 C$

923@2c

$750 @ 5 c$

$1216 @ 0.5$ C

$947 @ 0.5 \mathrm{C}$

835@1c

905.1@1c

$677.2 @ 2$ C

$1037 @ 0.5$ C

663@5c

$1244 @ 0.1 \mathrm{C}$

$1004 @ 2$ C

882@3c

502.3@2 C

$879.2 @ 0.2 \mathrm{C}$

$1270 @ 0.1 c$

$977 @ 1 \mathrm{C}$

$\approx 832 @ 2 \mathrm{C}$

$\approx 673$ @ 5 C

$969 @ 5$

$1075 @ 2$ C

624@6c

$735 @ 1 c$

$442 @ 4$ C

$1669 @ 0.1 \mathrm{C}$

$520 @ 5$ C

$615 @ 2$ C

$1508.1 @ 0.1 \mathrm{C}$

$795.5 @ 2$ C

$1082 @ 0.5 \mathrm{C}$

$792 @ 3 c$

476 @ $2 \mathrm{~A} \mathrm{~g}^{-1}$

$948 @ 1$ C

728@2 C

$743.7 @ 1$ C

$800 @ 2$ C 
Table 4. Continued.

\begin{tabular}{|c|c|c|c|c|c|c|c|c|}
\hline \multirow[t]{2}{*}{ Material } & & \multirow{2}{*}{$\begin{array}{l}\text { Sulfur loading } \\
{\left[\begin{array}{l}{\left[\mathrm{mg} \mathrm{cm}^{-2}\right]}\end{array}\right.}\end{array}$} & \multicolumn{4}{|c|}{ Cycling performance } & \multirow{2}{*}{$\begin{array}{c}\text { Rate performance } \\
\text { Capacity at current density } \\
{\left[\mathrm{mAh} \mathrm{g}^{-1} @ \mathrm{C} \text { rate }\right]}\end{array}$} & \multirow[t]{2}{*}{ Ref. } \\
\hline & & & $\begin{array}{c}\text { Current } \\
\text { density }[\mathrm{C}]\end{array}$ & $\begin{array}{c}\text { Initial Capacity } \\
{\left[\mathrm{mAh} \mathrm{g}^{-1}\right]}\end{array}$ & $\begin{array}{c}\text { Cycle } \\
\text { number }\end{array}$ & $\begin{array}{l}\text { Capacity } \\
\text { retention }\end{array}$ & & \\
\hline \multirow{5}{*}{$\begin{array}{l}\text { Separator/ } \\
\text { sulfur host }\end{array}$} & $\mathrm{a}-\mathrm{Ti}_{3} \mathrm{C}_{2} \mathrm{~T}_{x}$ nanoribbon/nanosheet & $0.7-1$ & $0.5 \mathrm{C}$ & $\approx 900$ & 200 & $\approx 400$ & $691 @ 1$ C & [109] \\
\hline & & & $2 \mathrm{C}$ & $\approx 800$ & 200 & $\approx 350$ & $403 @ 4 C$ & \\
\hline & & & & & & & $288 @ 10 \mathrm{C}$ & \\
\hline & $\mathrm{Ti}_{3} \mathrm{C}_{2} \mathrm{~T}_{x} / \mathrm{CNTs} / \mathrm{PEI}$ & 2.6 & $0.25 \mathrm{C}$ & 1227 & 200 & 1100 & $950 @ 2.5 \mathrm{C}$ & [101] \\
\hline & & & $1 \mathrm{C}$ & 1035 & 500 & 980 & & \\
\hline Anode & $\mathrm{Ti}_{3} \mathrm{C}_{2} /$ lithium film & 1 & 1 & 1 & 1 & 1 & I & [111] \\
\hline
\end{tabular}

\subsection{Sodium- and Potassium-Ion Storage}

SIBs and PIBs based on earth-abundant elemental $\mathrm{Na}$ and $\mathrm{K}$ have been gaining increasing interest in the battery research community. However, the large ionic radii of $\mathrm{Na}^{+}$and $\mathrm{K}^{+}$make them much more challenging to intercalate into many wellestablished LIB anode materials. In this regard, MXenes with tunable interlayer spacing, high electronic conductivity, and rich surface chemistry are predicted to be promising anodes for both the SIBs and PIBs. ${ }^{[52 b, c, 112]}$ Particularly, Xie et al. revealed both theoretically and experimentally that $\mathrm{Na}^{+}$and $\mathrm{K}^{+}$could be intercalated into functionalized MXene electrodes. ${ }^{[52 \mathrm{~b}]}$ They found that the surface functional groups and transition metal species have a significant impact on the capacity and voltage of MXenes. The $\mathrm{M}_{2} \mathrm{C}$ MXenes ( $\mathrm{M}=\mathrm{Sc}, \mathrm{V}, \mathrm{Ti}, \mathrm{V}$, etc.) with oxygen termination or without any functional groups, are demonstrated to be the most promising for metal ion storage. ${ }^{[52 \mathrm{c}]}$ In addition, a large number of experimental studies have confirmed the feasibility of MXenes for sodium/potassium-ion storage. In this section, we divide the MXene-based materials into three categories (MXenes, MXenebased hybrid materials, and MXene-derived materials) and discuss their utilization for sodium/potassium-ion storage.

\subsubsection{MXene Electrodes}

15

Up to date, various MXenes have been studied for SIBs and 16 PIBs. ${ }^{[13 f, 113]}$ With the accelerating development of MXene bat- 17 tery research, it is particularly important to investigate the 18 charge storage mechanism in MXenes. It was found that the 19 MXene electrode in nonaqueous $\mathrm{Na}^{+}$electrolyte behaves differ- 20 ently from that in aqueous $\mathrm{Na}^{+}$electrolyte or in nonaqueous $\mathrm{Li}^{+} 21$ electrolyte. For instance, the $\mathrm{Na}^{+}$ions can spontaneously inter- 22 calate into the MXene interlayer spaces by simple immersion, 23 while such a phenomenon cannot be observed in a nonaqueous 24 electrolyte (i.e., $\mathrm{NaPF}_{6}$ /ethylene carbonate/diethyl carbonate 25 mixture) ${ }^{[114]}$ Interestingly, Yamada et al. demonstrated that 26 the pillared $\mathrm{Ti}_{2} \mathrm{CT}_{x}$ structure was formed during the first cycle 27 because of the "activation" process. ${ }^{[113 \mathrm{~d}]}$ The activated electrode 28 allowed both reversible $\mathrm{Na}^{+}$interaction/deintercalation into the 29 layers and $\mathrm{Na}^{+}$adsorption/desorption on the surfaces. Later, a 30 similar storage behavior was observed in $\mathrm{Ti}_{3} \mathrm{C}_{2} \mathrm{~T}_{x}$ by the same 31 group. ${ }^{[115]}$ As schematically shown in Figure 11a, during the acti- 32 vation process, residual $\mathrm{Na}^{+}$along with the penetrated solvent 33 molecules are trapped in between the MXene layers. Such a 34 $\mathrm{Na}^{+}$-pillared structure can stabilize the electrode by minimizing 35
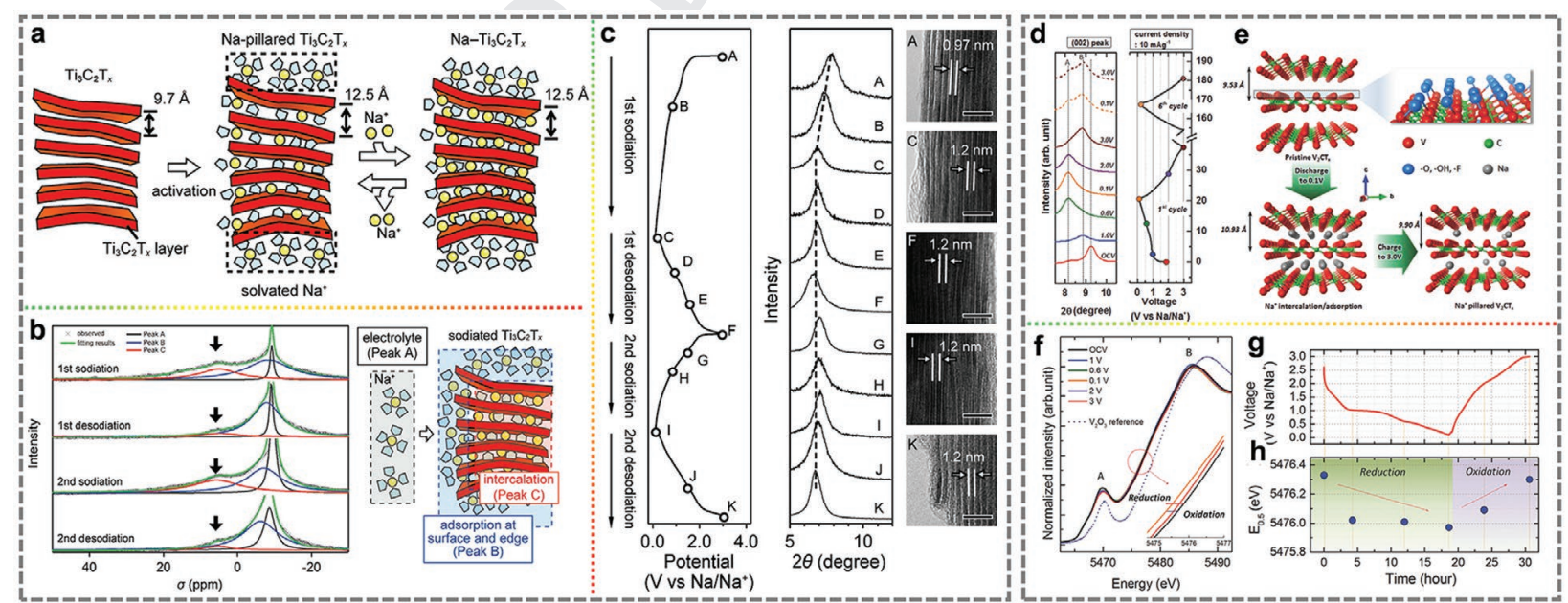

Figure 11. a) Schematic illustration for the proposed mechanism of reversible $\mathrm{Na}^{+}$insertion/desertion into $\mathrm{Ti}_{3} \mathrm{C}_{2} \mathrm{~T}_{x}$. b) ${ }^{23} \mathrm{Na}$ NMR spectra during the initial two cycles. c) Ex situ XRD patterns and TEM images for $\mathrm{Ti}_{3} \mathrm{C}_{2} \mathrm{~T}_{x}$ upon sodium intercalation and deintercalation. Scale bar: $5 \mathrm{~nm}$. Reproduced with permission. ${ }^{[15]}$ Copyright 2016, American Chemical of Society. d) Ex situ XRD patterns of $\mathrm{V}_{2} \mathrm{CT}_{x}$ during $\mathrm{Na}^{+}$insertion/desertion at the 1st and 6th cycles. e) Schematic illustration of the expansion/contraction behavior of $\mathrm{V}_{2} \mathrm{CT}_{x}$ during $\mathrm{Na}^{+}$intercalation/deintercalation. $\mathrm{f}$ ) Ex situ $\mathrm{V}$ K-edge hard X-ray absorption near edge spectroscopy results of $\mathrm{V}_{2} \mathrm{CT}_{x}$ at selected cell voltages during the first cycle (from open circuit voltage to fully discharged status and then recharged to $3 \mathrm{~V}$ ). g) Corresponding voltage profile, and c) variation of $\mathrm{V}$ edge energy at selected cell voltages. Reproduced with permission. ${ }^{[16]}$ Copyright 2017 , Wiley. 


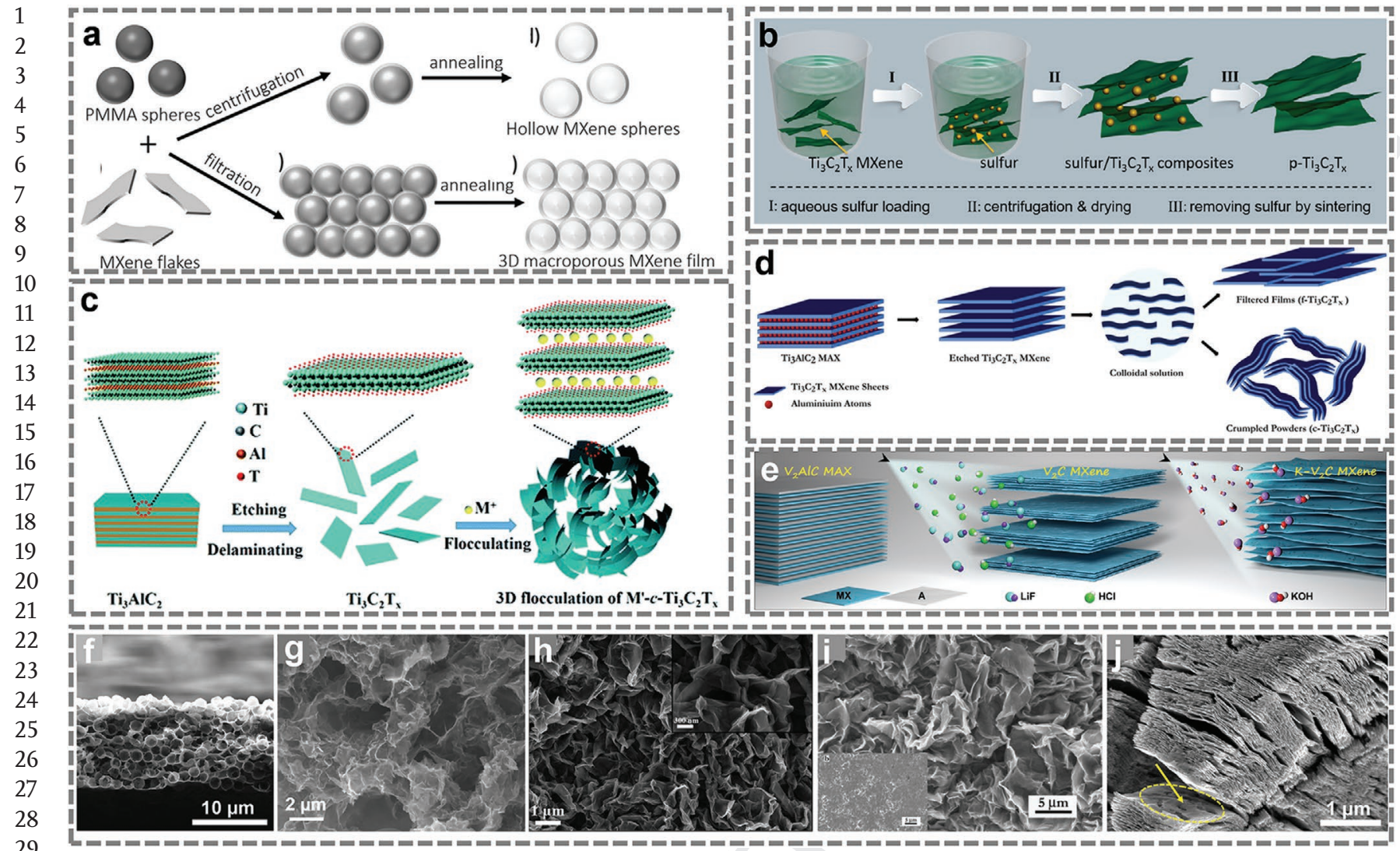

Figure 12. Synthesis strategies and corresponding SEM images of a,f) 3D hollow MXene spheres, b,g) porous $\left.\mathrm{Ti}_{3} \mathrm{C}_{2} \mathrm{~T}_{x}\left(\mathrm{p}-\mathrm{Ti}_{3} \mathrm{C}_{2} \mathrm{~T}_{x}\right), c, h\right)$ alkali-induced crumpled $\mathrm{Ti}_{3} \mathrm{C}_{2} T_{x}$, d,i) acid-induced crumpled $\mathrm{Ti}_{3} \mathrm{C}_{2} \mathrm{~T}_{x}$, and e,j) porous $\mathrm{K}-\mathrm{V}_{2} \mathrm{C}$ MXene, respectively. a,f) Reproduced with permission. ${ }^{[11 b]}$ Copyright 2017, Wiley. b,g) Reproduced with permission. ${ }^{[124]}$ Copyright 2018, American Chemical of Society. c,h) Reproduced with permission. ${ }^{[177 a]}$ Copyright 2018, Royal Society of Chemistry. d,i) Reproduced with permission. ${ }^{[17 b]}$ Copyright 2018, Taylor \& Francis. e,j) Reproduced with permission. ${ }^{[4 i]}$ Copyright 2019, Elsevier.

the structural expansion/shrinkage during the subsequent cycles, as confirmed by a wide spectrum of characterizations (Figure 11b,c) as well as DFT calculations. Meanwhile, the $\mathrm{Na}^{+}$ ion interaction and charge storage mechanism in $\mathrm{V}_{2} \mathrm{CT}_{x}$ MXene were studied by Yang et al. ${ }^{[16]}$ Except for the similar structural evolution as in the cases of $\mathrm{Ti}_{2} \mathrm{CT}_{x}$ and $\mathrm{Ti}_{3} \mathrm{C}_{2} \mathrm{~T}_{x}$, the reduction and oxidation of the vanadium element during the $\mathrm{Na}^{+}$intercalation/deintercalation was confirmed (Figure 11d-h), implying that the redox reaction of the transition metals contributes to the charge storage. ${ }^{[116]}$

Although MXenes have shown promising performance toward alkali ion storage, there are still some challenges that need to be addressed. For example, the etched MXene with a multilayer accordion-like structure could lead to low material utilization and poor flexibility. Whereas the restacking of exfoliated MXene nanosheets originating from van der Waals 52 force and/or hydrogen bonds would severely hinder the elec53 trolyte diffusion and permeation. Both of these effects could 54 result in inferior electrochemical performance. In order to 55 effectively address these issues, efforts have been devoted to 56 fabricating various 3D architectures, such as porous MXenes, 57 crumpled MXenes, and MXene hollow spheres, via different 58 strategies. Zhao et al. synthesized the 3D microporous MXene 59 films using spherical polymethylmethacrylate (PMMA) as the template. ${ }^{[11 b]}$ As depicted in Figure 12a, upon mixing the MXene nanosheets with PMMA spheres suspension, MXene nanosheets would spontaneously warp the surface of PMMA driven by the electrostatic force. The MXene hollow spheres and the 3D free-standing films can be readily obtained by facile centrifugation or vacuum filtration with the subsequent annealing process. More importantly, the size of the spheres is tunable, and this method can be extended to prepare other MXene compositions, such as $\mathrm{V}_{2} \mathrm{CT}_{x}$ and $\mathrm{Mo}_{2} \mathrm{CT}_{x}$. The asprepared $3 \mathrm{D} \mathrm{Mo}_{2} \mathrm{CT}_{x}$ film electrode can achieve a high reversible capacity of $370 \mathrm{mAh} \mathrm{g}^{-1}$ at $\left.0.25 \mathrm{C}(1 \mathrm{C}=200 \mathrm{~mA} \mathrm{~g})^{-1}\right)$, along with excellent rate capability and long-term stability for SIBs. After 1000 cycles, a reversible capacity of $290 \mathrm{mAh} \mathrm{g}^{-1}$ at $2.5 \mathrm{C}$ can be maintained. ${ }^{[11 \mathrm{~b}]}$ Later, Xie et al. reported the synthesis of a porous and anisotropic structure by a sulfur loading-removal strategy (Figure 12b). ${ }^{[17]}$ Because of the metallic conductivity, low charge diffusion barrier and efficient electrolyte contact, the $3 \mathrm{D}$ porous $\mathrm{Ti}_{3} \mathrm{C}_{2} \mathrm{~T}_{x}\left(\mathrm{p}-\mathrm{Ti}_{3} \mathrm{C}_{2} \mathrm{~T}_{x}\right)$ exhibited outstanding rate performance. Furthermore, similar crumpled MXene structures can also be achieved by simple acid or alkali treatment (Figure 12c,d). The resultant products showed much superior performance compared to pristine MXenes. Additionally, Ming et al. presented a simple method involving dual acid/alkali treatment to prepared 3D porous
1 2 3 4 5 6 7 8 9 
accordion-like $\mathrm{K}-\mathrm{V}_{2} \mathrm{C}$ MXene (Figure 12e), which shows greatly enhanced performance for $\mathrm{K}^{+}$storage with a high capacity of $152 \mathrm{mAh} \mathrm{g}^{-1}$ at $100 \mathrm{~mA} \mathrm{~g}^{-1}$. ${ }^{[4 i]}$ Bao et al. also presented the preparation of $\mathrm{Ti}_{3} \mathrm{C}_{2}$ MXene nanoribbons by alkalized treatment. ${ }^{[118]}$ Benefiting from the expanded interlayer distance and the 3D interconnected porous frameworks, the resulting MXene nanoribbons showed excellent sodium/potassium storage performance in terms of high capacity and stability compared to the pristine MXene. Apart from being used as anode electrodes, Simon et al. demonstrated the possibility of using $\mathrm{V}_{2} \mathrm{C}$ MXene as a cathode electrode for sodium-ion capacitors, which expands the potential applications of the MXene family. ${ }^{[119]}$
It is also demonstrated that elemental doping or incor- 1 poration can effectively modify the properties of MXenes, 2 leading to enhanced electrochemical performance toward 3 alkali ion storage. Particularly, Luo et al. synthesized the 4 $\mathrm{S}$ atom intercalated $\mathrm{Ti}_{3} \mathrm{C}_{2}$ MXene (CT-S@ $\mathrm{Ti}_{3} \mathrm{C}_{2}$ ) by mul- 5 tiple steps, i.e., CTAB preintercalation, thermal diffusion 6 with sulfur, and vacuum annealing process (Figure 13a). ${ }^{[120]} 7$ The interlayer distance of the pristine MXene expands from 8 0.98 to $1.37 \mathrm{~nm}$ upon $\mathrm{S}$ intercalation (Figure 13b-g). The as- 9 obtained CT-S@ $\mathrm{Ti}_{3} \mathrm{C}_{2}-450$ sample exhibited a high reversible 10 sodium-ion storage capacity of $492 \mathrm{mAh} \mathrm{g}^{-1}$ after 100 cycles. 11 According to the DFT computations (Figure 13h-i), both 12 the first and second adsorption layers of $\mathrm{Ti}_{3} \mathrm{C}_{2} \mathrm{~S}_{2}$ have lower 13
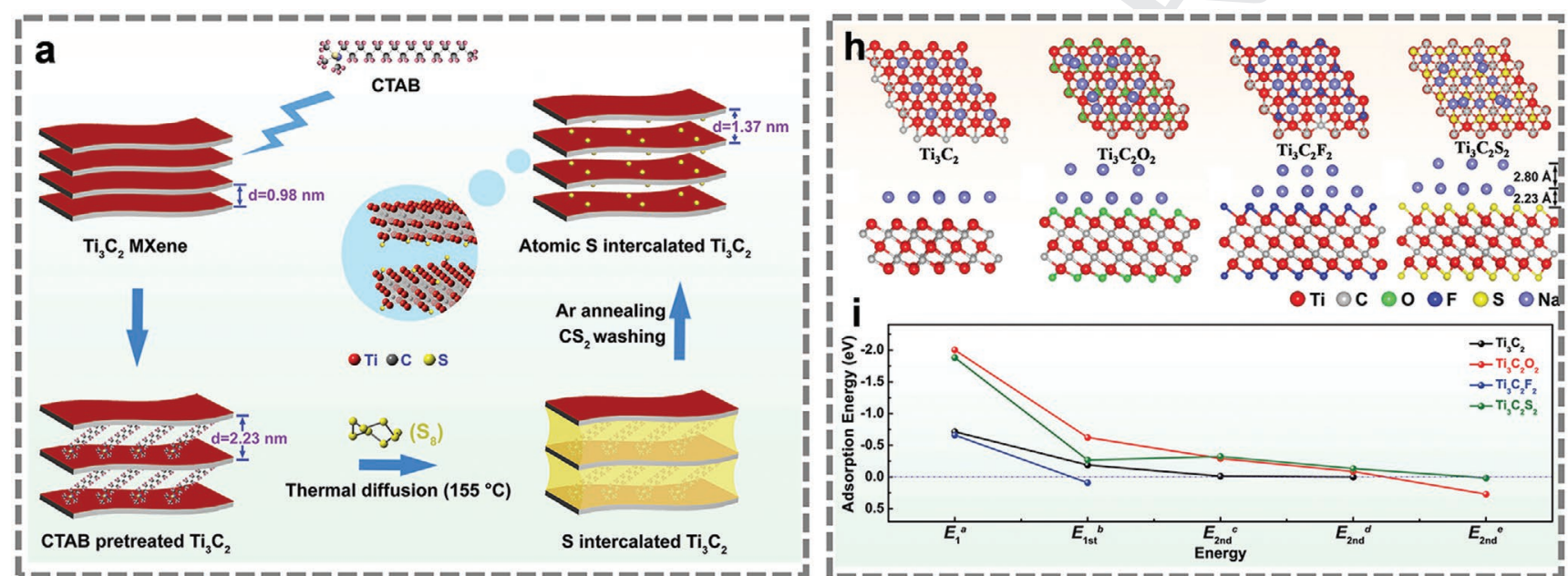

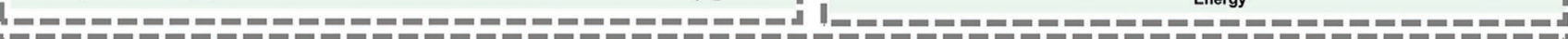

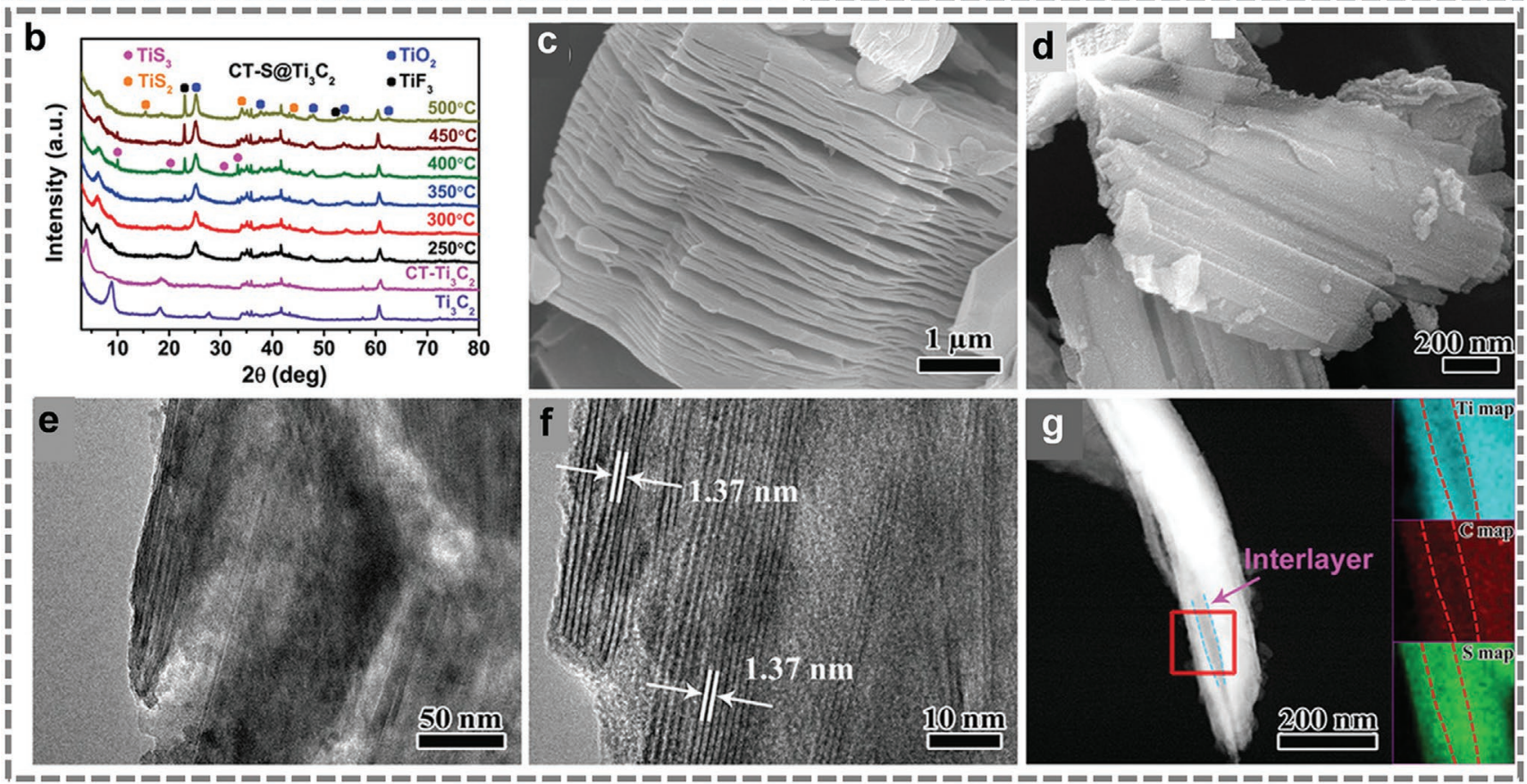

Figure 13. a) Schematic illustration of the preparation of $\mathrm{S}$ atoms intercalated $\mathrm{Ti}_{3} \mathrm{C}_{2}$. b) XRD patterns of $\mathrm{Ti}_{3} \mathrm{C}_{2}, \mathrm{CTAB}-$ pretreated $\mathrm{Ti}_{3} \mathrm{C}_{2}\left(\mathrm{CT}-\mathrm{Ti}_{3} \mathrm{C}_{2}\right)$, and $\mathrm{S}$ atoms intercalated $\mathrm{Ti}_{3} \mathrm{C}_{2}$ MXenes (CT-S@ $@ \mathrm{Ti}_{3} \mathrm{C}_{2}$ ) obtained at different annealing temperatures. SEM images of c) $\mathrm{Ti}_{3} \mathrm{C}_{2}$ and d) CT-S@Ti ${ }_{3} \mathrm{C}_{2}-450$. e,f) TEM images of CT-S@Ti $\left.\mathrm{C}_{2}-450 . \mathrm{g}\right)$ STEM images of CT-S@Ti $\mathrm{C}_{2}-450$ and the corresponding elemental maps. h) DFT calculations and geometric structures for $\mathrm{Na}$ adsorption on the $\mathrm{Ti}_{3} \mathrm{C}_{2}, \mathrm{Ti}_{3} \mathrm{C}_{2} \mathrm{O}_{2}, \mathrm{Ti}_{3} \mathrm{C}_{2} \mathrm{~F}_{2}$, and $\mathrm{Ti}_{3} \mathrm{C}_{2} \mathrm{~S}_{2}$ monolayer of top and side views. i) The calculated Na adsorption energies on the $\mathrm{Ti}_{3} \mathrm{C}_{2}, \mathrm{Ti}_{3} \mathrm{C}_{2} \mathrm{O}_{2}, \mathrm{Ti}_{3} \mathrm{C}_{2} \mathrm{~F}_{2}$, and $\mathrm{Ti}_{3} \mathrm{C}_{2} \mathrm{~S}_{2}$ monolayer. Reproduced with permission. ${ }^{[120]}$ Copyright 2019, Wiley. 
2

3
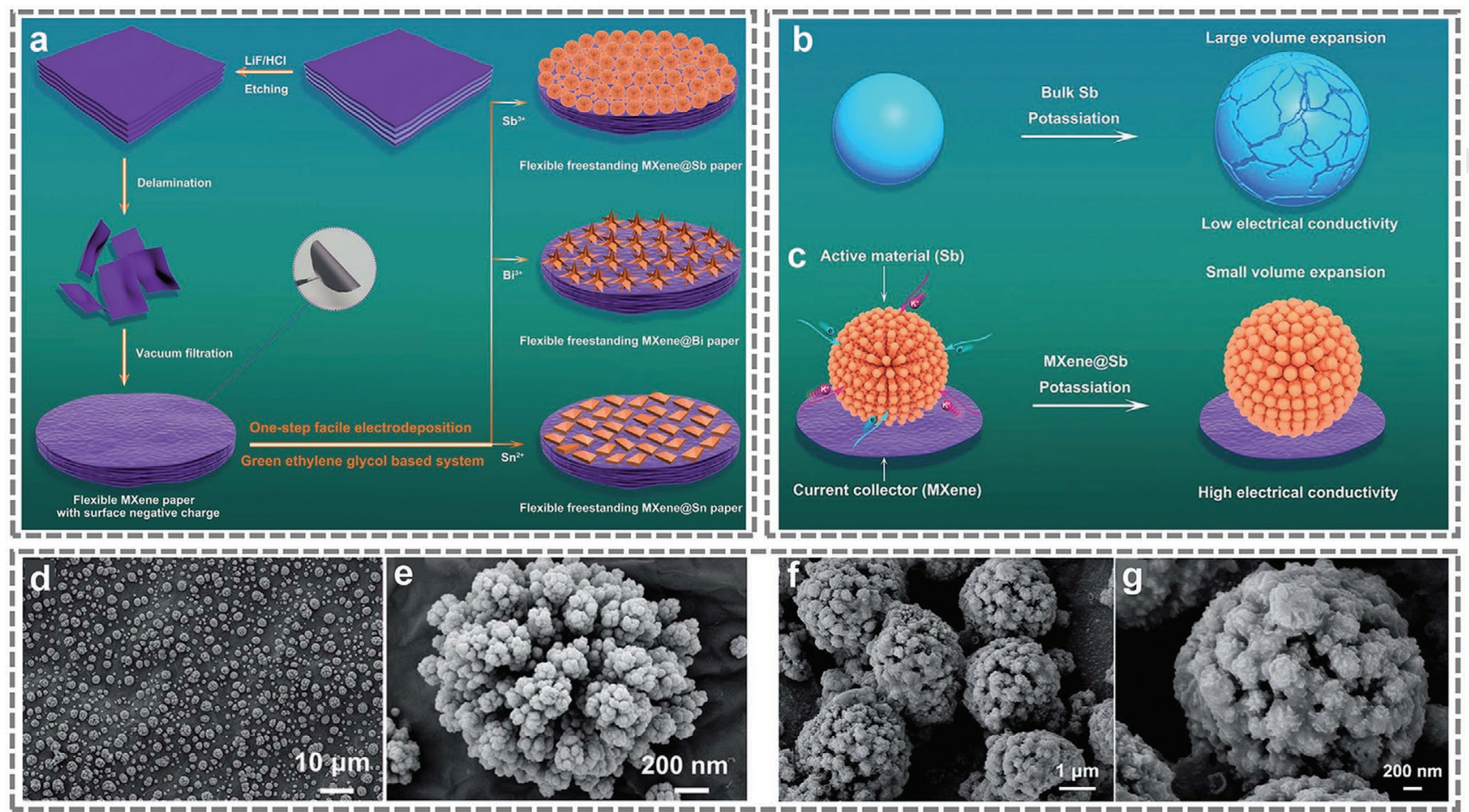

Figure 14. a) Schematic illustration of the synthesis process of flexible free-standing MXene@M paper (M = Sb, Bi, or Sn). SEM images of MXene@Sb electrode b,c) before electrochemical test, and d,e) after 100 cycles at $50 \mathrm{~mA} \mathrm{~g}^{-1}$. f,g) Potassiation schematics for bulk Sb and MXene@Sb electrodes for KIBs. Reproduced with permission. ${ }^{[29]}$ Copyright 2019, Royal Society of Chemistry.

adsorption energies to sodium ions, indicating the more energetically stable configurations of $\mathrm{Ti}_{3} \mathrm{C}_{2} \mathrm{~S}_{2}$. Besides, it was also found that the distance between the second layer and the host $\mathrm{Ti}_{3} \mathrm{C}_{2} \mathrm{~S}_{2}(0.5 \mathrm{~nm})$ is smaller than the increment of interlayer distance $(0.81 \mathrm{~nm})$ of CT-S@ $\mathrm{Ti}_{3} \mathrm{C}_{2}-450$, revealing the stable structure and the feasibility of "pillar effect" of the asprepared electrode. Finally, sodium-ion capacitors were fabricated by coupling with activated carbon cathode, showing both good rate performance and stability. ${ }^{[120]}$ Additionally, other approaches including sulfur decoration, ${ }^{[121]}$ sulfur doping, ${ }^{[122]}$ and cation pillaring ${ }^{[123]}$ are also proven to be efficient for enabling high-performance sodium-ion storage.

\subsubsection{MXene-Based Hybrid Electrodes}

Though MXenes possess high conductivity and thus high rate capability, they generally suffer from low capacity and therefore low energy density. In this regard, hybridizing MXenes with other materials (e.g., Sn, Bi, Sb, P, and their compounds) with high capacity would further boost the performance in terms of both the energy and power densities. On the one hand, such compositions can prevent MXene from restacking to some degree, thus are beneficial for the ion/electrolyte diffusion and material utilization. ${ }^{[125]}$ On the other hand, MXene could serve as a buffer layer to relieve the dramatic volumetric change of the electrode. In light of these facts, many MXenebased hybrid systems such as $\mathrm{Sb}_{2} \mathrm{O}_{3} / \mathrm{Ti}_{3} \mathrm{C}_{2} \mathrm{~T}_{x},{ }^{[126]} \mathrm{Ti}_{3} \mathrm{C}_{2} \mathrm{~T}_{x} /$ $\mathrm{SnS}_{2},{ }^{[127]}$ and $\mathrm{SnS} / \mathrm{Ti}_{3} \mathrm{C}_{2} \mathrm{~T}_{x}{ }^{[128]}$ have been developed as anodes of SIBs and they generally exhibit good structural stability and superior electrochemical performance. Notably, Qian et al. developed a general electrodeposition strategy to fabricate robust, flexible and free-standing MXene@M $(\mathrm{M}=\mathrm{Sb}, \mathrm{Sn}$, and $\mathrm{Bi}$ ) anodes for PIBs (Figure 14a). ${ }^{[129]}$ Thanks to the MXene buffer layer, these hybrids exhibited outstanding structural stability compared to the bulk metal anodes without the use of MXene (Figure 14b-g). For example, the MXene@Sb anode can stably deliver a high reversible capacity of $516.8 \mathrm{mAh} \mathrm{g}^{-1}$

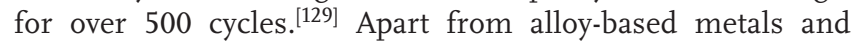
their compounds, phosphorus (e.g., red phosphorus, black phosphorus), and phosphides have also been hybridized with MXenes for high-performance SIBs. ${ }^{[130]}$ For example, Yang et al. demonstrated the black phosphorus quantum dot/ $\mathrm{Ti}_{3} \mathrm{C}_{2}$ MXene nanosheets (BPQD/TNS) for both the LIBs and SIBs. ${ }^{[130 b]}$ The composite was synthesized by an interfacial assembly strategy, which resulted in well-dispersed BPQDs anchored on the surface of MXenes. Specifically, the BPQDs with improved conductivity and relieved stress endowed a high capacity and stable cycling performance. In the meantime, the pseudocapacitive MXene provides a fast charge transfer, thus high rate performance. Wang et al. fabricated a phosphorene/ MXene hybrid material with in situ formed fluorinated interphase as anode for SIBs. ${ }^{[130 \mathrm{~d}]}$ The as-prepared anode not only promotes the transport of electrons and sodium ions, but also mitigates the volumetric expansion, leading to both the improved cycling stability and rate capability of the anode. Yin et al. coupled NiCoP bimetallic phosphide nanoparticles with crumpled porous $\mathrm{Ti}_{3} \mathrm{C}_{2}$ MXene as an anode for SIBs. ${ }^{[130 a]}$
1 
The interconnected 3D $\mathrm{Ti}_{3} \mathrm{C}_{2}$ crumpled architectures provide a conductive framework, rich open pores and large surface area, leading to a rapid charge transfer and electrolyte diffusion. Meanwhile, the NiCoP owns abundant redox reaction sites. The synergistic effect of these two components leads to an outstanding electrochemical performance. Remarkably, a capacity of $261.7 \mathrm{mAh} \mathrm{g}^{-1}$ can be maintained after 2000 cycles at a current density of $1 \mathrm{~A} \mathrm{~g}^{-1}$.

Additionally, conversion-type electrodes such as transition metal sulfides, selenides, and oxides have also attracted considerable attention for SIBs and PIBs. However, they suffer from poor conductivity and dramatic volumetric expansion caused by the phase change during discharge and charge, therefore inferior long-term stability and unsatisfied rate performance. Hybridizing these materials with MXenes can improve the conductivity and stability. Such a concept has been proven to be effective as confirmed in many MXene-based hybrid systems such as $\mathrm{MoS}_{2} / \mathrm{Ti}_{3} \mathrm{C}_{2} \mathrm{~T}_{x},{ }^{[131]} \mathrm{MoSe}_{2} / \mathrm{Ti}_{3} \mathrm{C}_{2} \mathrm{~T}_{x},{ }^{[132]} \mathrm{FeS}_{2} / \mathrm{Ti}_{3} \mathrm{C}_{2} \mathrm{~T}_{x},{ }^{[133]}$ $\mathrm{CoS} / \mathrm{Ti}_{3} \mathrm{C}_{2} \mathrm{~T}_{x}{ }^{[134]} \mathrm{CoNiO}_{2} / \mathrm{Ti}_{3} \mathrm{C}_{2} \mathrm{~T}_{x},{ }^{[135]} \mathrm{VO}_{2} / \mathrm{Ti}_{3} \mathrm{C}_{2} \mathrm{~T}_{x}{ }^{[136]} \mathrm{TiO}_{2} @$ $\mathrm{Ti}_{3} \mathrm{C}_{2} \mathrm{~T}_{x},{ }^{[137]}$ and so on. Particularly, Zhang et al. rationally designed a hierarchical carbon-coated $\mathrm{MoSe}_{2} / \mathrm{Ti}_{3} \mathrm{C}_{2}$ MXene hybrid material as a superior anode for PIBs. ${ }^{[132]}$ The $3 \mathrm{D}$ porous network of $\mathrm{MoSe}_{2}$ and $\mathrm{Ti}_{3} \mathrm{C}_{2}$ can prevent the restacking or aggregation of each other, while the MXene significantly boosts the electronic conductivity. Furthermore, the carbon layer serves as a protective layer that can reinforce the stability and conductivity of the hybrid materials. Notably, the strong interactions at the interfaces of the $\mathrm{MoSe}_{2}$ and MXene flakes promote the charge transfer and improve the stability. Consequently,

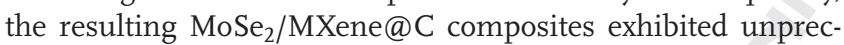
edented rate performance for PIBs, with capacities of 355 and $183 \mathrm{mAh} \mathrm{g}^{-1}$ at current densities of $200 \mathrm{~mA} \mathrm{~g}^{-1}$ and $10 \mathrm{~A} \mathrm{~g}^{-1}$, respectively. ${ }^{[132]}$

\subsubsection{MXene-Derived Materials}

In addition to being directly used as electrodes or conductive media, MXenes are also used as the precursor/template to prepare various materials, including oxides, nitrides, sulfide, MOF, etc. ${ }^{[51 d, 110,138]}$ This is particularly attractive for synthesizing materials with 1D or 2D morphologies that otherwise are more challenging to synthesize by common methods. For instance, Dong et al. synthesized sodium titanate (M-NTO) and potassium titanate (M-KTO) nanoribbons by simultaneous oxidation and alkalization of $\mathrm{Ti}_{3} \mathrm{C}_{2} \mathrm{~T}_{x}$ MXene in $\mathrm{NaOH}$ or $\mathrm{KOH}$ solution, respectively (Figure 15a-g). ${ }^{[138 \mathrm{~d}]}$ These highly anisotropic M-NTO and M-KTO nanoribbons with marcoporous 3D framework delivered high reversible capacities of $191 \mathrm{mAh} \mathrm{g}^{-1}$ for SIBs (at $200 \mathrm{~mA} \mathrm{~g}^{-1}$ ) and $151 \mathrm{mAh} \mathrm{g}^{-1}$ for PIBs (at $50 \mathrm{~mA} \mathrm{~g}^{-1}$ ), respectively. Similarly, sandwich-like $\mathrm{Na}_{0.23} \mathrm{TiO}_{2}$ nanobelt $/ \mathrm{Ti}_{3} \mathrm{C}_{2}$ composites were prepared by Yang et al. through a partial oxidation process of $\mathrm{Ti}_{3} \mathrm{C}_{2}{ }^{[110]}$ The as-prepared product showed superior high rate capability and long cycling stability with negligible capacity fading over 4000 cycles for SIBs. In addition, a confined transformation of assembled 2D MXene $\left(\mathrm{Ti}_{3} \mathrm{C}_{2} \mathrm{~T}_{x}\right)$ and rGO nanosheets was used to prepare composite with ultrathin sodium titanate (NTO)/potassium titanate (KTO) sandwiched between graphene layers (Figure 15h). ${ }^{[138 i]}$ The excellent flexibility of the sandwiched structure was confirmed by phys- 1 ical characterizations (Figure 15i-n). Both the NTO/KTO and 2 rGO layers showed a small thickness of 5-10 $\mathrm{nm}$ and were 3 stacked alternatively. The incorporation of highly conductive 4 graphene into the binder-free films can efficiently reduce the 5 diffusion barriers. Consequently, the NTO/rGO electrodes 6 retained $72 \mathrm{mAh} \mathrm{g}^{-1}$ at $5 \mathrm{~A} \mathrm{~g}^{-1}$ even after 10000 cycles for 7 SIBs, whereas the KTO/rGO electrodes exhibited $75 \mathrm{mAh} \mathrm{g}^{-1}$ at 8 $2 \mathrm{~A} \mathrm{~g}^{-1}$ after 700 cycles for PIBs. Zhang's group and Cao's group 9 also demonstrated the feasibility of MXene-derived $\mathrm{TiO}_{2} / \mathrm{rGO} \quad 10$ for alkali ion storage. ${ }^{[138 \mathrm{e}, \mathrm{f}]}$ Apart from oxides, MXene-derived 11 $\mathrm{TiS}_{2}$ nanosheets were successfully prepared by the in-situ con- 12 version of polyvinylpyrrolidone modified $\mathrm{Ti}_{3} \mathrm{C}_{2} \mathrm{~T}_{x}$ MXene under 13 $\mathrm{H}_{2} \mathrm{~S}$ gas flow. The as-obtained carbon-coated $\mathrm{TiS}_{2}$ nanosheets 14 exhibited both extraordinary rate performance and excellent 15 stability. ${ }^{[138 c]}$

Given the high conductivity, fast charge transfer, low dif- 17 fusion barrier, tunable interlayer distance, and rich surface 18 chemistry, MXene-based electrodes and conductive matrixes/ 19 additives have already shown great potential for SIBs and PIBs, 20 while delicate nanostructuring such as assembling 2D MXene 21 nanosheets into 3D hierarchical networks can further boost 22 the electrochemical performance. A brief summary of MXene- 23 based materials in the applications of SIBs and PIBs is shown 24 in Table 5.

\subsection{Multivalent Ion Storage (Mg, Al, $\mathrm{Zn}$ )}

\subsubsection{Magnesium-lon Storage}

25

Owing to the high abundance (23 300 vs 20 ppm of lithium), 32 high theoretical capacity, and dendrite free features of $\mathrm{Mg} 33$ anode, magnesium-ion batteries (MIBs) have drawn much 34 attention since the pioneering work conducted by Aurbach et al. 35 in 2000. ${ }^{[140]}$ However, the divalent charge of $\mathrm{Mg}^{2+}$ ions results in 36 strong ion-electrode bonds and sluggish ion diffusion kinetics. 37 Currently, MIBs still suffer from the lack of suitable cathodes 38 that allow fast diffusion/intercalation of $\mathrm{Mg}^{2+}$ ions as well as 39 stable electrolytes. ${ }^{[141]}$ Previous simulations imply that the $\mathrm{Mg}^{2+} \quad 40$ ions are able to form bilayers and trilayers on MXene surface, 41 leading to a theoretical capacity as high as $1050 \mathrm{mAh} \mathrm{g}^{-1}$.52b,c] $^{2} 42$ Several attempts have therefore been made to use MXene- 43 based materials for MIBs. For example, Xu et al. demonstrated 44 the capability of CTAB intercalated $\mathrm{Ti}_{3} \mathrm{C}_{2} \mathrm{~T}_{x}$ MXene for Mg-ion 45 storage, while the pristine $\mathrm{Ti}_{3} \mathrm{C}_{2} \mathrm{~T}_{x}$ exhibited poor performance 46 (Figure 16a,b). ${ }^{[142]}$ The as-prepared $\mathrm{Ti}_{3} \mathrm{C}_{2} \mathrm{~T}_{x} / \mathrm{CTAB}$ electrode 47 achieved a high capacity of $300 \mathrm{mAh} \mathrm{cm}^{-3}$ at $50 \mathrm{~mA} \mathrm{~g}^{-1}$ and 48 excellent rate capability. The DFT results indicated that the 49 significantly improved performance could be ascribed to 50 the reduced diffusion barrier (about $0.19 \mathrm{eV}$ ) of $\mathrm{Mg}^{2+}$ ions on 51 the MXene surface (Figure 16c-h). The same group also synthe- 52 sized $\mathrm{Ti}_{3} \mathrm{C}_{2} \mathrm{~T}_{x}$ MXene supported $\mathrm{MoS}_{2}$ composite for MIBs. ${ }^{[143]} 53$ Gao et al. found that the preintercalation of $\mathrm{K}^{+}$into $\mathrm{Ti}_{3} \mathrm{C}_{2} \mathrm{~T}_{x} 54$ MXene leads to improved Mg-ion storage in $1 \mathrm{M} \mathrm{MgSO}_{4}$ electro- 55 lyte. ${ }^{[144]}$ Gogotsi et al. also showed that the $\mathrm{Mg}^{2+}$ preintercalated 56 $\mathrm{Ti}_{3} \mathrm{C}_{2} \mathrm{~T}_{x}\left(\mathrm{Mg}_{0.21} \mathrm{Ti}_{3} \mathrm{C}_{2} \mathrm{~T}_{x}\right)$ microporous films could be used as the 57 cathode for MIBs, though the rate performance and stability 58 need to be further optimized. ${ }^{[145]}$ Besides, Fan et al. fabricated 59 

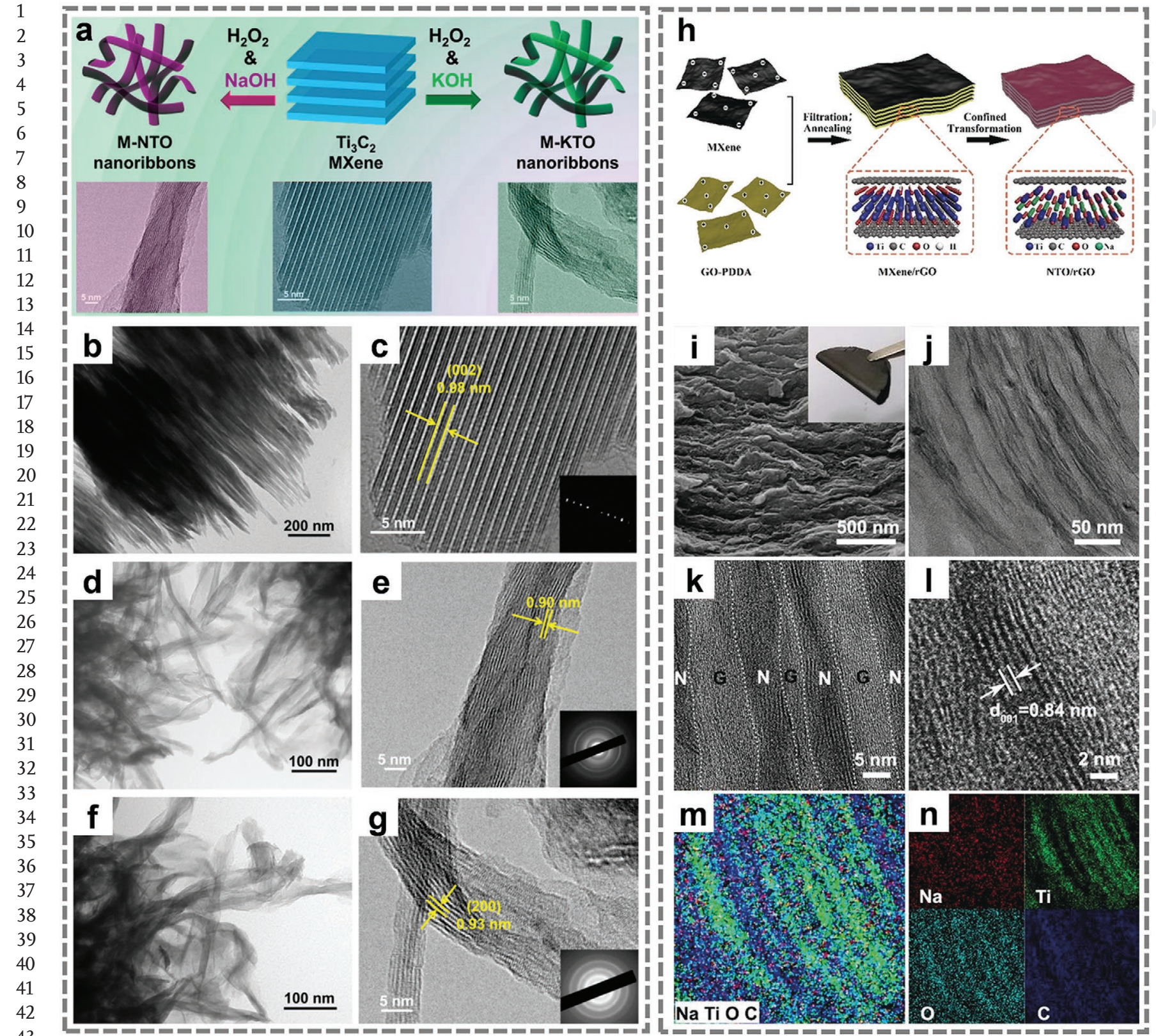

Figure 15. a) Schematic of the synthesis process of MXene derived M-NTO and M-KTO nanoribbons. TEM images of b,c) pristine $\mathrm{Ti}_{3} \mathrm{C}_{2} \mathrm{~T}_{x} \mathrm{MXene,d,e)}$ M-NTO nanoribbons, and f,g) M-KTO nanoribbons. Reproduced with permission. [138d] Copyright 2017, American Chemistry of Society. h) Schematic of the preparation of flexible NTO/rCO films. SEM and TEM characterizations of NTO/rGO-10\% hybrid film. i) SEM, j) TEM, and k,-I) HRTEM images ("N" refers to NTO, and " $\mathrm{C}$ " refers to r(CO). e,f) TEM elemental maps of $\mathrm{Na}, \mathrm{Ti}, \mathrm{O}$, and $\mathrm{C}$ elements. Reproduced with permission. ${ }^{[138 i]}$ Copyright 2018, American Chemistry of Society.

a sandwich-like $\mathrm{Ti}_{3} \mathrm{C}_{2} \mathrm{~T}_{x} @ \mathrm{C}$ spheres structure as a cathode for MIBs. ${ }^{[146]}$ The theoretical calculations revealed that the Mg ions are not affected by the steric hindrance caused by the incorporation of the carbon spheres. On the contrary, the expanded interlayer distance enabled by the $\mathrm{C}$ intercalation provides additional diffusion channels. Moreover, such a strategy can be extended to other MXenes, such as $\mathrm{V}_{2} \mathrm{CT}_{x}$.

Since MXene-based cathodes deliver a relatively high reversible capacity $\left(\approx 100-200 \mathrm{mAh} \mathrm{g}^{-1}\right)$ for MIBs, it is therefore of 59 great interest to investigate the charge storage mechanism. Very recently, Schnell et al. studied the Mg-ion storage performance of multilayer MXene particles (i.e., $\mathrm{Ti}_{3} \mathrm{C}_{2} \mathrm{~T}_{x}$ and $\mathrm{V}_{2} \mathrm{CT}_{x}$ ) in various electrolytes at room and elevated temperatures. ${ }^{[14]}$ The results demonstrated that almost no Mg-ion intercalation takes place at both room temperature and $60^{\circ} \mathrm{C}$ (the capacity is less than $5 \mathrm{mAh} \mathrm{g}^{-1}$ ). Furthermore, DFT computations revealed that the average voltage of $\mathrm{F}$ - and $\mathrm{OH}$-terminated $\mathrm{Ti}_{3} \mathrm{C}_{2} \mathrm{~T}_{2}$ MXene falls in the negative region, while the O-terminated $\mathrm{Ti}_{3} \mathrm{C}_{2} \mathrm{~T}_{2}$ MXene shows high migration barriers. What's more, it was found that upon discharge of multilayer $\mathrm{F}$ - and $\mathrm{OH}$-terminated
2

3

4

5

7

8

9 
Table 5. Summary of the electrochemical performance of MXene-based materials for sodium/potassium ion storage.

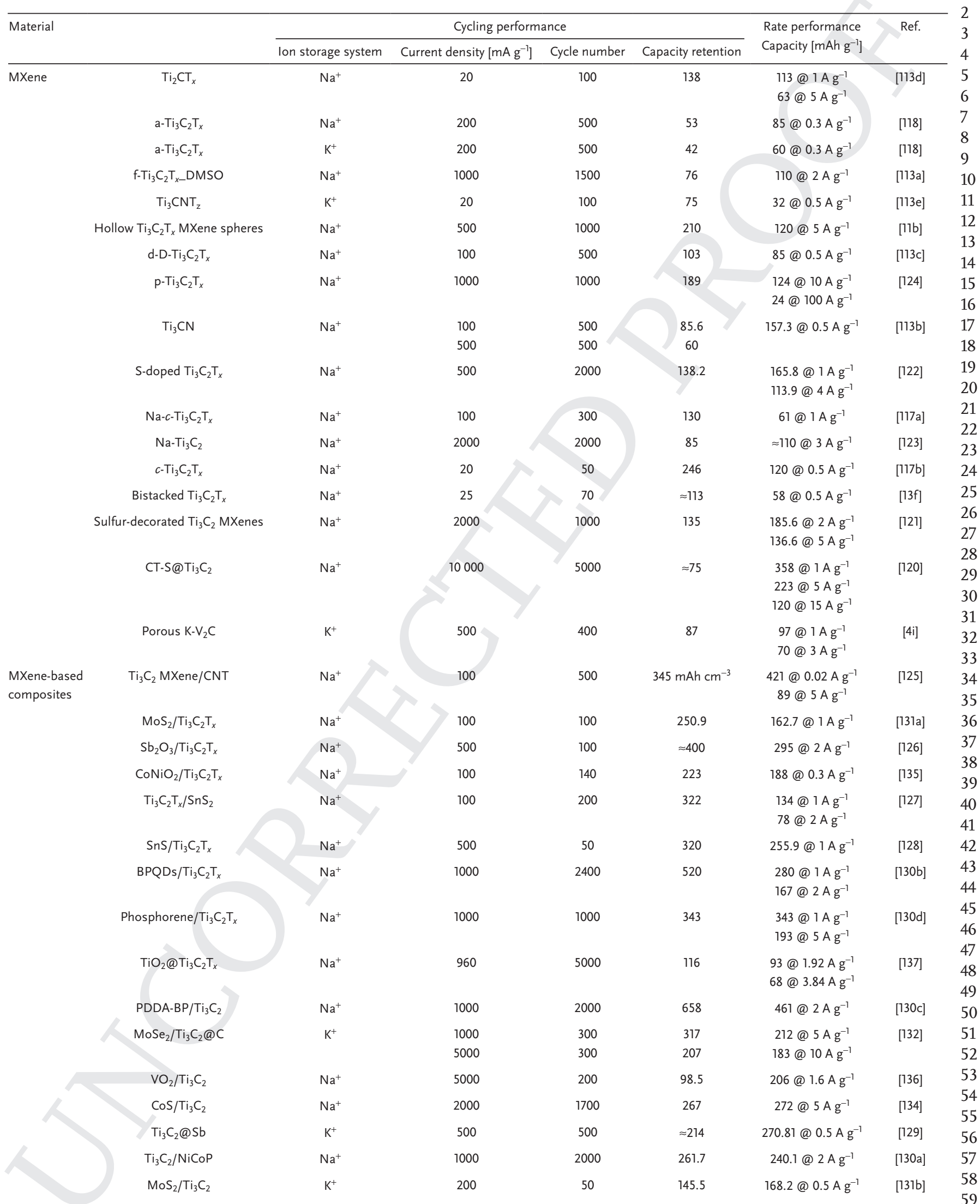


Table 5. Continued.

\begin{tabular}{|c|c|c|c|c|c|c|c|}
\hline \multirow[t]{2}{*}{ Material } & & \multicolumn{4}{|c|}{ Cycling performance } & \multirow{2}{*}{$\begin{array}{l}\text { Rate performance } \\
\text { Capacity }\left[\mathrm{mAh} \mathrm{g}^{-1}\right]\end{array}$} & \multirow[t]{2}{*}{ Ref. } \\
\hline & & lon storage system & Current density $\left[\mathrm{mA} \mathrm{g}^{-1}\right]$ & Cycle number & Capacity retention & & \\
\hline \multirow{9}{*}{$\begin{array}{l}\text { MXene-derived } \\
\text { materials }\end{array}$} & $\mathrm{NaTi}_{7.5} \mathrm{O}_{8.3}$ & $\mathrm{Na}^{+}$ & 200 & 150 & $\approx 135$ & $101 @ 2 \mathrm{Ag}^{-1}$ & [138d] \\
\hline & $\mathrm{K}_{2} \mathrm{Ti}_{4} \mathrm{O}_{9}$ & $\mathrm{~K}^{+}$ & 200 & 900 & $\approx 45$ & $81 @ 0.3 \mathrm{~A} \mathrm{~g}^{-1}$ & [138d] \\
\hline & $\mathrm{M}-\mathrm{TiO}_{2}-\mathrm{rGO}$ & $\mathrm{Na}^{+}$ & 1000 & 8000 & $\approx 87$ & $79 @ 2 \mathrm{Ag}^{-1}$ & [138e] \\
\hline & $\mathrm{Na}_{0.23} \mathrm{TiO}_{2} / \mathrm{Ti}_{3} \mathrm{C}_{2}$ & $\mathrm{Na}^{+}$ & 2000 & 4000 & 56 & $47 @ 3 \mathrm{Ag}^{-1}$ & [110] \\
\hline & $\mathrm{KTO} / \mathrm{rGO}$ & $\mathrm{K}^{+}$ & 2000 & 700 & 75 & $84 @ 1 \mathrm{Ag}^{-1}$ & {$[138 i]$} \\
\hline & $\mathrm{TiO}_{2} / \mathrm{rGO}$ & $\mathrm{K}^{+}$ & 1000 & 1000 & $\approx 85$ & $107.1 @ 1 \mathrm{~A} \mathrm{~g}^{-1}$ & {$[138 f]$} \\
\hline & $\mathrm{TiO}_{x} \mathrm{~N}_{y} / \mathrm{C}$ & $\mathrm{K}^{+}$ & 200 & 1200 & 150 & $72 @ 1.6 \mathrm{Ag} \mathrm{g}^{-1}$ & [138h] \\
\hline & $\mathrm{Na}_{2} \mathrm{Ti}_{3} \mathrm{O}_{7} @ \mathrm{C}$ & $\mathrm{Na}^{+}$ & 2000 & 200 & 119 & 115 @ $2 \mathrm{Ag}^{-1}$ & [138g] \\
\hline & $\mathrm{TiS}_{2} @ \mathrm{C}$ & $\mathrm{Na}^{+}$ & 10000 & 5000 & 321.4 & $387 @ 10 \mathrm{~A} \mathrm{~g}^{-1}$ & [138c] \\
\hline
\end{tabular}

$\mathrm{V}_{2} \mathrm{CT}_{2}$ MXene, $\mathrm{MgF}_{2}$ or $\mathrm{MgH}_{2}$ is formed instead of Mg-ion intercalation. Nevertheless, multilayer $\mathrm{V}_{2} \mathrm{CO}_{2}$ MXene displayed a relatively high average voltage of about $1.5 \mathrm{~V}$ with a low migration barrier of $480 \mathrm{meV}$, suggesting the potential for MIB anodes. ${ }^{[147]}$ The findings here also reveal the importance of regulating the surface chemistry of MXenes in enhancing their electrochemical performance as MIB electrodes.

Because of the huge challenges facing the development of suitable cathode materials for MIBs, the concept of hybrid $\mathrm{Mg}^{2+} / \mathrm{Li}^{+}$battery has been proposed. Such a hybrid system
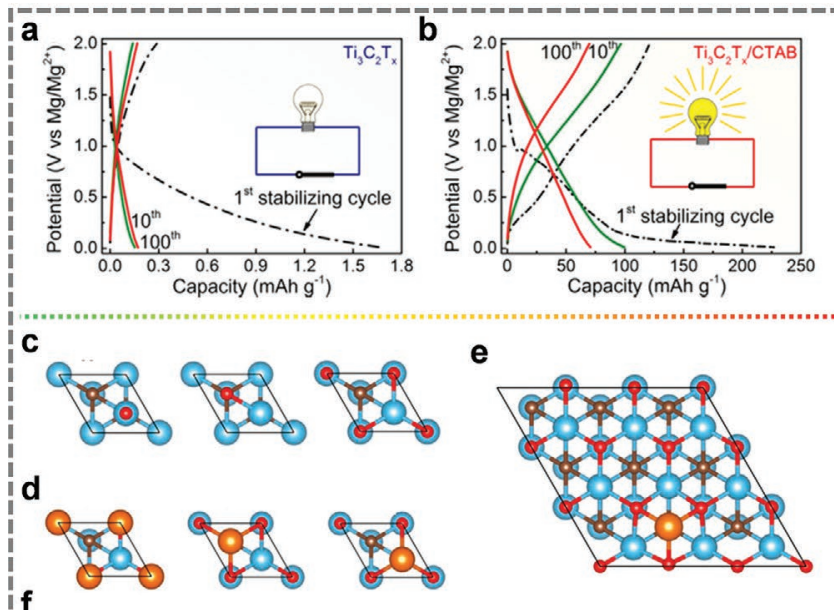

e

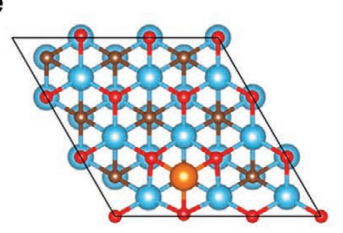

\section{g}
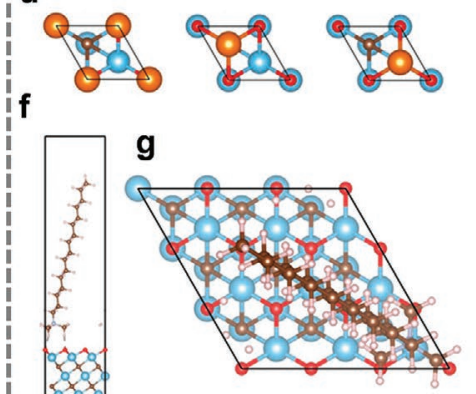

- $\mathbf{H}$

- $\mathbf{C}$

$\circ \mathbf{N}$

- $\mathbf{O}$
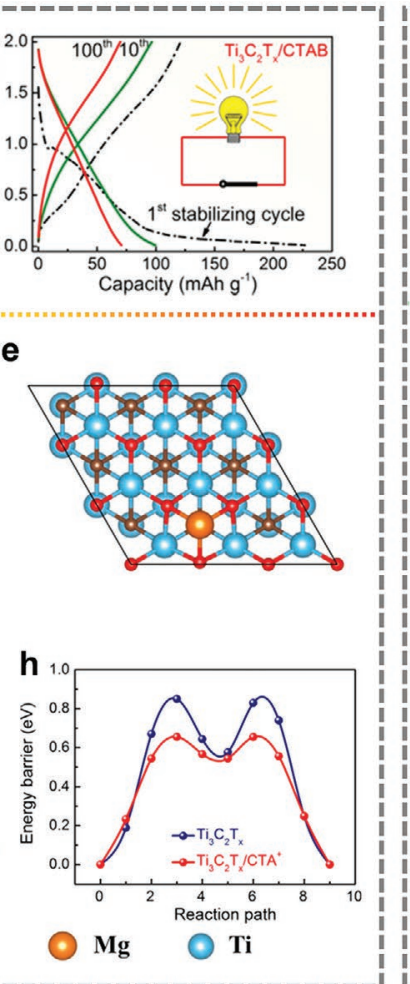

i
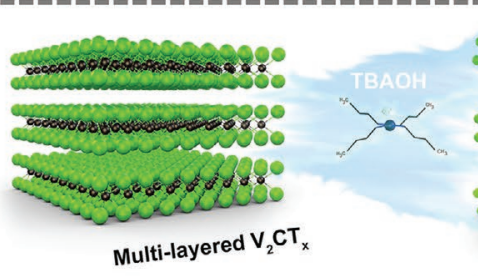

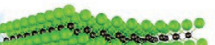

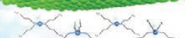

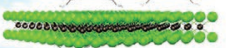
कर उन्द $x$ $-750800000^{\circ}$ TBAOH Intercalated $\mathrm{V}_{2} \mathrm{CT}_{x}$

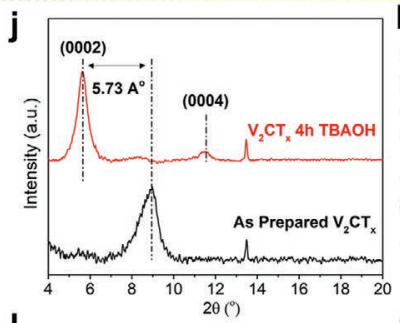

I
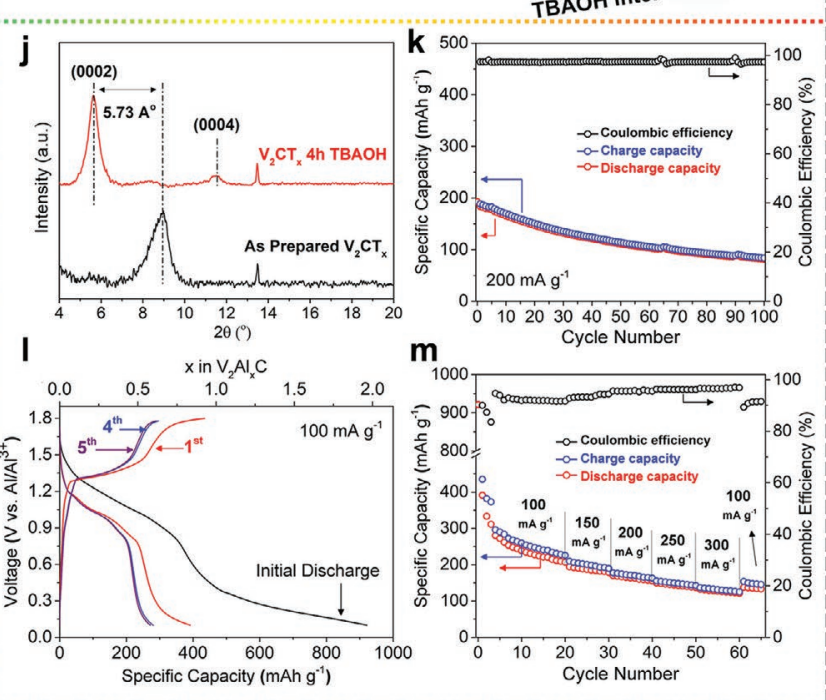

Figure 16. Charge/discharge profiles of a) $\mathrm{Ti}_{3} \mathrm{C}_{2} \mathrm{~T}_{x}$ electrode, and b) $\mathrm{Ti}_{3} \mathrm{C}_{2} \mathrm{~T}_{x} / \mathrm{CTAB}$ electrode at the 10th (green lines) and the 100th (red lines) cycles at $50 \mathrm{~mA} \mathrm{~g}^{-1}$. Top view of the structures of $\mathrm{c}$ ) an $\mathrm{O}$ atom and d) a $\mathrm{Mg}$ atom adsorbed on the $1 \times 1 \mathrm{Ti}_{3} \mathrm{C}_{2}$ surface at the top site, body-centered cubic (bcc) site, and face-centered cubic (fcc) site, respectively. Top view of e) $\mathrm{Mg}^{2+}$ and g) $\mathrm{CTA}^{+}$as well as $\mathrm{f}$ ) side view of $\mathrm{CTA}^{+}$adsorbed on the $3 \times 3 \mathrm{Ti}_{3} \mathrm{C}_{2} \mathrm{O}$ surface. h) Diffusion profile of $\mathrm{Mg}^{2+}$ on $\mathrm{Ti}_{3} \mathrm{C}_{2} \mathrm{O}$ and $\mathrm{CTA}^{+} / \mathrm{Ti}_{3} \mathrm{C}_{2} \mathrm{O}$ surface in nudged elastic band calculations. Reproduced with permission. ${ }^{[142]}$ Copyright 2018, American Chemistry of Society. i) Schematic illustration of interlayer expansion of multilayer $\mathrm{V}_{2} \mathrm{CT}_{x}$ MXene through TBAOH intercalation. j) XRD patterns of $\mathrm{V}_{2} \mathrm{CT}_{x}$ and TBAOH intercalated $\mathrm{V}_{2} \mathrm{CT}_{x}$. $\mathrm{k}$ ) Cyclic performance, l) charge-discharge curves of the first five cycles, and $\mathrm{m}$ ) rate performance of TBAOH intercalated few-layer $\mathrm{V}_{2} \mathrm{CT}_{x}$. Reproduced with permission. ${ }^{[33 a]}$ Copyright 2017, American Chemistry of Society. 
consists of an $\mathrm{Mg}$ anode, a lithium-ion intercalation cathode, and a $\mathrm{Mg}^{2+} / \mathrm{Li}^{+}$dual-salt electrolyte. The hybrid $\mathrm{Mg}^{2+} / \mathrm{Li}^{+}$battery could potentially inherit the advantages of fast $\mathrm{Li}^{+}$intercalation kinetics, high voltage and high capacity of LIB cathodes, as well as the low cost, dendrite-free features of $\mathrm{Mg}$ anodes. ${ }^{[148]}$ $\mathrm{Mo}_{2} \mathrm{CT}_{x}, \mathrm{Ti}_{3} \mathrm{C}_{2} \mathrm{~T}_{x}$, and prelithiated $\mathrm{V}_{2} \mathrm{CT}_{x}$ MXenes have shown promising applications for hybrid $\mathrm{Mg}^{2+} / \mathrm{Li}^{+}$batteries. ${ }^{[149]}$ Notably, the prelithiated $\mathrm{V}_{2} \mathrm{CT}_{x}$ electrode exhibits a reversible capacity of up to $230.3 \mathrm{mAh} \mathrm{g}^{-1}$ at $20 \mathrm{~mA} \mathrm{~g}^{-1}$ with $82 \%$ capacity retention after 480 cycles. ${ }^{[149 b]}$

\subsubsection{Zinc-Ion Storage}

Zinc-based batteries are technologies that have been around for centuries. Since the first utilization of zinc anode in $1799,{ }^{[150]}$ it has been regarded as an ideal negative electrode because of its high theoretical capacity $\left(820 \mathrm{mAh} \mathrm{g}^{-1}\right.$ or $\left.5855 \mathrm{mAh} \mathrm{cm}^{-3}\right)$, low cost, low redox potential $(-0.76 \mathrm{~V}$ vs standard hydrogen electrode) and high safety. Unlike the rechargeable alkaline $\mathrm{Zn}-\mathrm{MnO}_{2}$ batteries, whose cycle life is severely hampered by the formation of zinc dendrite and irreversible $\mathrm{ZnO}$ and $\mathrm{Zn}(\mathrm{OH})_{2}$ formation, the rechargeable aqueous ZIBs that use neutral or slightly acidic electrolytes (e.g., $\mathrm{ZnSO}_{4}$ ) pioneered by Yamamoto et al. in 1986 virtually eliminate the dendritic zinc deposition. ${ }^{[151]}$ Recently, aqueous rechargeable zinc-ion storage has regained significant attention. Previous studies have shown that MXenes are capable of storing zinc ions and can be used for zinc-ion capacitors. ${ }^{[152]}$ For example, a degradable Zn-MXene capacitor was fabricated by Zhi et al. ${ }^{[152 b]}$ The capacitor can maintain $82.5 \%$ of the capacitance after 1000 cycles, along with a very low self-discharge rate of $6.3 \mathrm{mV} \mathrm{h}^{-1}$. More importantly, the whole capacitor can be totally degraded within 7.25 days. The performance and degradation rate surpass many reported supercapacitor devices. Besides, aqueous zincion capacitors based on $\mathrm{MnO}_{2}$ cathode and MXene anode were also reported. ${ }^{[153]}$ Moreover, a porous 3D MXene-rGO aerogel cathode was synthesized for the zinc-ion capacitor, which displayed an ultralong cycle life with above $95 \%$ capacity retention over 75000 cycles. ${ }^{[154]}$ In addition, $\mathrm{MnO}_{x} @ \mathrm{Ti}_{3} \mathrm{C}_{2} \mathrm{~T}_{x}$ hierarchical structure was designed as the cathode of ZIBs. ${ }^{[155]}$ The assembly exhibited excellent rate performance with $50 \%$ capacity retention when the rate increased from 0.1 to $10 \mathrm{~A} \mathrm{~g}^{-1}$. Interestingly, Zhi et al. found an unusual capacity enhancement during cycling when using $\mathrm{V}_{2} \mathrm{CT}_{x}$ MXene as the cathode for zinc-ion hybrid batteries. ${ }^{[156]}$ Such an abnormality is originated from the exfoliation of MXene and its oxidization into $\mathrm{V}_{2} \mathrm{O}_{5}$ during the repeated cycling process. As a result, a capacity as high as $508 \mathrm{mAh} \mathrm{g}^{-1}$ and an energy density of $386.2 \mathrm{Wh} \mathrm{kg}^{-1}$ were achieved.

\subsubsection{Aluminum-lon Storage}

Aluminum is the most abundant metal in the earth's upper crust. An Al-based redox couple involves three electron transfer and therefore theoretically provides more capacity compared to the LIBs. In addition, Al-ion batteries (AIBs) are much safer and cheaper than LIBs. However, the large size of solvated $\mathrm{Al}^{3+}$ ions in electrolytes and their strong bonding force with the host materials seriously hamper the development of AIBs. Previous simulations have predicted that bare MXenes and O-termi- 1 nated MXenes exhibit high capacities toward the aluminum- 2 ion storage. ${ }^{[52 b]}$ Unfortunately, up to now, only $\mathrm{V}_{2} \mathrm{CT}_{x}$ MXene 3 shows reasonable Al-ion storage capacity. Beidaghi et al. dem- 4 onstrated that $\mathrm{Al}^{3+}$ could reversibly intercalate into the $\mathrm{V}_{2} \mathrm{CT}_{x} \quad 5$ MXene host. ${ }^{[33 a]}$ Moreover, the electrochemical performance 6 can be improved by delaminating multilayer $\mathrm{V}_{2} \mathrm{CT}_{x}$ into few- 7 layer counterpart with the assistance of TBAOH (Figure 16i). 8 The optimized MXene cathode can deliver a high capacity of 9 over $300 \mathrm{mAh} \mathrm{g}^{-1}$ at a current density of $100 \mathrm{~mA} \mathrm{~g}^{-1}$, along with 10 good rate performance (Figure $16 j-\mathrm{m}$ ). Although a continuous 11 capacity decay was observed, the specific capacity, intercala- 12 tion voltage, and cycle life reported here are among the best 13 achieved for intercalation-type AIB cathodes.

To summarize, although theoretical predictions indicate that 15 MXenes have very high capacities for various multivalent ions 16 (e.g., $\mathrm{Mg}^{2+}, \mathrm{Zn}^{2+}, \mathrm{Al}^{3+}$ ) storage, the experimental progress is 17 still limited. According to the existing publications, the surface 18 modification and structure manipulation are effective ways to 19 improve the metal ion storage performance of MXenes. Further, 20 the DFT calculation results suggest that bare MXenes or O-ter- 21 minated MXenes generally exhibit better performance than 22 the F- or OH-terminated ones. ${ }^{[52 \mathrm{~b}, \mathrm{c}]}$ Therefore, the synthesis 23 of MXene with controllable surface chemistry is of significant 24 importance for the future development of MXene electrodes for 25 multivalent metal ion storage.

\subsection{Anode Protection for Metal Batteries}

Currently, portable electronics and electric vehicles require 31 energy storage devices with increasingly higher energy density. 32 Metal batteries, including metal-sulfur, metal-air, metal-oxygen, 33 and metal- $\mathrm{CO}_{2}$ batteries exhibit much higher energy densities 34 compare to LIBs owing to the high theoretical specific capacities 35 of metal anodes (e.g., Li, Na, K, Zn). However, the development 36 of metal anodes is hampered by their high reactivity, uneven 37 dendrite formation, large volumetric changes during cycling, 38 poor long-term durability as well as safety issues. ${ }^{[103 g, 157]}$ A vast 39 amount of work has therefore been conducted to tackle these 40 problems, among which metal anode protection has been dem- 41 onstrated to be an effective way. Approaches developed to protect 42 metal anodes from uneven dendrite formation can be classified 43 into three categories: i) metal anode modification (e.g., trap- 44 ping metals in porous hosts by controlling metal diffusion, 45 regulating metal deposition by manipulating electrochemical 46 reactions); ii) building an (artificial) SEI film on the metal anodes; 47 iii) electrolyte engineering for achieving safe and stable metal 48 anodes. ${ }^{[103 g, 157]}$ MXene-based materials have some favorable fea- 49 tures that are beneficial for efficient metal anode protection. For 50 instance, the high conductivity and hydrophilicity properties of 51 MXenes allow fast electronic and ionic transport, the large inter- 52 layer spacing can greatly alleviate the volumetric changes during 53 metal plating/stripping, the 2D structure induces uniform nucle- 54 ation and growth of metals on MXene surface. Moreover, the flu- 55 orine termination could lead to the formation of uniform, dense 56 and durable SEI films dominated with LiF salt at the anode/elec- 57 trolyte interface. ${ }^{[158]}$ As a consequence, tremendous efforts have 58 been devoted to the protection of metal anodes using MXenes. 


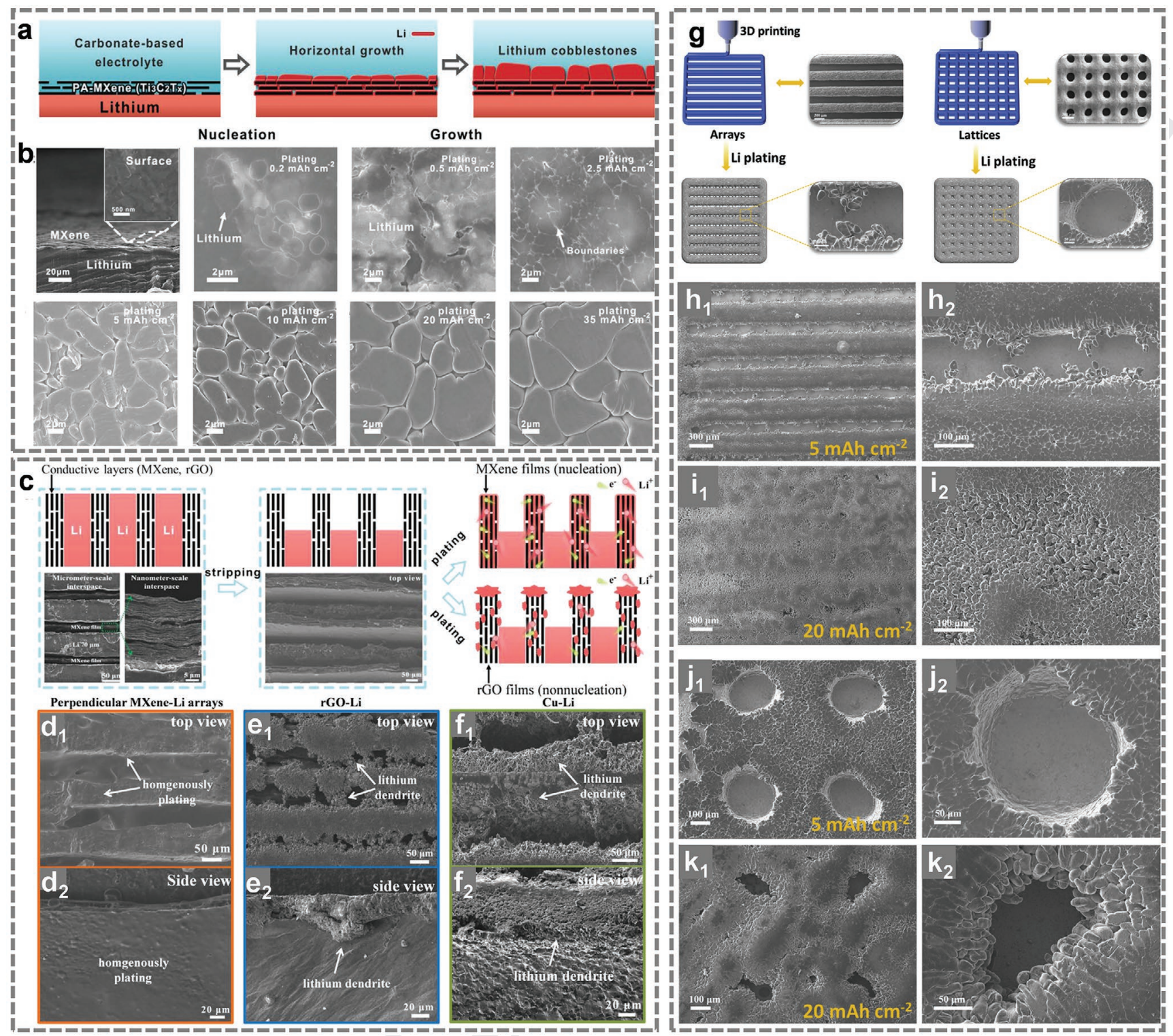

Figure 17. a) Schematic illustration of lithium plating on parallelly aligned MXene layers. b) SEM images of parallelly aligned MXene layers on lithium and MXene-lithium electrodes with various levels of lithium plating, showing the dendrite-free surface. Reproduced with permission. ${ }^{[158]}$ Copyright 2019, Wiley. c) Schematic illustration of the stripping and plating states of perpendicular MXene-Li and rGO-Li arrays. Top-view and side-view SEM images of lithium plating on the d) perpendicular MXene-Li arrays, e) rGO-Li arrays, and f) Cu-Li arrays, respectively. Reproduced with permission. ${ }^{[159 a]}$ Copyright 2020, Wiley. g) Scheme of 3D printing MXene arrays and lattices to guide the nucleation and growth of lithium. SEM images of 3D printingMXene arrays with h) 5 and i) $20 \mathrm{mAh} \mathrm{cm}^{-2}$ lithium plating at $0.5 \mathrm{~mA} \mathrm{~cm}^{-2}$. SEM images of 3D printing-MXene lattices with j) 5 and k) $20 \mathrm{mAh} \mathrm{cm}{ }^{-2}$ lithium plating at $0.5 \mathrm{~mA} \mathrm{~cm}^{-2}$. Reproduced with permission. ${ }^{[1596]}$ Copyright 2020, Elsevier.

\subsubsection{Lithium Metal Anode}

Yang's group developed several strategies to achieve dendrite2 free lithium anodes via using different MXene architec3 tures. ${ }^{[111,158,159]}$ For example, the parallel alignment of MXene 54 layers on top of the lithium anode can effectively induce the 5 formation of horizontally orientated deposition of lithium 56 (Figure 17a,b). This method greatly reduces the dendrite for57 mation, thus leading to a long cycle life up to $900 \mathrm{~h}$ and an 58 outstanding rate capability up to $35 \mathrm{mAh} \mathrm{cm}^{-2} \cdot{ }^{158]}$ Later, per59 pendicular MXene-Li arrays with dual periodic interphases, i.e., nanometer-scale interspaces in MXene walls and micrometer-scale interspaces between MXene walls, were fabricated through a rolling-cutting strategy. ${ }^{[159 a]}$ This unique structure not only enables fast ion transport upon lithium stripping and plating, but also effectively homogenizes the electric fields, which further prohibits the notorious lighting rod effect and accommodates the volumetric changes. The perpendicular MXene-Li arrays anode possessed a high capacity of $2056 \mathrm{mAh} \mathrm{g}^{-1}$, good rate performance and long cycle life up to $1700 \mathrm{~h}$, much superior to rGO-Li or Cu-Li arrays (Figure 17c-f). Recently, the emerging 3D printing technique was also applied
1 2 3 4 5 6 7 8 9 10 11 12 13 14 15 16 17 18 19 20 21 22 23 24 25 26 27 28 

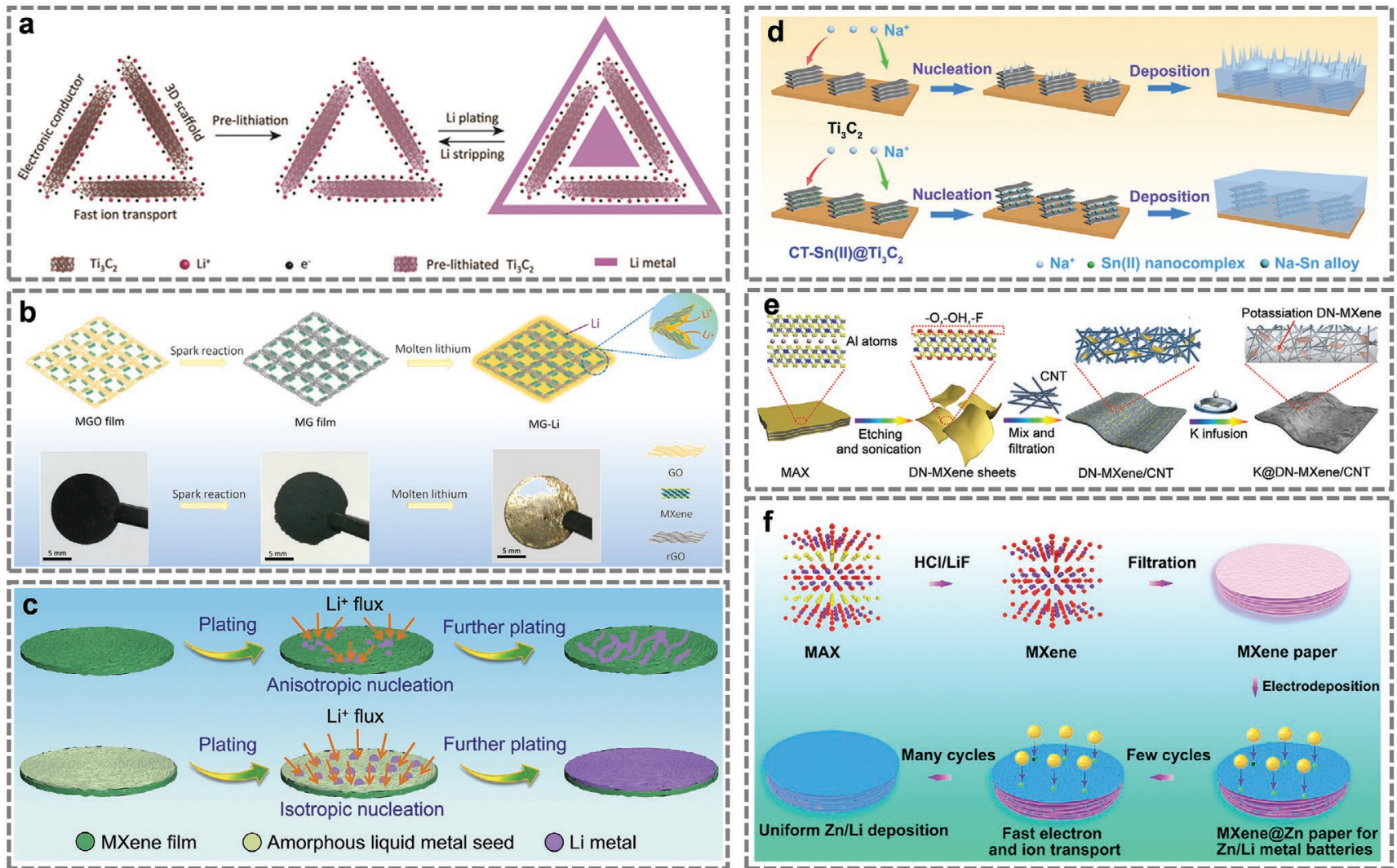

Figure 18. a) The lithium stripping/plating process on $\mathrm{Ti}_{3} \mathrm{C}_{2} \mathrm{MXene/rGO}$ aerogel. Reproduced with permission. ${ }^{[160]}$ Copyright 2018, Wiley. b) The fabrication process of the 3D MXene/graphene-Li anode and the corresponding photographs of the MXene/graphene oxide film, MXene/graphene film, and MXene/graphene-Li anode. Reproduced with permission. ${ }^{[161]}$ Copyright 2019, American Chemical Society. c) The plating process of Li on MXene film and MXene/liquid metal film, respectively. Reproduced with permission. ${ }^{[163]}$ Copyright 2020, Elsevier. d) The comparison of Na nucleation, deposition in $\mathrm{Ti}_{3} \mathrm{C}_{2}$ and CT-Sn(II)@Ti $\mathrm{C}_{2}$ matrixes. Reproduced with permission. ${ }^{[164]}$ Copyright 2019, Wiley. e) The preparation of the DN-MXene/CNT scaffold and K@DN-MXene/CNT metallic anodes. Reproduced with permission. ${ }^{[165]}$ Copyright 2019, Wiley. f) The synthesis process of MXene paper and the Li/Zn deposition on it. Reproduced with permission. ${ }^{[166]}$ Copyright 2019, American Chemical Society.

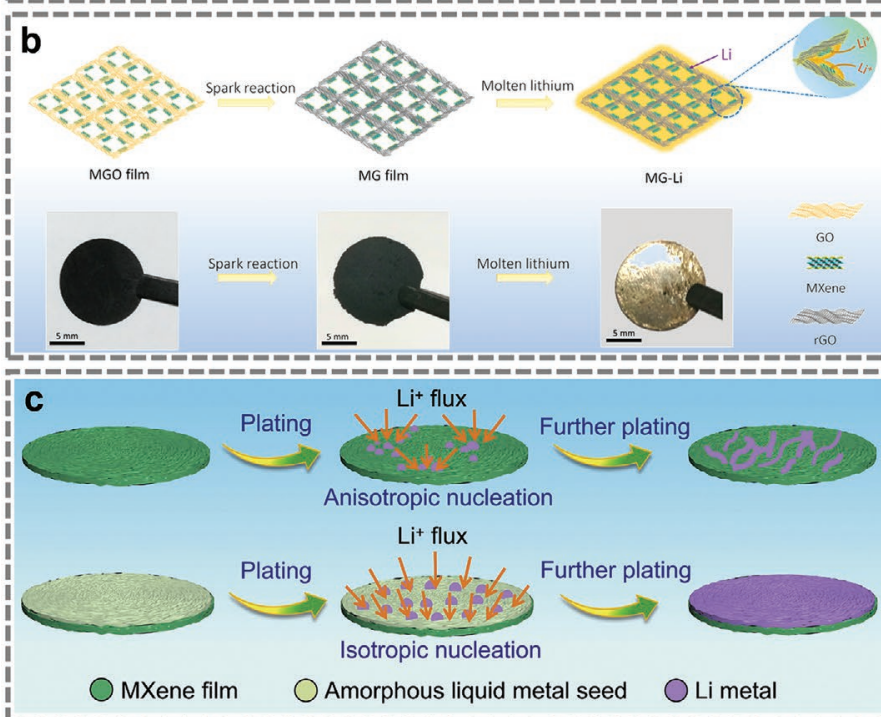
33 34
35

to fabricate MXene arrays and MXene lattices as lithium hosts (Figure 17g). Because of the largely available interspaces in MXene arrays, the growth of lithium was confined in the stripshaped channels (Figure $17 \mathrm{~h}-\mathrm{k}) .{ }^{[159 \mathrm{~b}]}$

Besides, other 3D scaffolds for Li metal anodes such as MXene/rGO aerogel (Figure 18a), ${ }^{[160]}$ MXene/graphene framework (Figure 18b), ${ }^{[161]}$ and interlayer-calated thin lithium electrode ${ }^{[162]}$ were also designed for high performance and dendrite-free lithium metal batteries. Notably, Qian et al. developed a novel method by using an amorphous liquid metal nucleation seed on MXene films to induce isotropic lithium nucleation and growth, so as to inhibit the growth of lithium dendrite (Figure 18c). ${ }^{[163]}$

\subsubsection{Other Metal Anodes ( $N a, K, Z n)$}

Apart from lithium metal anode, MXene-based materials have also been employed to protect other metal anodes from dendrite formation. For instance, Li et al. presented a $\mathrm{Sn}^{2+}$ pillared $\mathrm{Ti}_{3} \mathrm{C}_{2}$ MXene scaffold (CT-Sn(II)@ $\mathrm{Ti}_{3} \mathrm{C}_{2}$ ) as a stable matrix for high-performance dendrite-free sodium metal anodes. ${ }^{[164]}$ The intercalation of sodiophilic seeds $\left(\mathrm{Sn}^{2+}\right)$ into the MXene layers can effectively avoid the dendrite growth on the favorable 37 sites. Meanwhile, the expanded interlayer distance can miti- 38 gate volumetric change and accommodate more sodium ions 39 (Figure 18d). Wang et al. fabricated a defect-rich and nitrogen- 40 containing MXene/CNT free-standing host for potassium metal 41 (K@DN-MXene/CNT) and used it as anode for dendrite free 42 K-S batteries (Figure 18e). ${ }^{[165]}$ The fast $\mathrm{K}^{+}$diffusion and elec- 43 tronic transport in the highly conductive scaffold decreased 44 the local current density and achieved the homogeneous ionic 45 flux during plating/stripping. Both theoretical calculations and 46 experimental results verified that the $3 \mathrm{D}$ scaffold could induce 47 the homogeneous nucleation and thus a uniform distribution of 48 potassium. ${ }^{[165]}$ Notably, Qian et al. showed that the flexible and 49 free-standing $\mathrm{Ti}_{3} \mathrm{C}_{2} \mathrm{~T}_{x}$ MXene@Zn paper could serve as a matrix 50 for both aqueous zinc and nonaqueous lithium metal batteries 51 (Figure 18f). ${ }^{[166]}$ In the former case, the stable and reversible 52 zinc plating/stripping process was enabled by the high conduc- 53 tivity and good hydrophilicity of the MXene@Zn films. While in 54 the latter case, the zinc in the MXene@Zn host severed as the 55 nucleation agent because of the Zn-Li alloy reaction. 56

It is evident from the above results that benefiting from 57 the high conductivity, large interlayer spacing, and abundant 58 surface functional groups (particularly the $-F$ ), MXene-based 59 
materials have shown great potential in protecting metal anodes from the growth of dendrites. However, it should be noted that the application of MXenes in metal anode protection is still in the infancy stage and more work is required in this direction.

\section{Conclusion and Perspective}

In this review, we have summarized the synthetic strategies and properties of MXenes and the recent progress on using MXenes for energy storage applications. Specifically, we covered various strategies for designing MXene and MXene-based materials and their applications in alkali-ion (e.g., $\mathrm{Na}^{+}, \mathrm{K}^{+}$) storage, multivalent-ion (e.g., $\mathrm{Mg}^{2+}, \mathrm{Zn}^{2+}$, and $\mathrm{Al}^{3+}$ ) storage, and metal batteries (Figure 19). The versatile MXenes with high conductivity and rich surface terminations have shown great potential and are being intensively evaluated as different components in energy storage devices, including electrodes, metal anode protective layers, sulfur hosts, separator interlayers, and conductive additives. Despite the significant progress that has been made in recent years, many challenges remain. In our view, there are several important research directions that are needed to make further progress in using MXenes and MXenebased materials for electrochemical energy storage applications.

The current synthesis methods of MXenes generally involve the use of HF, which is harmful and hazardous for human beings. Identifying other etchants that are safer than HF as well as developing low cost, efficient and environmentally-friendly 1 etching processes are of great interest and importance for the large-scale production of high quality MXenes. The Lewis acid molten salts and electrochemical routes are good examples, while more cost-efficient and scalable methods are required. What's more, it is clear that the synthesis route of MXenes could also affect their conductivities. So exploring new etchants that have less environmental impacts might also lead to improved MXene conductivity. One the other hand, bottom-up methods (e.g., CVD) have shown their efficacy of directly synthesizing metal carbides and thus could also be a promising approach to synthesize high quality MXenes. Such a process avoids the use of etchants and therefore, can obtain "pure" MXenes without functional groups, which offers the opportunity to study the intrinsic properties of MXenes and could be appealing for many specific applications.

The surface chemistry of MXenes plays an essential role in determining their properties and therefore the electrochemical activity. These terminations can selectively interact with specific compounds (e.g., S termination with LiPSs) and thus affect the energy storage performance (e.g., specific capacity, coulombic efficiency). Regulating the surface termination, including the type and composition can further optimize the electrochemical performance of MXenes but remains challenging. The molten salts method has shown great ability to control and change the functional groups. ${ }^{[43-45]}$ However, much more efforts are required to explore more facile approaches to synthesize MXenes with controllable terminations, especially those

\section{2} 3 4 5 6 7

Figure 19. Schematic illustration of the various strategies that can be used to exploit MXenes to improve the performance of emerging batteries (beyond the Li ion). 
with the same kind of moieties and those without any terminations. A careful selection of etchants and delicately designed etching process can be helpful. Further, post-treatment could be another direction to adjust the surface chemistry. For instance, plasma modification is verified to be an effective way to manipulate the surface chemistry of various materials. ${ }^{[167]}$

Delaminated MXene flakes possess more active sites and larger surface area but tend to restack or aggregate because of the van der Waals interaction and/or hydrogen bonding force. In this respect, hybridizing MXenes with other low-dimensional nanomaterials is an effective approach that not only prevents MXenes from restacking but also improves their performance. For instance, hybridizing MXenes with conductive polymers (e.g., polyaniline, polypyrrole), 2D nanosheets (e.g., $\mathrm{MoS}_{2}$, $\mathrm{MoSe}_{2}$ ), one-dimensional nanotube/nanorods (e.g., CNT), and OD quantum dots has been shown enhanced electrochemical performance. Apart from traditional chemical methods, physical deposition (e.g., atomic layer deposition $)^{[168]}$ can be another possible direction to synthesize MXene-based composites with precisely controlled composition.

MXenes typically suffer from rapid oxidation/degradation in the air and water. ${ }^{[169]}$ On the one hand, the surface oxides might enhance the electrochemical activity. On the other hand, they could reduce the conductivity and further bring about complexities in studying the intrinsic properties of MXenes. Thorough investigations on the oxidation behavior are required to better understand and control the oxidation process. In the meantime, preventing MXenes from oxidation is also pivotal as the high stability is a prerequisite for their practical applications. Therefore, it is crucial to develop effective approaches that can improve the stability of MXene under various conditions. It has demonstrated that storing the MXene colloidal solutions in hermetic inert gas-filled bottles at low temperatures (e.g., $5^{\circ} \mathrm{C}$ ) is an efficient way to eliminate the main oxidant (i.e., dissolved oxygen) of the MXene flakes. ${ }^{[169 a]}$ Besides, surface coatings also can effectively protect MXene flakes from irreversible oxidization, ${ }^{[170]}$ yet the optimal composition of surface coating layers and the coating conditions that could prevent the oxidation but without affecting the electrochemical activity of MXenes remain to be further explored.

MXene electrodes typically show pseudocapacitive characteristic with heavily sloped discharge curves. Given the high electronic conductivities, MXene electrodes normally exhibit excellent rate performance and are good candidates for high rate hybrid ion capacitors, however, might be less appealing for high energy devices owing to their low capacitances. Fortunately, the versatile composition of MXenes enables the possibility of tuning their electrochemical performance; whereas further hybridizing MXenes with other high specific capacity materials provides the opportunity of using MXenes for high energy/power density devices.

In spite of the thriving development of MXenes in the field of energy storage, the ion dynamic and charge storage behavior of MXenes in various energy storage devices (especially the $\mathrm{K}^{+} / \mathrm{Zn}^{2+} / \mathrm{Al}^{3+}$ ion batteries) are still not fully understood. A better understanding of the reaction mechanism is vital to provide valuable information for the design and optimization of MXene electrodes, which can be achieved by using various state-of-the-art in situ and ex situ characterizations and analyses, including TEM, NMR, and synchrotron investigations 1 (e.g., XRD, X-ray absorption near-edge spectroscopy, soft X-ray 2 absorption spectroscopy).

Despite the fact that more than 30 MXenes have been experi- 4 mentally synthesized, the most studied and best optimized 5 one is still the first MXene, i.e., $\mathrm{Ti}_{3} \mathrm{C}_{2} \mathrm{~T}_{x}$. Although it exhibits 6 various unique and promising features, it is by no means the 7 best MXene for every application. Different properties and per- 8 formances can be reasonably expected given the large family 9 of MXenes with various compositions. For example, $\mathrm{M}_{2} \mathrm{CT}_{x} 10$ MXenes (e.g., $\mathrm{V}_{2} \mathrm{CT}_{x}$ ) possess the higher theoretical gravimetric 11 capacity $\left(>400 \mathrm{mAh} \mathrm{g}^{-1}\right)$ toward mobile ion storage because of 12 their lighter molar mass than $\mathrm{Ti}_{3} \mathrm{C}_{2} \mathrm{~T}_{x} \cdot{ }^{\left[{ }^{[5 c}\right]}$ In addition, nitride 13 MXenes have been predicted to have a higher conductivity and 14 could provide faster electronic transport. ${ }^{[171]}$ Unfortunately, the 15 etching and exfoliation conditions for MXenes beyond $\mathrm{Ti}_{3} \mathrm{C}_{2} \mathrm{~T}_{x} 16$ are far from optimized because of the considerably less research 17 activity (compared to that of $\mathrm{Ti}_{3} \mathrm{C}_{2} \mathrm{~T}_{x}$ ). On the other hand, this 18 also means that there is a huge room for further improving the 19 overall performance. We anticipate that more MXenes (beyond 20 $\mathrm{Ti}_{3} \mathrm{C}_{2} \mathrm{~T}_{x}$ ) will be intensively investigated in the years ahead. A 21 prerequisite for such development is the reliable methods 22 for the preparation of these (non-Ti) MXenes, which unfortu- 23 nately are still premature (especially for the nitride MXenes). 24 More efforts should therefore be devoted to developing effi- 25 cient methods for the large-scale and controllable synthesis of 26 (nitride) MXenes. This will also help to understand the chem- 27 istry of these MXenes and further to optimize their properties. 28

Finally, it would be practically meaningless if the target mate- 29 rial has no potential to transfer "from lab to fab." Although 2D 30 materials have shown great potential in many fields, only few 31 of them have successfully been commercialized. The main 32 limitation is that the materials for laboratorial use are produced 33 in very small quantities and the cost is often less considered. 34 Further, there are also scalability issues since some precursors 35 are not sufficiently abundant which would increase the overall 36 cost. In this regard, Ti-based MXenes are the most appealing 37 as the precursors (i.e., $\mathrm{Ti}, \mathrm{Al}, \mathrm{C}$ ) are relatively abundant and 38 cheap. Further, MXenes are generally produced by selectively 39 etching the MAX precursors through scalable chemical routes, 40 which has the potential to meet the requirements of industrial 41 production. Another potential issue is whether MXenes pro- 42 duced at industrial scale (e.g., kilogram level) could preserve 43 their desirable properties. A recent study demonstrated that 44 there is no loss of properties of $\mathrm{Ti}_{3} \mathrm{C}_{2} \mathrm{~T}_{x}$ MXene when the batch 45 size is increased from 1 to 50 g. ${ }^{[172]}$ Though much larger size is 46 required for industrial usage, it points out the possibility of pro- 47 ducing MXenes at large scale without sacrificing their excellent 48 properties. In fact, Murata Manufacturing Co., Ltd. is pushing 49 forward with the production of MXenes at kilogram scale by 50 using larger reactors. ${ }^{[173]}$ Nonetheless, more efforts are still 51 needed to reach larger scale, as well as to develop safer, more 52 energy-efficient, and cost-efficient approaches. This requires 53 not only the development of the best practices for processing 54 MXenes in various forms (e.g., powder, films, etc.), but also 55 the deep understanding of the synthesis-structure-property 56 relationship. In addition, the electrochemical measurements of 57 MXenes, especially those that hold the potential to be commer- 58 cialized, should follow the standard procedure used in industry. 59 
However, some MXenes, such as Sc-based MXenes, are highly unlikely to be used in widespread applications due to the high cost and therefore investigations at laboratorial level would be appropriate so as to study the fundamental properties. As both the scientist and engineer communities are working synergistically to overcome the challenges (e.g., safety, scalability, stability), we believe that major breakthroughs will be made in the commercialization of MXenes in the future.

\section{Acknowledgements}

F.M. and H.L. contributed equally to this work. The research reported in this publication was supported by King Abdullah University of Science and Technology (KAUST).

\section{Conflict of Interest}

The authors declare no conflict of interest.

\section{Keywords}

2D materials, energy storage, MXene, rechargeable batteries

Received: June 13, 2020 Revised: July 31, 2020 Published online:

[1] a) J.-M. Tarascon, M. Armand, Materials for Sustainable Energy: A Collection of Peer-Reviewed Research and Review Articles from Nature Publishing Group, World Scientific, Singapore 2011, p. 171; b) J. R. Miller, P. Simon, Science 2008, 321, 651; c) M. Winter, R. J. Brodd, Chem. Rev. 2004, 104, 4245; d) W. Zhang, F. Zhang, F. Ming, H. N. Alshareef, EnergyChem 2019, 1, 100012; e) D. P. Dubal, O. Ayyad, V. Ruiz, P. Gomez-Romero, Chem. Soc. Rev. 2015, 44, 1777.

[2] M. Li, J. Lu, Z. Chen, K. Amine, Adv. Mater. 2018, 30, 1800561.

[3] a) C.-X. Zu, H. Li, Energy Environ. Sci. 2011, 4, 2614; b) F. Risacher, B. Fritz, Aquat. Geochem. 2009, 15, 123.

[4] a) L. Peng, Y. Zhu, D. Chen, R. S. Ruoff, G. Yu, Adv. Energy Mater. 2016, 6, 1600025; b) H. Kim, J. C. Kim, M. Bianchini, D.-H. Seo, J. Rodriguez-Garcia, G. Ceder, Adv. Energy Mater. 2018, 8, 1702384; c) Y. Li, Y. Lu, C. Zhao, Y.-S. Hu, M.-M. Titirici, H. Li, X. Huang, L. Chen, Energy Storage Mater. 2017, 7, 130; d) X. Xiang, K. Zhang, J. Chen, Adv. Mater. 2015, 27, 5343; e) J. C. Pramudita, D. Sehrawat, D. Goonetilleke, N. Sharma, Adv. Energy Mater. 2017, 7, 1602911; f) C. Vaalma, D. Buchholz, S. Passerini, Curr. Opin. Electrochem. 2018, 9, 41; g) Q. Zhang, Z. Wang, S. Zhang, T. Zhou, J. Mao, Z. Guo, Electrochem. Energy Rev. 2018, 1, 625; h) M. M. Huie, D. C. Bock, E. S. Takeuchi, A. C. Marschilok, K. J. Takeuchi, Coord. Chem. Rev. 2015, 287, 15; i) F. Ming, H. Liang, W. Zhang, J. Ming, Y. Lei, A.-H. Emwas, H. N. Alshareef, Nano Energy 2019, 62, 853; j) R. Mohtadi, M. Matsui, T. S. Arthur, S.-J. Hwang, Angew. Chem., Int. Ed. 2012, 51, 9780; k) L. Fu, N. Li, Y. Liu, W. Wang, Y. Zhu, Y. Wu, Chin. J. Chem. 2017, 35, 13; I) X. Zhang, Y. Tang, F. Zhang, C.-S. Lee, Adv. Energy Mater. 2016, 6, 1502588; m) S. K. Das, Angew. Chem., Int. Ed. 2018, 57, 16606; n) Y. Zhang, S. Liu, Y. Ji, J. Ma, H. Yu, Adv. Mater. 2018, 30, 1706310; o) F. Ming, H. Liang, Y. Lei, W. Zhang, H. N. Alshareef, Nano Energy 2018, 53, 11; p) C. Xu, B. Li, H. Du, F. Kang, Angew. Chem., Int. Ed. 2012, 51, 933; q) J. Ming, J. Guo, C. Xia, W. Wang, H. N. Alshareef, Mater. Sci. 1 Eng., $R$ 2019, 135, 58; r) P. He, Q. Chen, M. Yan, X. Xu, L. Zhou, 2 L. Mai, C.-W. Nan, EnergyChem 2019, 1, 100022; s) B. Tang, L. Shan, S. Liang, J. Zhou, Energy Environ. Sci. 2019, 12, 3288; t) C. Li, X. Xie, S. Liang, J. Zhou, Energy Environ. Mater. 2020, 3, 146; u) F. Ming, H. Liang, Y. Lei, S. Kandambeth, M. Eddaoudi, H. N. Alshareef, ACS Energy Lett. 2018, 3, 2602; v) C. Xia, J. Guo, Y. Lei, H. Liang, C. Zhao, H. N. Alshareef, Adv. Mater. 2018, 30, 1705580.

[5] a) J. Besenhard, H. Fritz, J. Electroanal. Chem. Interfacial Electrochem. 1974, 53, 329; b) ।. Besenhard, Carbon 1976, 14, 111; c) M. Arakawa, J.-I. Yamaki, J. Electroanal. Chem. Interfacial Electrochem. 1987, 219, 273; d) E. Peled, J. Electrochem. Soc. 1979, 126, 2047.

[6] a) K. Mizushima, P. Jones, P. Wiseman, J. B. Goodenough, Mater. Res. Bull. 1980, 15, 783; b) N. Godshall, I. Raistrick, R. Huggins, Mater. Res. Bull. 1980, 15, 561; c) G. Amatucci, J. Tarascon, L. Klein, J. Electrochem. Soc. 1996, 143, 1114.

[7] a) M. S. Whittingham, Chem. Rev. 2004, 104, 4271; b) M. S. Whittingham, Science 1976, 192, 1126; c) M. S. Whittingham, F. R. Gamble Jr., Mater. Res. Bull. 1975, 10, 363.

[8] K. S. Novoselov, A. K. Geim, S. V. Morozov, D. Jiang, Y. Zhang S. V. Dubonos, I. V. Grigorieva, A. A. Firsov, Science 2004, 306, 666

[9] M. Naguib, M. Kurtoglu, V. Presser, J. Lu, J. Niu, M. Heon, L. Hultman, Y. Gogotsi, M. W. Barsoum, Adv. Mater. 2011, 23, 4248.

[10] a) B. Anasori, M. R. Lukatskaya, Y. Gogotsi, Nat. Rev. Mater. 2017, 2, 16098; b) M. Naguib, V. N. Mochalin, M. W. Barsoum, Y. Gogotsi, Adv. Mater. 2014, 26, 992.

[11] a) M. Ghidiu, M. R. Lukatskaya, M.-Q. Zhao, Y. Gogotsi, M. W. Barsoum, Nature 2014, 516, 78; b) M.-Q. Zhao, X. Xie C. E. Ren, T. Makaryan, B. Anasori, G. Wang, Y. Gogotsi, Adv. Mater. 2017, 29, 1702410; c) Z. Ling, C. E. Ren, M.-Q. Zhao, J. Yang, J. M. Giammarco, J. Qiu, M. W. Barsoum, Y. Gogotsi, Proc. Natl. Acad. Sci. USA 2014, 111, 16676.

[12] a) Z. Wang, H. Kim, H. N. Alshareef, Adv. Mater. 2018, 30, 1706656; b) C. Zhang, B. Anasori, A. Seral-Ascaso, S. H. Park, N. McEvoy, A. Shmeliov, G. S. Duesberg, J. N. Coleman, Y. Gogotsi, V. Nicolosi, Adv. Mater. 2017, 29, 1702678; c) G. Ying, S. Kota, A. D. Dillon, A. T. Fafarman, M. W. Barsoum, FlatChem 2018, 8, 25

[13] a) Q. Jiang, N. Kurra, M. Alhabeb, Y. Gogotsi, H. N. Alshareef, Adv. Energy Mater. 2018, 8, 1703043; b) Q. Jiang, C. Wu, Z. Wang, A. C. Wang, J.-H. He, Z. L. Wang, H. N. Alshareef, Nano Energy 2018, 45, 266; c) Q. Jiang, N. Kurra, K. Maleski, Y. Lei, H. Liang, Y. Zhang, Y. Gogotsi, H. N. Alshareef, Adv. Energy Mater. 2019, 9, 1901061; d) N. Kurra, B. Ahmed, Y. Gogotsi, H. N. Alshareef Adv. Energy Mater. 2016, 6, 1601372; e) B. Ahmed, D. H. Anjum, M. N. Hedhili, Y. Gogotsi, H. N. Alshareef, Nanoscale 2016, 8, 7580; f) N. Kurra, M. Alhabeb, K. Maleski, C.-H. Wang, H. N. Alshareef, Y. Gogotsi, ACS Energy Lett. 2018, 3, 2094 g) Y.-Y. Peng, B. Akuzum, N. Kurra, M.-Q. Zhao, M. Alhabeb, B. Anasori, E. C. Kumbur, H. N. Alshareef, M.-D. Ger, Y. Gogotsi, Energy Environ. Sci. 2016, 9, 2847; h) M. R. Lukatskaya, S. Kota Z. Lin, M.-Q. Zhao, N. Shpigel, M. D. Levi, J. Halim, P.-L. Taberna, M. W. Barsoum, P. Simon, Nat. Energy 2017, 2, 17105; i) A. Byeon, A. M. Glushenkov, B. Anasori, P. Urbankowski, J. Li, B. W. Byles, B. Blake, K. L. Van Aken, S. Kota, E. Pomerantseva, J. Power Sources 2016, 326, 686; j) C. Zhan, M. Naguib, M. Lukatskaya, P. R. Kent, Y. Gogotsi, D.-e. Jiang, J. Phys. Chem. Lett. 2018, 9, 1223; k) M. Naguib, J. Come, B. Dyatkin, V. Presser, P.-L. Taberna, P. Simon, M. W. Barsoum, Y. Gogotsi, Electrochem. Commun. 2012 $16,61$.

[14] a) D. Xiong, X. Li, Z. Bai, S. Lu, Small 2018, 14, 1703419; b) J. Pang, R. G. Mendes, A. Bachmatiuk, L. Zhao, H. Q. Ta, T. Gemming, H. Liu, Z. Liu, M. H. Rummeli, Chem. Soc. Rev. 2019, 48, 72;

\section{2}


c) M. Greaves, S. Barg, M. A. Bissett, Batteries Supercaps 2020, 3, 214; d) X. Zhang, Z. Zhang, Z. Zhou, J. Energy Chem. 2018, 27, 73; e) H. Tang, Q. Hu, M. Zheng, Y. Chi, X. Qin, H. Pang, Q. Xu, Prog. Nat. Sci.: Mater. Int. 2018, 28, 133; f) L. Verger, V. Natu, M. Carey, M. W. Barsoum, Trends Chem 2019, 1, 656; g) Q. Jiang, Y. Lei, H. Liang, K. Xi, C. Xia, H. N. Alshareef, Energy Storage Mater. 2020, 27, 78; h) K. Li, M. Liang, H. Wang, X. Wang, Y. Huang, J. Coelho, S. Pinilla, Y. Zhang, F. Qi, V. Nicolosi, Adv. Funct. Mater. 2020, 2000842; i) A. Zhang, R. Liu, J. Tian, W. Huang, J. Liu, Chem. - Eur. J. 2020, 26, 6342 .

[15] a) S. Sun, C. Liao, A. M. Hafez, H. Zhu, S. Wu, Chem. Eng. J. 2018, 338, 27; b) X. Tang, X. Guo, W. Wu, G. Wang, Adv. Energy Mater. 2018, 8, 1801897.

[16] a) Q. Tao, M. Dahlqvist, J. Lu, S. Kota, R. Meshkian, J. Halim, J. Palisaitis, L. Hultman, M. W. Barsoum, P. O. Å. Persson, Nat. Commun. 2017, 8, 1; b) L. Qin, Q. Tao, A. El Ghazaly, J. Fernandez-Rodriguez, P. O. Å. Persson, J. Rosen, F. Zhang, Adv. Funct. Mater. 2018, 28, 1703808; c) R. Meshkian, M. Dahlqvist, J. Lu, B. Wickman, J. Halim, J. ThĂśrnberg, Q. Tao, S. Li, S. Intikhab, J. Snyder, Adv. Mater. 2018, 30, 1706409; d) P. Srimuk, J. Halim, J. Lee, Q. Tao, J. Rosen, V. Presser, ACS Sustainable Chem. Eng. 2018, 6, 3739; e) J. Halim, J. Palisaitis, J. Lu, J. Thörnberg, E. Moon, M. Precner, P. Eklund, P. O. Å. Persson, M. Barsoum, J. Rosen, ACS Appl. Nano Mater. 2018, 1, 2455; f) R. Meshkian, H. Lind, J. Halim, A. El Ghazaly, J. Thörnberg, Q. Tao, M. Dahlqvist, J. Palisaitis, P. O. Å. Persson, J. Rosen, ACS Appl. Nano Mater. 2019, 2, 6209.

[17] a) M. Naguib, O. Mashtalir, J. Carle, V. Presser, J. Lu, L. Hultman, Y. Gogotsi, M. W. Barsoum, ACS Nano 2012, 6, 1322; b) J.-C. Lei, X. Zhang, Z. Zhou, Front. Phys. 2015, 10, 276; c) M. Naguib, J. Halim, J. Lu, K. M. Cook, L. Hultman, Y. Gogotsi, M. W. Barsoum, J. Am. Chem. Soc. 2013, 135, 15966; d) R. Meshkian, L.-Å. Näslund, J. Halim, J. Lu, M. W. Barsoum, J. Rosen, Scr. Mater. 2015, 108, 147; e) J. Halim, S. Kota, M. R. Lukatskaya, M. Naguib, M.-Q. Zhao, E. J. Moon, J. Pitock, J. Nanda, S. J. May, Y. Gogotsi, Adv. Funct. Mater. 2016, 26, 3118; f) B. Soundiraraju, B. K. George, ACS Nano 2017, 11, 8892; g) A. Djire, A. Bos, J. Liu, H. Zhang, E. M. Miller, N. R. Neale, ACS Appl. Nano Mater. 2019, 2, 2785; h) P. Urbankowski, B. Anasori, K. Hantanasirisakul, L. Yang, L. Zhang, B. Haines, S. J. May, S. J. Billinge, Y. Gogotsi, Nanoscale 2017, 9, 17722; i) I. Persson, A. El Ghazaly, Q. Tao, J. Halim, S. Kota, V. Darakchieva, J. Palisaitis, M. W. Barsoum, J. Rosen, P. O. Å. Persson, Small 2018, 14, 1703676; j) J. Thörnberg, J. Halim, J. Lu, R. Meshkian, J. Palisaitis, L. Hultman, P. O. A. Persson, J. Rosen, Nanoscale 2019, 11, 14720.

[18] a) Y. I. Jhon, J. Koo, B. Anasori, M. Seo, J. H. Lee, Y. Gogotsi, Y. M. Jhon, Adv. Mater. 2017, 29, 1702496; b) J. Zhou, X. Zha, F. Y. Chen, Q. Ye, P. Eklund, S. Du, Q. Huang, Angew. Chem., Int. Ed. 2016, 55, 5008; c) J. Zhou, X. Zha, X. Zhou, F. Chen, G. Gao, S. Wang, C. Shen, T. Chen, C. Zhi, P. Eklund, ACS Nano 2017, 11, 3841; d) B. Anasori, Y. Xie, M. Beidaghi, J. Lu, B. C. Hosler, L. Hultman, P. R. Kent, Y. Gogotsi, M. W. Barsoum, ACS Nano 2015, 9, 9507; e) R. Meshkian, Q. Tao, M. Dahlqvist, J. Lu, L. Hultman, J. Rosen, Acta Mater. 2017, 125, 476; f) Z. Jing, H. Wang, X. Feng, B. Xiao, Y. Ding, K. Wu, Y. Cheng, J. Phys. Chem. Lett. 2019, 10, 5721; g) J. Yang, X. Zhou, X. Luo, S. Zhang, L. Chen, Appl. Phys. Lett. 2016, 109, 203109; h) X. Zhan, C. Si, J. Zhou, Z. Sun, Nanoscale Horiz. 2020, 5, 235.

[19] a) P. Urbankowski, B. Anasori, T. Makaryan, D. Er, S. Kota, P. L. Walsh, M. Zhao, V. B. Shenoy, M. W. Barsoum, Y. Gogotsi, Nanoscale 2016, 8, 11385; b) M. H. Tran, T. Schäfer, A. Shahraei, M. Dürrschnabel, L. Molina-Luna, U. I. Kramm, C. S. Birkel, ACS Appl. Energy Mater. 2018, 1, 3908; c) J. Zhou, S. Lin, Y. Huang, P. Tong, B. Zhao, X. Zhu, Y. Sun, Chem. Eng. J. 2019, 373, 203; d) X. Wang, S. Lin, H. Tong, Y. Huang, P. Tong, B. Zhao, J. Dai,
C. Liang, H. Wang, X. Zhu, Electrochim. Acta 2019, 307, 414; 1 e) S. Zhao, X. Meng, K. Zhu, F. Du, G. Chen, Y. Wei, Y. Gogotsi, 2 Y. Gao, Energy Storage Mater. 2017, 8, 42; f) M. Ghidiu, M. Naguib, 3 C. Shi, O. Mashtalir, L. Pan, B. Zhang, J. Yang, Y. Gogotsi, 4 S. J. Billinge, M. W. Barsoum, Chem. Commun. 2014, 50, 9517; g) R. Syamsai, A. N. Grace, J. Alloys Compd. 2019, 792, 1230; h) H. Lin, Y. Wang, S. Gao, Y. Chen, J. Shi, Adv. Mater. 2018, 30, 1703284; i) J. Yang, M. Naguib, M. Ghidiu, L.-M. Pan, J. Gu, J. Nanda, J. Halim, Y. Gogotsi, M. W. Barsoum, J. Am. Ceram. Soc. 2016, 99, 660; j) P. Cai, Q. He, L. Wang, X. Liu, J. Yin, Y. Liu, Y. Huang, Z. Huang, Ceram. Int. 2019, 45, 5761.

[20] G. Deysher, C. E. Shuck, K. Hantanasirisakul, N. C. Frey, 11 A. C. Foucher, K. Maleski, A. Sarycheva, V. B. Shenoy, E. A. Stach, B. Anasori, ACS Nano 2020, 14, 204.

[21] G. Bei, B. J. Pedimonte, T. Fey, P. Greil, J. Am. Ceram. Soc. 2013, 96, 1359.

[22] M. Radovic, A. Ganguly, M. Barsoum, J. Mater. Res. 2008, 23, 1517.

[23] a) Y.-W. Cheng, J.-H. Dai, Y.-M. Zhang, Y. Song, J. Phys. Chem. C 2018, 122, 28113; b) J. Zhang, Y. Zhao, X. Guo, C. Chen, C.-L. Dong, R.-S. Liu, C.-P. Han, Y. Li, Y. Gogotsi, G. Wang, Nat. Catal. 2018, 1, 985; c) H. Kim, B. Anasori, Y. Gogotsi, H. N. Alshareef, Chem. Mater. 2017, 29, 6472.

[24] B. Ahmed, A. E. Ghazaly, J. Rosen, Adv. Funct. Mater. 2020, 2000894.

[25] A. Petruhins, M. Dahlqvist, J. Lu, L. Hultman, J. Rosen, Cryst. Growth Des. 2020, 20, 55.

[26] a) M. Dahlqvist, J. Lu, R. Meshkian, Q. Tao, L. Hultman, J. Rosen, Sci. Adv. 2017, 3, el700642; b) J. Lu, A. Thore, R. Meshkian, Q. Tao L. Hultman, J. Rosen, Cryst. Growth Des. 2017, 17, 5704; c) L. Chen M. Dahlqvist, T. Lapauw, B. Tunca, F. Wang, J. Lu, R. Meshkian, K. Lambrinou, B. Blanpain, J. Vleugels, Inorg. Chem. 2018, 57, 6237; d) M. Dahlqvist, A. Petruhins, J. Lu, L. Hultman, J. Rosen, ACS Nano 2018, 12, 7761

[27] a) G. Eda, H. Yamaguchi, D. Voiry, T. Fujita, M. Chen, M. Chhowalla, Nano Lett. 2011, 11, 5111; b) X. Rui, Z. Lu, H. Yu, D. Yang, H. H. Hng, T. M. Lim, Q. Yan, Nanoscale 2013, 5, 556; c) J. Kang, J. D. Wood, S. A. Wells, J.-H. Lee, X. Liu, K.-S. Chen, M. C. Hersam, ACS Nano 2015, 9, 3596.

[28] M. W. Barsoum, T. El-Raghy, L. Farber, M. Amer, R. Christini, A. Adams, J. Electrochem. Soc. 1999, 146, 3919.

[29] T. El-Raghy, M. Barsoum, M. Sika, Mater. Sci. Eng., A 2001, 298, 174.

[30] M. Barsoum, J. Golczewski, H. Seifert, F. Aldinger, J. Alloys Compd. 2002, 340, 173

[31] a) Y. Gogotsi, A. Nikitin, H. Ye, W. Zhou, J. E. Fischer, B. Yi, H. C. Foley, M. W. Barsoum, Nat. Mater. 2003, 2, 591; b) E. N. Hoffman, G. Yushin, M. W. Barsoum, Y. Gogotsi, Chem. Mater. 2005, 17, 2317; c) E. N. Hoffman, G. Yushin, T. El-Raghy, Y. Gogotsi, M. W. Barsoum, Microporous Mesoporous Mater. 2008, 112, 526; d) J. Chmiola, C. Largeot, P.-L. Taberna, P. Simon, Y. Gogotsi, Science 2010, 328, 480; e) V. Presser, J. McDonough, S.-H. Yeon, Y. Gogotsi, Energy Environ. Sci. 2011, 4, 3059.

[32] M. Naguib, V. Presser, N. Lane, D. Tallman, Y. Gogotsi, J. Lu, L. Hultman, M. W. Barsoum, RSC Adv. 2011, 1, 1493.

[33] a) A. VahidMohammadi, A. Hadjikhani, S. Shahbazmohamadi, M. Beidaghi, ACS Nano 2017, 11, 11135; b) B. Philippe, R. Dedryvère, M. Gorgoi, H. Rensmo, D. Gonbeau, K. Edström, J. Am. Chem. Soc. 2013, 135, 9829.

[34] N. Driscoll, A. G. Richardson, K. Maleski, B. Anasori, O. Adewole, P. Lelyukh, L. Escobedo, D. K. Cullen, T. H. Lucas, Y. Gogotsi, ACS Nano 2018, 12, 10419.

[35] O. Mashtalir, M. Naguib, B. Dyatkin, Y. Gogotsi, M. W. Barsoum, Mater. Chem. Phys. 2013, 139, 147.

[36] a) F. Shahzad, M. Alhabeb, C. B. Hatter, B. Anasori, S. M. Hong, C. M. Koo, Y. Gogotsi, Science 2016, 353, 1137; b) A. Lipatov, 43 5

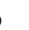
. 8 21 22 23 24 27 28 29 30 31 32 33 34 35 36 37 38 39 40 . 4 44 45 46 46 47 48 49 50 s1 52 53 54 55 56 57 58 59 
M. Alhabeb, M. R. Lukatskaya, A. Boson, Y. Gogotsi, A. Sinitskii, Adv. Electron. Mater. 2016, 2, 1600255; c) X. Sang, Y. Xie, M.-W. Lin, M. Alhabeb, K. L. Van Aken, Y. Gogotsi, P. R. Kent, K. Xiao, R. R. Unocic, ACS Nano 2016, 10, 9193.

[37] C. Peng, P. Wei, X. Chen, Y. Zhang, F. Zhu, Y. Cao, H. Wang, H. Yu, F. Peng, Ceram. Int. 2018, 44, 18886.

[38] a) F. Liu, J. Zhou, S. Wang, B. Wang, C. Shen, L. Wang, Q. Hu, Q. Huang, A. Zhou, J. Electrochem. Soc. 2017, 164, A709; b) M. Wu, B. Wang, Q. Hu, L. Wang, A. Zhou, Materials 2018, 11, 2112 c) F. Liu, A. Zhou, J. Chen, J. Jia, W. Zhou, L. Wang, Q. Hu, Appl. Surf. Sci. 2017, 416, 781.

[39] J. Halim, M. R. Lukatskaya, K. M. Cook, J. Lu, C. R. Smith, L.-Å. Näslund, S. J. May, L. Hultman, Y. Gogotsi, P. Eklund, Chem. Mater. 2014, 26, 2374.

[40] L. Wang, H. Zhang, B. Wang, C. Shen, C. Zhang, Q. Hu, A. Zhou, B. Liu, Electron. Mater. Lett. 2016, 12, 702.

[41] T. Li, L. Yao, Q. Liu, J. Gu, R. Luo, J. Li, X. Yan, W. Wang, P. Liu, B. Chen, Angew. Chem., Int. Ed. 2018, 57, 6115.

[42] J. Mei, G. A. Ayoko, C. Hu, J. M. Bell, Z. Sun, Sustainable Mater. Technol. 2020, 25, e00156.

[43] M. Li, J. Lu, K. Luo, Y. Li, K. Chang, K. Chen, J. Zhou, J. Rosen, L. Hultman, P. Eklund, J. Am. Chem. Soc. 2019, 141, 4730.

[44] Y. Li, H. Shao, Z. Lin, J. Lu, L. Liu, B. Duployer, P. O. Å. Persson, P. Eklund, L. Hultman, M. Li, K. Chen, X.-H. Zha, S. Du, P. Rozier, Z. Chai, E. Raymundo-Piñero, P.-L. Taberna, P. Simon, Q. Huang, Nat. Mater. 2020, 19, 894

[45] V. Kamysbayev, A. S. Filatov, H. Hu, X. Rui, F. Lagunas, D. Wang, R. F. Klie, D. V. Talapin, Science 2020, eaba8311.

[46] a) W. Sun, S. Shah, Y. Chen, Z. Tan, H. Gao, T. Habib, M. Radovic M. Green, J. Mater. Chem. A 2017, 5, 21663; b) S. Yang, P. Zhang F. Wang, A. G. Ricciardulli, M. R. Lohe, P. W. Blom, X. Feng, Angew. Chem., Int. Ed. 2018, 130, 15717.

[47] a) C. Xu, L. Wang, Z. Liu, L. Chen, J. Guo, N. Kang, X.-L. Ma, H.-M. Cheng, W. Ren, Nat. Mater. 2015, 14, 1135; b) D. Geng, X. Zhao, Z. Chen, W. Sun, W. Fu, J. Chen, W. Liu, W. Zhou, K. P. Loh, Adv. Mater. 2017, 29, 1700072.

[48] O. Mashtalir, M. R. Lukatskaya, M.-Q. Zhao, M. W. Barsoum, Y. Gogotsi, Adv. Mater. 2015, 27, 3501.

[49] M. Naguib, R. R. Unocic, B. L. Armstrong, J. Nanda, Dalton Trans. 2015, 44, 9353

[50] a) M. R. Lukatskaya, O. Mashtalir, C. E. Ren, Y. Dall'Agnese, P. Rozier, P. L. Taberna, M. Naguib, P. Simon, M. W. Barsoum, Y. Gogotsi, Science 2013, 341, 1502; b) O. Mashtalir, M. Naguib, V. N. Mochalin, Y. Dall'Agnese, M. Heon, M. W. Barsoum, Y. Gogotsi, Nat. Commun. 2013, 4, 1716.

[51] a) A. Lipatov, M. Alhabeb, H. Lu, S. Zhao, M. J. Loes, N. S. Vorobeva, Y. Dall'Agnese, Y. Gao, A. Gruverman, Y. Gogotsi, Adv. Electron. Mater. 2020, 6, 1901382; b) M. Lu, Z. Zhang, L. Kang, X. He, Q. Li, J. Sun, R. Jiang, H. Xu, F. Shi, Z. Lei, J. Mater. Chem. A 2019, 7, 12582; c) M. Alhabeb, K. Maleski, T. S. Mathis, A. Sarycheva, C. B. Hatter, S. Uzun, A. Levitt, Y. Gogotsi, Angew. Chem., Int. Ed. 2018, 57, 5444; d) H. Wu, M. Almalki, X. Xu, Y. Lei, F. Ming, A. Mallick, V. Roddatis, S. Lopatin, O. Shekhah, M. Eddaoudi, J. Am. Chem. Soc. 2019, 141, 20037; e) Z. Ma, X. Zhou, W. Deng, D. Lei, Z. Liu, ACS Appl. Mater. Interfaces 2018, 10, 3634.

[52] a) Y. Xie, M. Naguib, V. N. Mochalin, M. W. Barsoum, Y. Gogotsi, X. Yu, K.-W. Nam, X.-Q. Yang, A. I. Kolesnikov, P. R. Kent, J. Am Chem. Soc. 2014, 136, 6385; b) Y. Xie, Y. Dall'Agnese, M. Naguib, Y. Gogotsi, M. W. Barsoum, H. L. Zhuang, P. R. Kent, ACS Nano 2014, 8, 9606; c) C. Eames, M. S. Islam, J. Am. Chem. Soc. 2014 136,16270

[53] a) X. Liu, X. Shao, F. Li, M. Zhao, Appl. Surf. Sci. 2018, 455, 522; b) Q. Meng, J. Ma, Y. Zhang, Z. Li, C. Zhi, A. Hu, J. Fan, Nanoscale 2018, 10, 3385 .
[54] a) Q. Peng, J. Guo, Q. Zhang, J. Xiang, B. Liu, A. Zhou, R. Liu, 1 Y. Tian, J. Am. Chem. Soc. 2014, 136, 4113; b) R. B. Rakhi, B. Ahmed, M. N. Hedhili, D. H. Anjum, H. N. Alshareef, Chem. Mater. 2015, 27, 5314; c) R. Cheng, T. Hu, H. Zhang, C. Wang, M. Hu, J. Yang, C. Cui, T. Guang, C. Li, C. Shi, J. Phys. Chem. C 2019, 123, 1099.

[55] a) M. A. Hope, A. C. Forse, K. J. Griffith, M. R. Lukatskaya, M. Ghidiu, Y. Gogotsi, C. P. Grey, Phys. Chem. Chem. Phys. 2016 18, 5099; b) M. Hu, T. Hu, Z. Li, Y. Yang, R. Cheng, J. Yang, C. Cui, X. Wang, ACS Nano 2018, 12, 3578.

[56] L. Li, Comput. Mater. Sci. 2016, 124, 8.

[57] a) Y. Xie, P. Kent, Phys. Rev. B 2013, 87, 235441; b) M. Khazaei, A. Ranjbar, M. Arai, S. Yunoki, Phys. Rev. B 2016, 94, 125152; c) M. Khazaei, M. Arai, T. Sasaki, C.-Y. Chung, N. S. Venkataramanan, M. Estili, Y. Sakka, Y. Kawazoe, Adv. Funct. Mater. 2013, 23, 2185; d) X. Zhang, Z. Ma, X. Zhao, Q. Tang, Z. Zhou, J. Mater. Chem. A 2015, 3, 4960.

[58] Q. Tang, Z. Zhou, P. Shen, J. Am. Chem. Soc. 2012, 134, 16909.

[59] a) K. J. Harris, M. Bugnet, M. Naguib, M. W. Barsoum, G. R. Goward, J. Phys. Chem. C 2015, 119, 13713; b) L. H. Karlsson, J. Birch, J. Halim, M. W. Barsoum, P. O. Persson, Nano Lett. 2015 15, 4955; c) H.-W. Wang, M. Naguib, K. Page, D. J. Wesolowski, Y. Gogotsi, Chem. Mater. 2016, 28, 349.

[60] F. Chang, C. Li, J. Yang, H. Tang, M. Xue, Mater. Lett. 2013, 109, 295.

[61] M. Ghidiu, J. Halim, S. Kota, D. Bish, Y. Gogotsi, M. W. Barsoum, Chem. Mater. 2016, 28, 3507.

[62] J. Luo, W. Zhang, H. Yuan, C. Jin, L. Zhang, H. Huang, C. Liang, Y. Xia, J. Zhang, Y. Gan, ACS Nano 2017, 11, 2459.

[63] M. Ghidiu, S. Kota, J. Halim, A. W. Sherwood, N. Nedfors, J. Rosen V. N. Mochalin, M. W. Barsoum, Chem. Mater. 2017, 29, 1099.

[64] a) D. Magne, V. Mauchamp, S. Celerier, P. Chartier, T. Cabioc'h Phys. Rev. B 2015, 91, 201409; b) A. N. Enyashin, A. L. Ivanovskii, J. Solid State Chem. 2013, 207, 42; c) A. N. Enyashin, A. L. Ivanovskii, J. Phys. Chem. C 2013, 117, 13637.

[65] I. R. Shein, A. L. Ivanovskii, Comput. Mater. Sci. 2012, 65, 104.

[66] a) M. Kurtoglu, M. Naguib, Y. Gogotsi, M. W. Barsoum, MRS Commun. 2012, 2, 133; b) M. Khazaei, M. Arai, T. Sasaki, M. Estili, Y. Sakka, Phys. Chem. Chem. Phys. 2014, 16, 7841.

[67] M. Ashton, K. Mathew, R. G. Hennig, S. B. Sinnott, J. Phys. Chem C 2016, 120, 3550.

[68] B. Anasori, C. Shi, E. J. Moon, Y. Xie, C. A. Voigt, P. R. C. Kent, S. J. May, S. J. L. Billinge, M. W. Barsoum, Y. Gogotsi, Nanoscale Horiz. 2016, 1, 227.

[69] H. Weng, A. Ranjbar, Y. Liang, Z. Song, M. Khazaei, S. Yunoki, M. Arai, Y. Kawazoe, Z. Fang, X. Dai, Phys. Rev. B 2015, 92, 075436.

[70] T. Hu, H. Zhang, J. Wang, Z. Li, M. Hu, J. Tan, P. Hou, F. Li, X. Wang, Sci. Rep. 2015, 5, 16329.

[71] A. D. Dillon, M. J. Ghidiu, A. L. Krick, J. Griggs, S. J. May, Y. Gogotsi, M. W. Barsoum, A. T. Fafarman, Adv. Funct. Mater. 2016, 26, 4162.

[72] a) Y. Dong, S. Chertopalov, K. Maleski, B. Anasori, L. Hu, S. Bhattacharya, A. M. Rao, Y. Gogotsi, V. N. Mochalin, R. Podila, Adv. Mater. 2018, 30, 1705714; b) S. Chertopalov, V. N. Mochalin ACS Nano 2018, 12, 6109.

[73] a) S. Lai, J. Jeon, S. K. Jang, J. Xu, Y. J. Choi, J.-H. Park, E. Hwang, S. Lee, Nanoscale 2015, 7, 19390; b) J. Xu, J. Shim, J.-H. Park, S. Lee, Adv. Funct. Mater. 2016, 26, 5328.

[74] a) S. S. Zhang, J. Power Sources 2013, 231, 153; b) L. Ma K. E. Hendrickson, S. Wei, L. A. Archer, Nano Today 2015, 10, 315; c) H.-J. Peng, J.-Q. Huang, X.-B. Cheng, Q. Zhang, Adv. Energy Mater. 2017, 7, 1700260; d) Z. Xiao, Z. Li, X. Meng, R. Wang, J. Mater. Chem. A 2019, 7, 22730; e) H.-J. Peng, Q. Zhang, Angew. Chem., Int. Ed. 2015, 54, 11018.

[75] X. Liang, L. F. Nazar, 2D Metal Carbides and Nitrides (MXenes), Springer, Berlin 2019, p. 381.

\section{2}


[76] X. Liang, A. Garsuch, L. F. Nazar, Angew. Chem., Int. Ed. 2015, 54, 3907.

[77] X. Liang, Y. Rangom, C. Y. Kwok, Q. Pang, L. F. Nazar, Adv. Mater. 2017, 29, 1603040.

[78] D. Rao, L. Zhang, Y. Wang, Z. Meng, X. Qian, J. Liu, X. Shen, G. Qiao, R. Lu, J. Phys. Chem. C 2017, 121, 11047.

[79] E. S. Sim, G. S. Yi, M. Je, Y. Lee, Y.-C. Chung, J. Power Sources 2017, 342, 64.

[80] E. S. Sim, Y.-C. Chung, Appl. Surf. Sci. 2018, 435, 210.

[81] D. Wang, F. Li, R. Lian, J. Xu, D. Kan, Y. Liu, G. Chen, Y. Gogotsi, Y. Wei, ACS Nano 2019, 13, 11078.

[82] L.-C. Yin, J. Liang, G.-M. Zhou, F. Li, R. Saito, H.-M. Cheng, Nano Energy 2016, 25, 203.

[83] H. R. Jiang, W. Shyy, M. Liu, Y. X. Ren, T. S. Zhao, J. Mater. Chem. A 2018, 6, 2107.

[84] S. Mukherjee, L. Kavalsky, K. Chattopadhyay, C. V. Singh, Nanoscale 2018, 10, 21335.

[85] N. Li, Q. Meng, X. Zhu, Z. Li, J. Ma, C. Huang, J. Song, J. Fan, Nanoscale 2019, 11, 8485.

[86] H. Lin, D.-D. Yang, N. Lou, S.-G. Zhu, H.-Z. Li, Ceram. Int. 2019, 45, 1588.

[87] a) Y. Wang, J. Shen, L.-C. Xu, Z. Yang, R. Li, R. Liu, X. Li, Phys. Chem. Chem. Phys. 2019, 21, 18559; b) P. Liang, L. Zhang, D. Wang, X. Man, H. Shu, L. Wang, H. Wan, X. Du, H. Wang, Appl. Surf. Sci. 2019, 489, 677.

[88] X. Zhao, M. Liu, Y. Chen, B. Hou, N. Zhang, B. Chen, N. Yang, K. Chen, J. Li, L. An, J. Mater. Chem. A 2015, 3, 7870.

[89] W. Bao, L. Liu, C. Wang, S. Choi, D. Wang, G. Wang, Adv. Energy Mater. 2018, 8, 1702485.

[90] Y. Song, Z. Sun, Z. Fan, W. Cai, Y. Shao, G. Sheng, M. Wang, L. Song, Z. Liu, Q. Zhang, Nano Energy 2020, 70, 104555.

[91] a) H. Tang, W. Li, L. Pan, C. P. Cullen, Y. Liu, A. Pakdel, D. Long, J. Yang, N. McEvoy, G. S. Duesberg, Adv. Sci. 2018, 5, 1800502; b) H. Tang, W. Li, L. Pan, K. Tu, F. Du, T. Qiu, J. Yang, C. P. Cullen, N. McEvoy, C. Zhang, Adv. Funct. Mater. 2019, 29, 1901907.

[92] Z. Xiao, Z. Li, P. Li, X. Meng, R. Wang, ACS Nano 2019, 13, 3608.

[93] Z. Xiao, Z. Yang, Z. Li, P. Li, R. Wang, ACS Nano 2019, 13, 3404.

[94] a) W. Bao, X. Xie, J. Xu, X. Guo, J. Song, W. Wu, D. Su, G. Wang, Chem. - Eur. J. 2017, 23, 12613; b) J. Song, X. Guo, J. Zhang, Y. Chen, C. Zhang, L. Luo, F. Wang, G. Wang, J. Mater. Chem. A 2019, 7, 6507; c) W. Bao, D. Su, W. Zhang, X. Guo, G. Wang, Adv. Funct. Mater. 2016, 26, 8746; d) Q. Zhao, Q. Zhu, J. Miao, P. Zhang, B. Xu, Nanoscale 2019, 11, 8442; e) L.-P. Lv, C.-F. Guo, W. Sun, Y. Wang, Small 2019, 15, 1804338; f) N. Li, W. Cao, Y. Liu, H. Ye, K. Han, Colloids Surf., A 2019, 573, 128; g) R. Gan, N. Yang, Q. Dong, N. Fu, R. Wu, C. Li, Q. Liao, J. Li, Z. Wei, J. Mater. Chem. A 2020, 8, 7253; h) H.-Y. Zhou, Z.-Y. Sui, K. Amin, L.-W. Lin, H.-Y. Wang, B.-H. Han, ACS Appl. Mater. Interfaces 2020, 12, 13904.

[95] X. Zhang, H. Xie, C.-S. Kim, K. Zaghib, A. Mauger, C. Julien, Mater. Sci. Eng., R 2017, 121, 1.

[96] X. T. Gao, Y. Xie, X. D. Zhu, K. N. Sun, X. M. Xie, Y. T. Liu, J. Y. Yu, B. Ding, Small 2018, 14, 1802443.

[97] M.-S. Song, S.-C. Han, H.-S. Kim, J.-H. Kim, K.-T. Kim, Y.-M. Kang, H.-J. Ahn, S. Dou, J.-Y. Lee, J. Electrochem. Soc. 2004, 151, A791.

[98] a) H. Pan, X. Huang, R. Zhang, D. Wang, Y. Chen, X. Duan, G. Wen, Chem. Eng. J. 2019, 358, 1253; b) C. Du, J. Wu, P. Yang, S. Li, J. Xu, K. Song, Electrochim. Acta 2019, 295, 1067; c) L. Jiao, C. Zhang, C. Geng, S. Wu, H. Li, W. Lv, Y. Tao, Z. Chen, G. Zhou, J. Li, G. Ling, Y. Wan, Q.-H. Yang, Adv. Energy Mater. 2019, 9, 1900219; d) Y. Zhang, Z. Mu, C. Yang, Z. Xu, S. Zhang, X. Zhang, Y. Li, J. Lai, Z. Sun, Y. Yang, Adv. Funct. Mater. 2018, 28, 1707578; e) H. Zhang, Q. Qi, P. Zhang, W. Zheng, J. Chen, A. Zhou, W. Tian, W. Zhang, Z. Sun, ACS Appl. Energy Mater. 2019, 2, 705.

[99] X. Wang, C. Yang, X. Xiong, G. Chen, M. Huang, J.-H. Wang, Y. Liu, M. Liu, K. Huang, Energy Storage Mater. 2019, 16, 344.
[100] Y. Yao, W. Feng, M. Chen, X. Zhong, X. Wu, H. Zhang, Y. Yu, Small 1 2018, 14, 1802516.

[101] D. Guo, F. Ming, H. Su, Y. Wu, W. Wahyudi, M. Li, M. N. Hedhili, 3 G. Sheng, L.-J. Li, H. N. Alshareef, Nano Energy 2019, 61, 478.

[102] a) Y.-S. Su, A. Manthiram, Chem. Commun. 2012, 48, 8817; b) Y.-S. Su, A. Manthiram, Nat. Commun. 2012, 3, 1166; c) J. He, Y. Chen, A. Manthiram, Energy Environ. Sci. 2018, 11, 2560; d) H.-J. Peng, D.-W. Wang, J.-Q. Huang, X.-B. Cheng, Z. Yuan, F. Wei, Q. Zhang, Adv. Sci. 2016, 3, 1500268; e) C.-H. Chang, S.-H. Chung, A. Manthiram, J. Mater. Chem. A 2015, 3, 18829.

[103] a) N.-W. Li, Y. Shi, Y.-X. Yin, X.-X. Zeng, J.-Y. Li, C.-J. Li, L.-J. Wan, 10 R. Wen, Y.-G. Guo, Angew. Chem., Int. Ed. 2018, 57, 1505; 11 b) E. Cha, M. D. Patel, J. Park, J. Hwang, V. Prasad, K. Cho, W. Choi, 12 Nat. Nanotechnol. 2018, 13, 337; c) X. Zhang, Q. Zhang, X. G. Wang, 13 C. Wang, Y. N. Chen, Z. Xie, Z. Zhou, Angew. Chem., Int. Ed. 2018, 130, 12996; d) J. Liang, X. Li, Y. Zhao, L. V. Goncharova, G. Wang, K. R. Adair, C. Wang, R. Li, Y. Zhu, Y. Qian, Adv. Mater. 2018, 30, 1804684; e) K. Liao, S. Wu, X. Mu, Q. Lu, M. Han, P. He, Z. Shao, H. Zhou, Adv. Mater. 2018, 30, 1705711; f) T. Kang, Y. Wang, F. Guo, C. Liu, J. Zhao, J. Yang, H. Lin, Y. Qiu, Y. Shen, W. Lu, ACS Cent. Sci. 2019, 5, 468; g) Z. A. Ghazi, Z. Sun, C. Sun, F. Qi, B. An, F. Li, H.-M. Cheng, Small 2019, 15, 1900687.

[104] C. Lin, W. Zhang, L. Wang, Z. Wang, W. Zhao, W. Duan, Z. Zhao, 21 B. Liu, J. Jin, J. Mater. Chem. A 2016, 4, 5993.

[105] J. Song, D. Su, X. Xie, X. Guo, W. Bao, G. Shao, G. Wang 22 ACS Appl. Mater. Interfaces 2016, 8, 29427.

[106] L. Yin, G. Xu, P. Nie, H. Dou, X. Zhang, Chem. Eng. J. 2018, 352 695.

[107] N. Li, Y. Xie, S. Peng, X. Xiong, K. Han, J. Energy Chem. 2020, 42, 116.

[108] G. Jiang, N. Zheng, X. Chen, G. Ding, Y. Li, F. Sun, Y. Li, Chem. Eng. J. 2019, 373, 1309.

[109] Y. Dong, S. Zheng, J. Qin, X. Zhao, H. Shi, X. Wang, J. Chen, Z.-S. Wu, ACS Nano 2018, 12, 2381.

[110] J. Huang, R. Meng, L. Zu, Z. Wang, N. Feng, Z. Yang, Y. Yu, J. Yang, Nano Energy 2018, 46, 20.

[111] B. Li, D. Zhang, Y. Liu, Y. Yu, S. Li, S. Yang, Nano Energy 2017, 39, 654.

[112] a) D. Er, J. Li, M. Naguib, Y. Gogotsi, V. B. Shenoy, ACS Appl. Mater. Interfaces 2014, 6, 11173; b) Y.-X. Yu, J. Phys. Chem. C 2016, 120,$5288 ;$ c) V. Shukla, N. K. Jena, S. R. Naqvi, W. Luo, R. Ahuja, Nano Energy 2019, 58, 877.

[113] a) Y. Wu, P. Nie, J. Wang, H. Dou, X. Zhang, ACS Appl. Mater. Interfaces 2017, 9, 39610; b) J. Zhu, M. Wang, M. Lyu, Y. Jiao, A. Du, B. Luo, I. Gentle, L. Wang, ACS Appl. Nano Mater. 2018, 1, 41 6854; c) G. Lv, J. Wang, Z. Shi, L. Fan, Mater. Lett. 2018, 219, 45; 42 d) X. Wang, S. Kajiyama, H. linuma, E. Hosono, S. Oro, 43 I. Moriguchi, M. Okubo, A. Yamada, Nat. Commun. 2015, 6, 6544; e) M. Naguib, R. A. Adams, Y. Zhao, D. Zemlyanov, A. Varma, J. Nanda, V. G. Pol, Chem. Commun. 2017, 53, 6883.

[114] M. R. Lukatskaya, O. Mashtalir, C. E. Ren, Y. Dall-Agnese, P. Rozier, P. L. Taberna, M. Naguib, P. Simon, M. W. Barsoum, Y. Gogotsi, Science 2013, 341, 1502.

[115] S. Kajiyama, L. Szabova, K. Sodeyama, H. linuma, R. Morita, K. Gotoh, Y. Tateyama, M. Okubo, A. Yamada, ACS Nano 2016, 10, 3334.

[116] S.-M. Bak, R. Qiao, W. Yang, S. Lee, X. Yu, B. Anasori, H. Lee, Y. Gogotsi, X.-Q. Yang, Adv. Energy Mater. 2017, 7, 1700959.

[117] a) D. Zhao, M. Clites, G. Ying, S. Kota, J. Wang, V. Natu, X. Wang, E. Pomerantseva, M. Cao, M. W. Barsoum, Chem. Commun. 2018, 54, 4533; b) V. Natu, M. Clites, E. Pomerantseva, M. W. Barsoum, Mater. Res. Lett. 2018, 6, 230.

[118] P. Lian, Y. Dong, Z.-S. Wu, S. Zheng, X. Wang, S. Wang, C. Sun, J. Qin, X. Shi, X. Bao, Nano Energy 2017, 40, 1.

[119] Y. Dall'Agnese, P.-L. Taberna, Y. Gogotsi, P. Simon, J. Phys. Chem. Lett. 2015, 6, 2305.

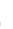
4 4 
[120] J. Luo, J. Zheng, J. Nai, C. Jin, H. Yuan, O. Sheng, Y. Liu, R. Fang, W. Zhang, H. Huang, Adv. Funct. Mater. 2019, 29, 1808107.

[121] S. Sun, Z. Xie, Y. Yan, S. Wu, Chem. Eng. J. 2019, 366, 460.

[122] J. Li, D. Yan, S. Hou, Y. Li, T. Lu, Y. Yao, L. Pan, J. Mater. Chem. A 2018, 6, 1234.

[123] J. Luo, C. Fang, C. Jin, H. Yuan, O. Sheng, R. Fang, W. Zhang, H. Huang, Y. Gan, Y. Xia, J. Mater. Chem. A 2018, 6, 7794.

[124] X. Xie, K. Kretschmer, B. Anasori, B. Sun, G. Wang, Y. Gogotsi, ACS Appl. Nano Mater. 2018, 1, 505.

[125] X. Xie, M.-Q. Zhao, B. Anasori, K. Maleski, C. E. Ren, J. Li, B. W. Byles, E. Pomerantseva, G. Wang, Y. Gogotsi, Nano Energy 2016, 26, 513.

[126] X. Guo, X. Xie, S. Choi, Y. Zhao, H. Liu, C. Wang, S. Chang, G. Wang, J. Mater. Chem. A 2017, 5, 12445.

[127] Y. Wu, P. Nie, L. Wu, H. Dou, X. Zhang, Chem. Eng. J. 2018, 334, 932.

[128] Y. Zhang, B. Guo, L. Hu, Q. Xu, Y. Li, D. Liu, M. Xu, J. Alloys Compd. 2018, 732, 448.

[129] Y. Tian, Y. An, S. Xiong, J. Feng, Y. Qian, J. Mater. Chem. A 2019, 7, 9716.

[130] a) D. Zhao, R. Zhao, S. Dong, X. Miao, Z. Zhang, C. Wang, L. Yin, Energy Environ. Sci. 2019, 12, 2422; b) R. Meng, J. Huang, Y. Feng, L. Zu, C. Peng, L. Zheng, L. Zheng, Z. Chen, G. Liu, B. Chen, Adv. Energy Mater. 2018, 8, 1801514; c) R. Zhao, Z. Qian, Z. Liu, D. Zhao, X. Hui, G. Jiang, C. Wang, L. Yin, Nano Energy 2019, 65, 104037; d) X. Guo, W. Zhang, J. Zhang, D. Zhou, X. Tang, X. Xu, B. Li, H. Liu, G. Wang, ACS Nano 2020, 14, 3651.

[131] a) Y. Wu, P. Nie, J. Jiang, B. Ding, H. Dou, X. Zhang, ChemElectroChem 2017, 4, 1560; b) J. Li, B. Rui, W. Wei, P. Nie, L. Chang, Z. Le, M. Liu, H. Wang, L. Wang, X. Zhang, J. Power Sources 2020, 449, 227481.

[132] H. Huang, J. Cui, G. Liu, R. Bi, L. Zhang, ACS Nano 2019, 13, 3448

[133] C.-F. Du, Q. Liang, Y. Zheng, Y. Luo, H. Mao, Q. Yan, ACS Appl. Mater. Interfaces 2018, 10, 33779.

[134] Y. Zhang, R. Zhan, Q. Xu, H. Liu, M. Tao, Y. Luo, S. Bao, C. Li, M. Xu, Chem. Eng. J. 2019, 357, 220.

[135] M. Tao, Y. Zhang, R. Zhan, B. Guo, Q. Xu, M. Xu, Mater. Lett. 2018, 230, 173.

[136] F. Wu, Y. Jiang, Z. Ye, Y. Huang, Z. Wang, S. Li, Y. Mei, M. Xie, L. Li, R. Chen, J. Mater. Chem. A 2019, 7, 1315.

[137] X. Guo, J. Zhang, J. Song, W. Wu, H. Liu, G. Wang, Energy Storage Mater. 2018, 14, 306.

[138] a) S. Tu, F. Ming, J. Zhang, X. Zhang, H. N. Alshareef, Adv. Mater. 2019, 31, 1806860; b) S. Tu, M. Mizohata, G. Sheng, L. Liu, F. Ming, C.-N. Xu, D. Tu, X. Zhang, H. N. Alshareef, Adv. Funct. Mater. 2020, 88, 1909843; c) J. Tang, X. Huang, T. Lin, T. Qiu, H. Huang, X. Zhu, Q. Gu, B. Luo, L. Wang, Energy Storage Mater. 2020, 26, 550; d) Y. Dong, Z.-S. Wu, S. Zheng, X. Wang, J. Qin, S. Wang, X. Shi, X. Bao, ACS Nano 2017, 11, 4792; e) R. Wang, S. Wang, Y. Zhang, D. Jin, X. Tao, L. Zhang, J. Mater. Chem. A 2018, 6, 1017; f) Y. Fang, R. Hu, B. Liu, Y. Zhang, K. Zhu, J. Yan, K. Ye, K. Cheng, G. Wang, D. Cao, J. Mater. Chem. A 2019, 7, 5363; g) W. Zhong, M. Tao, W. Tang, W. Gao, T. Yang, Y. Zhang, R. Zhan, S.-J. Bao, M. Xu, Chem. Eng. J. 2019, 378, 122209; h) M. Tao, G. Du, Y. Zhang, W. Gao, D. Liu, Y. Luo, J. Jiang, S. Bao, M. Xu, Chem. Eng. J. 2019, 369, 828; i) C. Zeng, F. Xie, X. Yang, M. Jaroniec, L. Zhang, S.-Z. Qiao, Angew. Chem., Int. Ed. 2018, 57, 8540.

[139] M. Tao, G. Du, T. Yang, W. Gao, L.-C. Zhang, W. Du, J. Jiang, S.-J. Bao, M.-W. Xu, J. Mater. Chem. A 2020, 8, 3018.

[140] D. Aurbach, Z. Lu, A. Schechter, Y. Gofer, H. Gizbar, R. Turgeman, Y. Cohen, M. Moshkovich, E. Levi, Nature 2000, 407, 724.

[141] a) Y.-s. Guo, F. Zhang, J. Yang, F.-f. Wang, Y. NuLi, S.-i. Hirano, Energy Environ. Sci. 2012, 5, 9100; b) H. D. Yoo, I. Shterenberg, Y. Gofer, G. Gershinsky, N. Pour, D. Aurbach, Energy Environ. Sci. 2013, 6, 2265; c) E. Levi, Y. Gofer, D. Aurbach, Chem. Mater. 2010, 22, 860.

[142] M. Xu, S. Lei, J. Qi, Q. Dou, L. Liu, Y. Lu, Q. Huang, S. Shi, X. Yan, ACS Nano 2018, 12, 3733.
[143] M. Xu, N. Bai, H.-X. Li, C. Hu, J. Qi, X.-B. Yan, Chin. Chem. Lett. 1 2018, 29, 1313.

[144] Q. Gao, J. Come, M. Naguib, S. Jesse, Y. Gogotsi, N. Balke, Faraday Discuss. 2017, 199, 393.

[145] M.-Q. Zhao, C. E. Ren, M. Alhabeb, B. Anasori, M. W. Barsoum Y. Gogotsi, ACS Appl. Energy Mater. 2019, 2, 1572.

[146] F. Liu, Y. Liu, X. Zhao, X. Liu, L.-Z. Fan, J. Mater. Chem. A 2019, 7, 16712.

[147] H. Kaland, J. Hadler-Jacobsen, F. H. Fagerli, N. P. Wagner, Z. Wang, S. M. Selbach, F. Vullum-Bruer, K. Wiik, S. K. Schnell, Sustainable Energy Fuels 2020, 4, 2956.

[148] a) T. Gao, F. Han, Y. Zhu, L. Suo, C. Luo, K. Xu, C. Wang, Adv. Energy Mater. 2015, 5, 1401507; b) Y. Cheng, H. J. Chang, H. Dong, D. Choi, V. L. Sprenkle, J. Liu, Y. Yao, G. Li, J. Mater. Res. 2016, 31, 3125; c) X. Fan, R. R. Gaddam, N. A. Kumar, X. S. Zhao, Adv. Energy Mater. 2017, 7, 1700317; d) S. Su, Y. NuLi, Z. Huang, Q. Miao, J. Yang, J. Wang, ACS Appl. Mater. Interfaces 2016, 8, 7111.

[149] a) A. Byeon, M.-Q. Zhao, C. E. Ren, J. Halim, S. Kota, P. Urbankowski, B. Anasori, M. W. Barsoum, Y. Gogotsi, ACS Appl. Mater. Interfaces 2017, 9, 4296; b) F. Liu, Y. Liu, X. Zhao, K. Liu, H. Yin, L.-Z. Fan, Small 2020, 16, 1906076.

[150] A. Volta, Philos. Trans. R. Soc. London 1800, 403.

[151] T. Yamamoto, T. Shoji, Inorg. Chim. Acta 1986, 117, L27.

[152] a) P. A. Maughan, N. Tapia-Ruiz, N. Bimbo, Electrochim. Acta 2020 341, 136061; b) Q. Yang, Z. Huang, X. Li, Z. Liu, H. Li, G. Liang, D. Wang, Q. Huang, S. Zhang, S. Chen, ACS Nano 2019, 13, 8275.

[153] a) S. Wang, Q. Wang, W. Zeng, M. Wang, L. Ruan, Y. Ma, NanoMicro Lett. 2019, 11, 70; b) J. Shi, S. Wang, Q. Wang, X. Chen, X. Du, M. Wang, Y. Zhao, C. Dong, L. Ruan, W. Zeng, J. Power Sources 2020, 446, 227345.

[154] Q. Wang, S. Wang, X. Guo, L. Ruan, N. Wei, Y. Ma, J. Li, M. Wang, W. Li, W. Zeng, Adv. Electron. Mater. 2019, 5, 1900537.

[155] S. Luo, L. Xie, F. Han, W. Wei, Y. Huang, H. Zhang, M. Zhu, O. G. Schmidt, L. Wang, Adv. Funct. Mater. 2019, 29, 1901336.

[156] X. Li, M. Li, Q. Yang, H. Li, H. Xu, Z. Chai, K. Chen, Z. Liu, Z. Tang, L. Ma, ACS Nano 2020, 14, 541.

[157] a) L. Wang, Z. Zhou, X. Yan, F. Hou, L. Wen, W. Luo, J. Liang, S. X. Dou, Energy Storage Mater. 2018, 14, 22; b) X.-B. Cheng, R. Zhang, C.-Z. Zhao, Q. Zhang, Chem. Rev. 2017, 117, 10403.

[158] D. Zhang, S. Wang, B. Li, Y. Gong, S. Yang, Adv. Mater. 2019, 31, 1901820.

[159] a) Z. Cao, Q. Zhu, S. Wang, D. Zhang, H. Chen, Z. Du, B. Li, S. Yang, Adv. Funct. Mater. 2020, 30, 1908075; b) K. Shen, B. Li, S. Yang, Energy Storage Mater. 2020, 24, 670.

[160] X. Zhang, R. Lv, A. Wang, W. Guo, X. Liu, J. Luo, Angew. Chem., Int. Ed. 2018, 57, 15028.

[161] H. Shi, C. J. Zhang, P. Lu, Y. Dong, P. Wen, Z.-S. Wu, ACS Nano 2019, 13, 14308.

[162] X. Chen, M. Shang, J. Niu, Nano Lett. 2020, 20, 2639.

[163] C. Wei, H. Fei, Y. Tian, Y. An, H. Guo, J. Feng, Y. Qian, Energy Storage Mater. 2020, 26, 223.

[164] J. Luo, C. Wang, H. Wang, X. Hu, E. Matios, X. Lu, W. Zhang, X. Tao, W. Li, Adv. Funct. Mater. 2019, 29, 1805946.

[165] X. Tang, D. Zhou, P. Li, X. Guo, B. Sun, H. Liu, K. Yan, Y. Gogotsi, G. Wang, Adv. Mater. 2020, 32, 1906739.

[166] Y. Tian, Y. An, C. Wei, B. Xi, S. Xiong, J. Feng, Y. Qian, ACS Nano 2019, 13, 11676.

[167] a) H. Liang, F. Ming, H. N. Alshareef, Adv. Energy Mater. 2018, 8, 1801804; b) H. Liang, C. Xia, A.-H. Emwas, D. H. Anjum, X. Miao, H. N. Alshareef, Nano Energy 2018, 49, 155.

[168] B. Ahmed, D. H. Anjum, Y. Gogotsi, H. N. Alshareef, Nano Energy 2017, 34, 249.

[169] a) C. J. Zhang, S. Pinilla, N. McEvoy, C. P. Cullen, B. Anasori, E. Long, S.-H. Park, A. Seral-Ascaso, A. Shmeliov, D. Krishnan, Chem. Mater. 2017, 29, 4848; b) T. Habib, X. Zhao, S. A. Shah, Y. Chen, W. Sun, H. An, J. L. Lutkenhaus, M. Radovic, M. J. Green, npj 2D Mater. Appl. 2019, 3, 8; c) R. Lotfi, M. Naguib, D. E. Yilmaz, 
J. Nanda, A. C. T. Van Duin, J. Mater. Chem. A 2018, 6, 12733;

d) Y. Lee, S. J. Kim, Y.-J. Kim, Y. Lim, Y. Chae, B.-J. Lee, Y.-T. Kim, H. Han, Y. Gogotsi, C. W. Ahn, J. Mater. Chem. A 2020, 8, 573.

[170] a) X. Wu, Z. Wang, M. Yu, L. Xiu, J. Qiu, Adv. Mater. 2017, 29, 1607017; b) C.-W. Wu, B. Unnikrishnan, I. W. P. Chen, S. G. Harroun, H.-T. Chang, C.-C. Huang, Energy Storage Mater. 2020, 25, 563.

[171] N. Zhang, Y. Hong, S. Yazdanparast, M. A. Zaeem, 2D Mater. 1 2018, 5, 045004.

[172] C. E. Shuck, A. Sarycheva, M. Anayee, A. Levitt, Y. Zhu, S. Uzun, 3 V. Balitskiy, V. Zahorodna, O. Gogotsi, Y. Gogotsi, Adv. Eng. Mater. 2020, 22, 1901241.

[173] C. E. Shuck, Y. Gogotsi, Chem. Eng. J. 2020, 401, 125786.
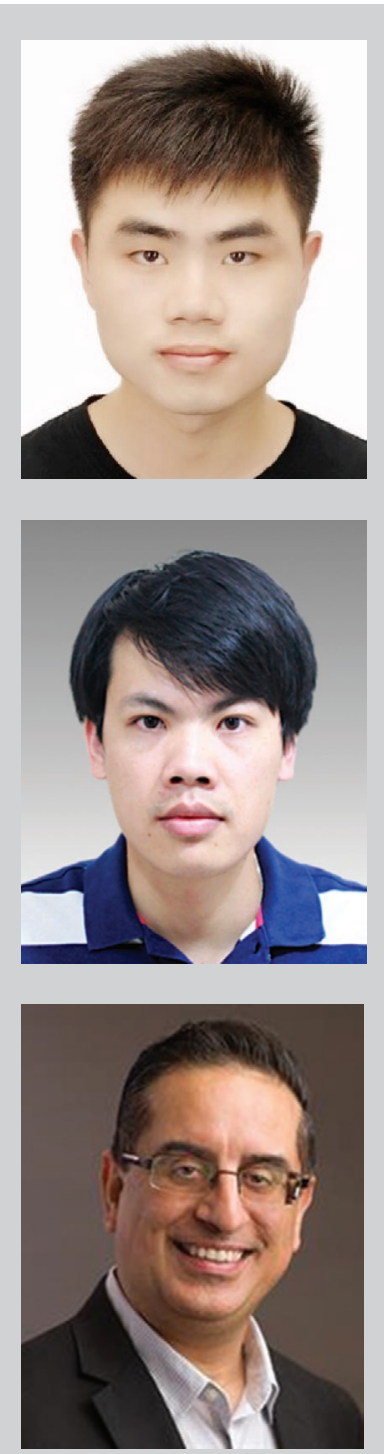

Husam N. Alshareef is a professor of Materials Science and Engineering at King Abdullah University of Science and Technology (KAUST). He obtained his Ph.D. at North Carolina State University, Raleigh, USA. He then did his postdoctoral work at Sandia National Laboratory, USA. Following ten years in the semiconductor industry, he joined KAUST in 2009, where he has been running a research group focused on developing inorganic nanomaterials for energy and electronics.
Fangwang Ming received his master degree in chemical engineering in 2017 from Xiamen University. He is currently a Ph.D. student under the supervision of professor Husam N. Alshareef at King Abdullah University of Science \& Technology (KAUST). His research interest relates to functional nanomaterials, especially 2D materials, for efficient energy storage and conversion.

Hanfeng Liang received his Ph.D. in applied chemistry in 2015 from Xiamen University. As a visiting graduate student, he studied at University of Wisconsin - Madison from 2013 to 2015. He is currently a postdoc in Prof. Husam N. Alshareef's group at KAUST. His research focuses on earth-abundant materials for catalysis and electrochemical energy storage and conversion. 


\section{Reprint Order Form}

Charges for Reprints in Euro (excl. VAT), prices are subject to change. Minimum order 50 copies; single issues for authors at a reduced price.

\begin{tabular}{l|rrrrrr} 
No. of pages & $\begin{array}{c}\mathbf{5 0} \\
\text { copies }\end{array}$ & $\begin{array}{c}\mathbf{1 0 0} \\
\text { copies }\end{array}$ & $\begin{array}{c}\mathbf{1 5 0} \\
\text { copies }\end{array}$ & $\begin{array}{c}\mathbf{2 0 0} \\
\text { copies }\end{array}$ & $\begin{array}{c}\mathbf{3 0 0} \\
\text { copies }\end{array}$ & $\begin{array}{c}\mathbf{5 0 0} \\
\text { copies }\end{array}$ \\
\hline $\mathbf{1 - 4}$ & $345,-$ & $395,-$ & $425,-$ & $445,-$ & $548,-$ & $752,-$ \\
$\mathbf{5 - 8}$ & $490,-$ & $573,-$ & $608,-$ & $636,-$ & $784,-$ & $1077,-$ \\
$\mathbf{9 - 1 2}$ & $640,-$ & $739,-$ & $786,-$ & $824,-$ & $1016,-$ & $1396,-$ \\
$\mathbf{1 3 - 1 6}$ & $780,-$ & $900,-$ & $958,-$ & $1004,-$ & $1237,-$ & $1701,-$ \\
$\mathbf{1 7 - 2 0}$ & $930,-$ & $1070,-$ & $1138,-$ & $1196,-$ & $1489,-$ & $2022,-$ \\
\hline & & & & & & \\
every additional & $147,-$ & $169,-$ & $175,-$ & $188,-$ & $231,-$ & $315,-$ \\
4 pages & & & & & &
\end{tabular}

Please send me send bill me for

$$
\begin{aligned}
& \square \text { no. of reprints } \\
& \text { no. of issue } \\
& \text { (1 copy: } 28 \text { Euro) } \\
& \text { high-resolution PDF file (330 Euro excl. VAT) } \\
& \text { E-mail address: } \\
& \text { Special Offer: } \\
& \text { If you order } 200 \text { or more reprints you will get } \\
& \text { a PDF file for half price. }
\end{aligned}
$$

Please note: It is not permitted to present the PDF file on the internet or on company homepages.

Cover Posters (prices excl. VAT)

Posters of published covers are available in two sizes:

DIN A2 42 × 60 cm / $17 \times 24$ in (one copy: 39 Euro)

DIN A1 60 x 84 cm / 24 x 33in (one copy: 49 Euro)

Postage for shipping (prices excl. VAT)

overseas +25 Euro
within Europe +15 Euro

Manuscript No.:

Customer No.: (if available)

Purchase Order No.:

Author:

Information regarding VAT: The charges for publication of reprints/ issues/poster are considered to be "supply of services" and therefore subject to German VAT. However, if you are an institutional customer outside Germany, the tax can be waived if you provide us with the valid VAT number of your company. Non-EU customers may have a VAT number starting with "EU" instead of their country code, if they are registered with the EU tax authorities. If you do not have a valid EU VAT number and you are a taxable person doing business in a non-EU country, please provide a certification from your local tax authorities confirming that you are a taxable person under local tax law. Please note that the certification must confirm that you are a taxable person and are conducting an economic activity in your country. Note: certifications confirming that you are a tax-exempt legal body (non-profit organization, public body, school, political party, etc.) in your country do not exempt you from paying German VAT.
Send bill to:

Mail reprints / copies of the issue to:

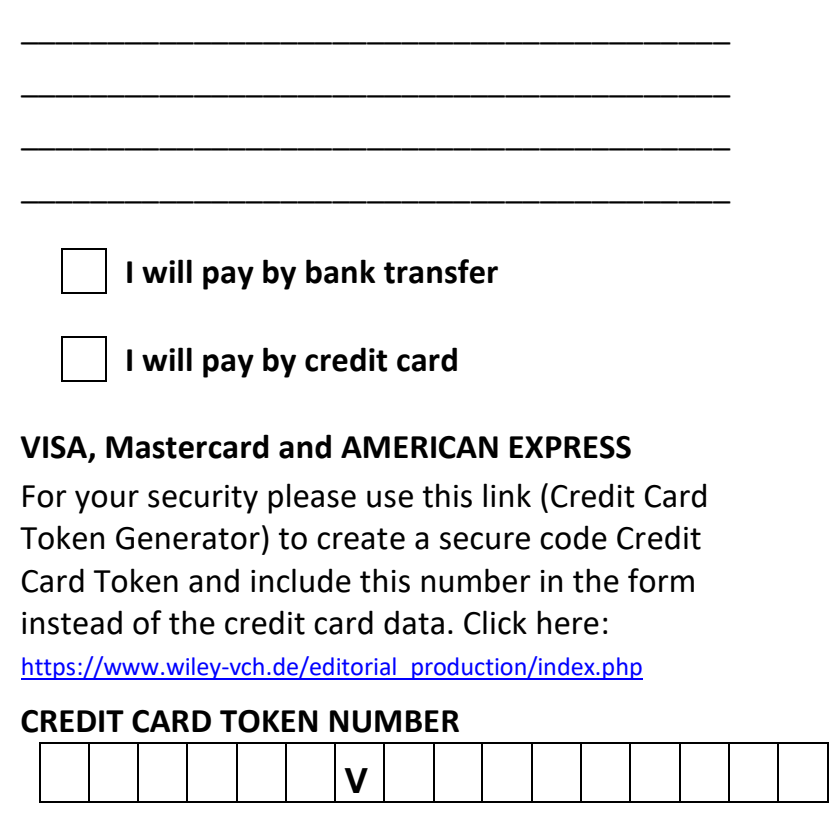

\section{Date, Signature}

